\title{
Visible-Light-Induced, Base-Promoted Transition- Metal-Free Dehalogenation of Aryl Fluorides, Chlorides, Bromides, and Iodides
}

Ting-Hui Ding, ${ }^{\dagger}$ Jian-Ping Qu, ${ }^{*,+}$ and Yan-Biao Kang ${ }^{*}, \dagger$

†Department of Chemistry, University of Science and Technology of China, Hefei, Anhui 230026, China

$\$$ Institute of Advanced Synthesis, School of Chemistry and Molecular Engineering, Nanjing Tech University, Nanjing 211816, China

Email: ybkang@ustc.edu.cn; ias_jpqu@njtech.edu.cn

\section{Contents}

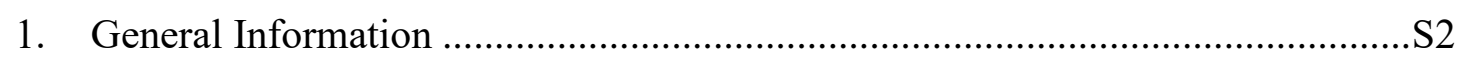

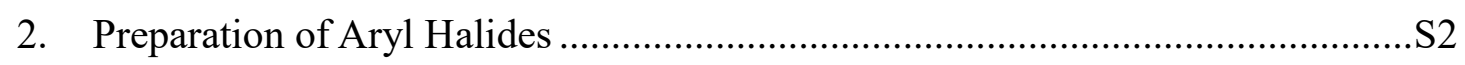

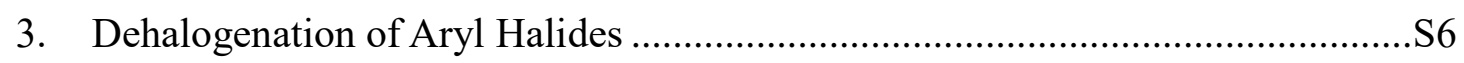

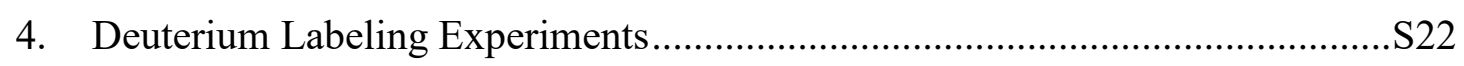

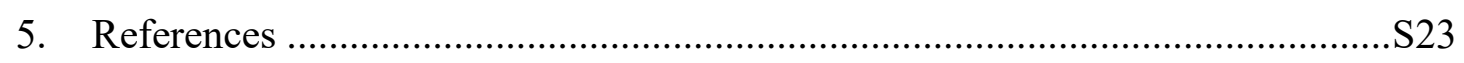

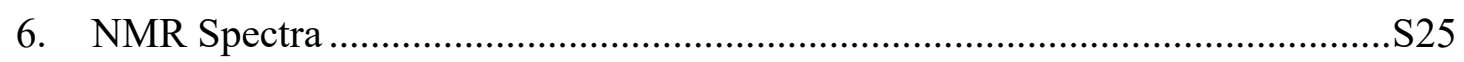




\section{General Information}

Solvents were pre-dried over activated $4 \AA$ molecular sieves and heated to reflux over sodium (toluene and octane) or calcium hydride (DMF, DMA, DMSO and dioxane) under argon atmosphere and collected by distillation. ${ }^{1} \mathrm{H},{ }^{13} \mathrm{C}$ NMR spectra were recorded on a Bruker spectrometer; Chemical shifts are reported in $\delta$ units relative to $\mathrm{CDCl}_{3}\left[{ }^{1} \mathrm{H} \delta=7.26,{ }^{13} \mathrm{C} \delta=77.36\right]$, DMSO $\left[{ }^{1} \mathrm{H} \delta=2.50,{ }^{13} \mathrm{C} \delta=39.1\right] . \quad$ Aryl halides 1a-1d, 1h, 1i, 1l, 1o-1w, 3a-3h, 4a-4g, 5a-5k were purchased from commercial sources.

\section{Preparation of Aryl Halides}

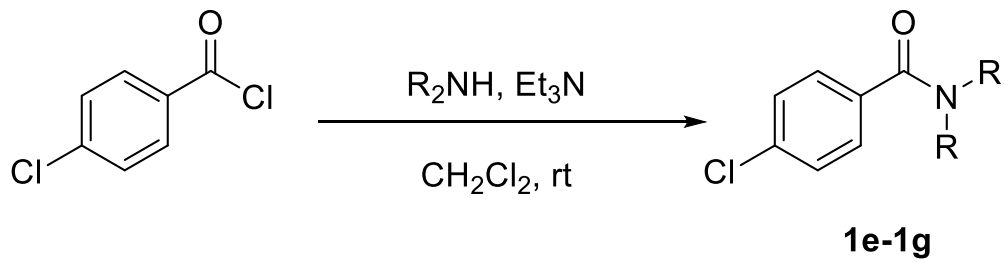

General procedure for the preparation of 1e-g (GP1): Acyl chloride was dissolved in $10 \mathrm{~mL}$ dry $\mathrm{CH}_{2} \mathrm{Cl}_{2}$, and the solution was then added dropwisely to a $20 \mathrm{~mL}$ solution of $\mathrm{R}_{2} \mathrm{NH}(6 \mathrm{mmol})$ and $\mathrm{Et}_{3} \mathrm{~N}(12 \mathrm{mmol})$ in dry $\mathrm{CH}_{2} \mathrm{Cl}_{2}$ at $0{ }^{\circ} \mathrm{C}$. After stirring for $6 \mathrm{~h}$ at r.t., the resulting mixture was washed with brine, and extracted with $\mathrm{CH}_{2} \mathrm{Cl}_{2}$, dried over anhydrous $\mathrm{MgSO}_{4}$, filtered, concentrated and purified on flash column chromatography on silica gel (PE/EA 50:1-10:1) to give the product.<smiles>CCCN(C(=O)c1ccccc1)C(=O)c1ccc(Cl)cc1</smiles>

\section{4-Chloro- $N, N$-diisopropylbenzamide (1e)}

Prepared according to GP1, white solid, $1.2 \mathrm{~g}, 100 \%$. ${ }^{1} \mathrm{H}$ NMR (400 MHz, $\mathrm{CDCl}_{3}$ ) $\delta$ 7.37-7.35 (m, 2H), 7.27-7.24 (m, 2H), 3.65(brs, 2H), 1.35 (brs, $12 \mathrm{H}) .{ }^{13} \mathrm{C}\left\{{ }^{1} \mathrm{H}\right\} \mathrm{NMR}$ $\left(100 \mathrm{MHz}, \mathrm{CDCl}_{3}\right) \delta 170.7,137.3,134.6,128.8,127.2,50.9,46.2,20.8 .^{1}$ 
<smiles>CN(C)C(=O)c1ccc(Cl)cc1</smiles>

\section{4-Chloro- $N, N$-dimethylbenzamide (1f)}

Prepared according to GP1, yellow oil, $201.3 \mathrm{mg}, 22 \% .{ }^{1} \mathrm{H}$ NMR (400 MHz, $\left.\mathrm{CDCl}_{3}\right) \delta$ 7.40-7.34 (m, 4H), $3.09(\mathrm{~s}, 3 \mathrm{H}), 2.97(\mathrm{~s}, 3 \mathrm{H}) .{ }^{13} \mathrm{C}\left\{{ }^{1} \mathrm{H}\right\}$ NMR $(100 \mathrm{MHz}$, $\left.\mathrm{CDCl}_{3}\right) \delta 170.7,135.7,134.7,128.7,39.7,35.6{ }^{1}$<smiles>CCN(CC)C(=O)c1ccc(Cl)cc1</smiles>

\section{4-Chloro- $N$, $N$-diethylbenzamide (1g)}

Prepared according to GP1, yellow oil, $1.06 \mathrm{~g}, 100 \%$. ${ }^{1} \mathrm{H}$ NMR (400 MHz, $\mathrm{CDCl}_{3}$ ) $\delta$ 7.33-7.30 (m, 2H), 7.28-7.25 (m, 2H), 3.47(s, 2H), $3.20(\mathrm{~s}, 2 \mathrm{H}), 1.17(\mathrm{~s}, 3 \mathrm{H}), 1.07(\mathrm{~s}$, $3 \mathrm{H}) .{ }^{13} \mathrm{C}\left\{{ }^{1} \mathrm{H}\right\} \mathrm{NMR}\left(100 \mathrm{MHz}, \mathrm{CDCl}_{3}\right) \delta 170.1,135.7,135.1,128.6,127.8,43.3,39.4$, $14.2,12.9 .^{1}$
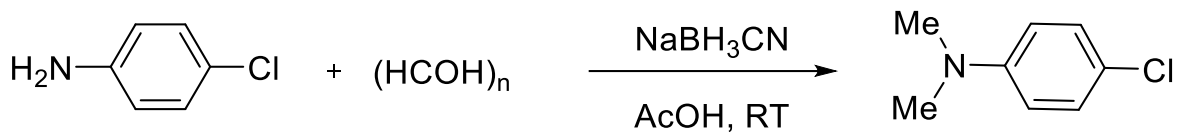

1]

4-Chlorideaniline $(10 \mathrm{mmol})$ was dissolved in acetic acid $(50 \mathrm{~mL})$. Paraformaldehyde $(100 \mathrm{mmol})$ was added and slowly added sodium cyanoborohydride (50 mmol). The reaction mixture was stirred at room temperature for $12 \mathrm{~h}$. Then the solution of $\mathrm{NaOH}(1 \mathrm{M})$ was slowly added until it turned strongly basic. The mixture was extracted with ethyl acetate and the combined organic extracts were washed with brine, dried over anhydrous $\mathrm{MgSO}_{4}$, filtered, concentrated and purified on flash column chromatography on silica gel (PE/EA 50:1-10:1) to give the product as a yellow solid, $622.5 \mathrm{mg}, 80 \% .{ }^{1} \mathrm{H}$ NMR (400 MHz, $\left.\mathrm{CDCl}_{3}\right) \delta$ 7.20-7.16 (m, 2H), 6.66-6.62 (m, 2H), 2.93(s, 6H). ${ }^{13} \mathrm{C}\left\{{ }^{1} \mathrm{H}\right\}$ NMR $\left(100 \mathrm{MHz}, \mathrm{CDCl}_{3}\right) \delta 149.3,128.9,121.5,113.8,40.8 .{ }^{2}$

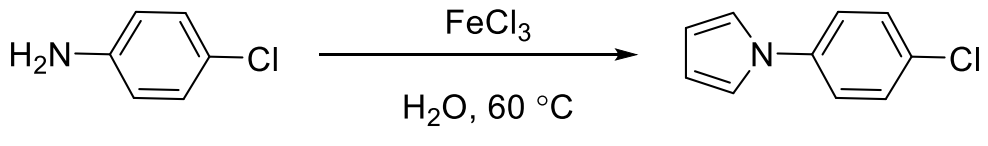

$1 \mathrm{k}$

4-Chlorideaniline $(5 \mathrm{mmol})$ and 2,5-dimethoxytetrahydrofuran $(6 \mathrm{mmol})$ were dissolved in water $(4 \mathrm{~mL})$ at $60{ }^{\circ} \mathrm{C}$, then $\mathrm{FeCl}_{3}(2 \mathrm{~mol} \%)$ was added. The mixture was 
stirred for $4 \mathrm{~h}$ and extracted with $\mathrm{Et}_{2} \mathrm{O}$. The combined organic extracts were washed with brine, dried over anhydrous $\mathrm{MgSO}_{4}$, filtered, concentrated and purified on flash column chromatography on silica gel (PE/EA 50:1-10:1) to give the product as a yellow solid, $880 \mathrm{mg}, 66 \%$. ${ }^{1} \mathrm{H}$ NMR $\left(400 \mathrm{MHz}, \mathrm{CDCl}_{3}\right) \delta 7.41-7.38(\mathrm{~m}, 2 \mathrm{H}), 7.35$ $7.31(\mathrm{~m}, 2 \mathrm{H}), 7.05(\mathrm{t}, J=2.0 \mathrm{~Hz}, 2 \mathrm{H}), 6.36(\mathrm{t}, J=2.4 \mathrm{~Hz}, 2 \mathrm{H}) .{ }^{13} \mathrm{C} \mathrm{NMR}(100 \mathrm{MHz}$, $\left.\mathrm{CDCl}_{3}\right) \delta 139.5,131.2,129.8,121.8,119.4,111.0 .^{3}$

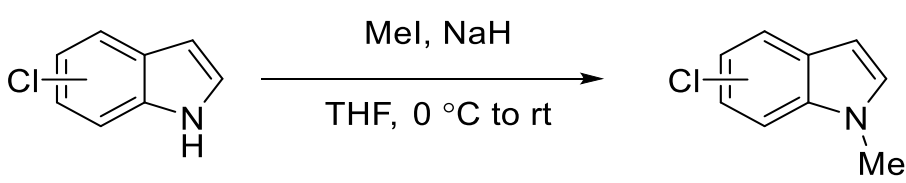

General procedures for the preparation of 1m-n (GP2): 5-Chloroindole was weighed directly into a Schlenk tube and dried under vacuum for $15 \mathrm{~min}$. Then THF was added and stirred. $\mathrm{NaH}$ (1.5 equiv) was slowly added at $0{ }^{\circ} \mathrm{C}$. After stirring for 30 min, methyl iodide (1.5 equiv) was added. The mixture was then warmed up to r.t. and the resulting reaction mixture was monitored by TLC. The reaction was quenched by $\mathrm{H}_{2} \mathrm{O}$ and extracted with $\mathrm{Et}_{2} \mathrm{O}$. The combined organic extracts were washed with brine, dried over anhydrous $\mathrm{MgSO}_{4}$, filtered, concentrated and purified on flash column chromatography on silica gel (PE/EA 50:1-10:1) to give the product.<smiles>Cn1ccc2cc(Cl)ccc21</smiles>

5-Chloro-1-methyl-1H-indole (1m)

Prepared according to GP2, yellow oil, $825.2 \mathrm{mg}, 100 \%$. ${ }^{1} \mathrm{H}$ NMR (400 MHz, $\left.\mathrm{CDCl}_{3}\right) \delta 7.61(\mathrm{~s}, 1 \mathrm{H}), 7.25-7.23(\mathrm{~m}, 1 \mathrm{H}), 7.19-7.17(\mathrm{~m}, 1 \mathrm{H}), 7.08(\mathrm{~d}, J=2.8 \mathrm{~Hz}, 1 \mathrm{H})$, $6.44(\mathrm{~d}, J=2.8 \mathrm{~Hz}, 1 \mathrm{H}), 3.78(\mathrm{~s}, 3 \mathrm{H}) .{ }^{13} \mathrm{C}\left\{{ }^{1} \mathrm{H}\right\} \mathrm{NMR}\left(100 \mathrm{MHz}, \mathrm{CDCl}_{3}\right) \delta 135.2,130.2$, $129.5,125.2,121.9,120.3,110.3,100.7,33.1 .^{4}$<smiles>Cn1ccc2ccc(Cl)cc21</smiles>

\section{6-Chloro-1-methyl-1H-indole (1n)}

Prepared according to GP2, yellow oil, $825.2 \mathrm{mg}, 100 \%$. ${ }^{1} \mathrm{H}$ NMR (400 MHz, $\left.\mathrm{CDCl}_{3}\right) \delta 7.51(\mathrm{~d}, J=8.4 \mathrm{~Hz}, 1 \mathrm{H}), 7.31(\mathrm{~m}, 1 \mathrm{H}), 7.08(\mathrm{dt}, J=1.6,8.4 \mathrm{~Hz}, 1 \mathrm{H}), 7.03(\mathrm{~d}$, $J=3.2 \mathrm{~Hz}, 1 \mathrm{H}), 6.46(\mathrm{dt}, J=3.2,0.8, \mathrm{~Hz}, 1 \mathrm{H}), 3.76(\mathrm{~s}, 3 \mathrm{H}) .{ }^{13} \mathrm{C}\left\{{ }^{1} \mathrm{H}\right\} \mathrm{NMR}(100 \mathrm{MHz}$, 
$\left.\mathrm{CDCl}_{3}\right) \delta 137.2,129.6,127.7,127.1,121.8,120.1,109.4,101.3,33.0 .{ }^{5}$

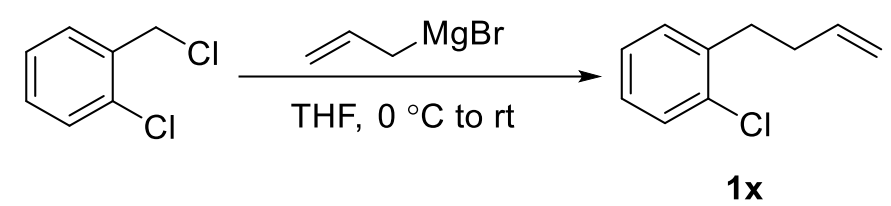

Vinyl magnesium bromide (2.0 equiv, 1.0 M in THF) was added slowly to a stirred solution of flashly distilled 1-(chloromethyl)-2-chlorobenzene (20 mmol, 1.0 equiv) in THF $(0.5 \mathrm{M})$ below $5{ }^{\circ} \mathrm{C}$. After $15 \mathrm{~min}$, the reaction was allowed to warm to r.t. and stirred for additional $3 \mathrm{~h}$. The reaction was quenched with sat. $\mathrm{NH}_{4} \mathrm{Cl}$ aq. and extracted with $\mathrm{Et}_{2} \mathrm{O}$. The combined organic extracts were washed with brine, dried over $\mathrm{MgSO}_{4}$, filtered, concentrated and purified on flash column chromatography on silica gel (PE/EA 100:1-10:1) to give the product as a colorless oil, $313 \mathrm{mg}, 47 \% .{ }^{1} \mathrm{H}$ NMR (400 $\left.\mathrm{MHz} \mathrm{CDCl}_{3}\right) \delta 7.34(\mathrm{~d}, J=7.6 \mathrm{~Hz}, 1 \mathrm{H}), 7.22-7.12(\mathrm{~m}, 3 \mathrm{H}), 5.93-5.83(\mathrm{~m}, 1 \mathrm{H}), 5.06$ $(\mathrm{d}, J=16.8 \mathrm{~Hz}, 1 \mathrm{H}), 5.00(\mathrm{~d}, J=7.2 \mathrm{~Hz}, 1 \mathrm{H}), 2.83(\mathrm{t}, J=7.6 \mathrm{~Hz}, 2 \mathrm{H}), 2.41-2.36(\mathrm{~m}$, $2 \mathrm{H}) .{ }^{13} \mathrm{C}\left\{{ }^{1} \mathrm{H}\right\} \mathrm{NMR}\left(100 \mathrm{MHz}, \mathrm{CDCl}_{3}\right) \delta 139.5,137.9,134.1,130.5,129.6,127.4$, $126.8,115.3,33.8,33.2 .^{6}$ 


\section{Dehalogenation of Aryl Halides}

General procedures for the dehalogenation of aryl halides (GP3). The ${ }^{t} \mathrm{BuOK}$ (280.3 mg, $2.5 \mathrm{mmol}, 5$ equiv) was weighed directly into a glass Schlenk tube (Reaction of 1a was also carried out in quartz Schlenk tube and could give similar result) and dried under high vacuum for $15 \mathrm{~min}$. Solvent (4 mL) and aldehyde (1, 3, 4 or 5) $(0.5$ mmol, 1 equiv) were added under argon and stirred. Then the tube was irradiated by a $27 \mathrm{~W}$ Blue LED and the reaction was monitored by TLC. Upon completion, $20 \mathrm{~mL}$ of water and $10 \mathrm{~mL}$ of ethyl acetate was added. After extarction of the aqueous phase with ethyl acetate, the combined organic extracts were washed with brine, dried over $\mathrm{Na}_{2} \mathrm{SO}_{4}$, and concentrated. The crude product was purified on flash column chromatography on silica gel to afford the desired product.

The light source uses nine LED light bars that each has $3 \mathrm{~W}$ white LED beads. The bars were pasted on the inner wall of an aluminum hollow cylinder with an inner diameter of $5 \mathrm{~cm}$. A fan was used in the cylinder to control the temperature at $35^{\circ} \mathrm{C}$.

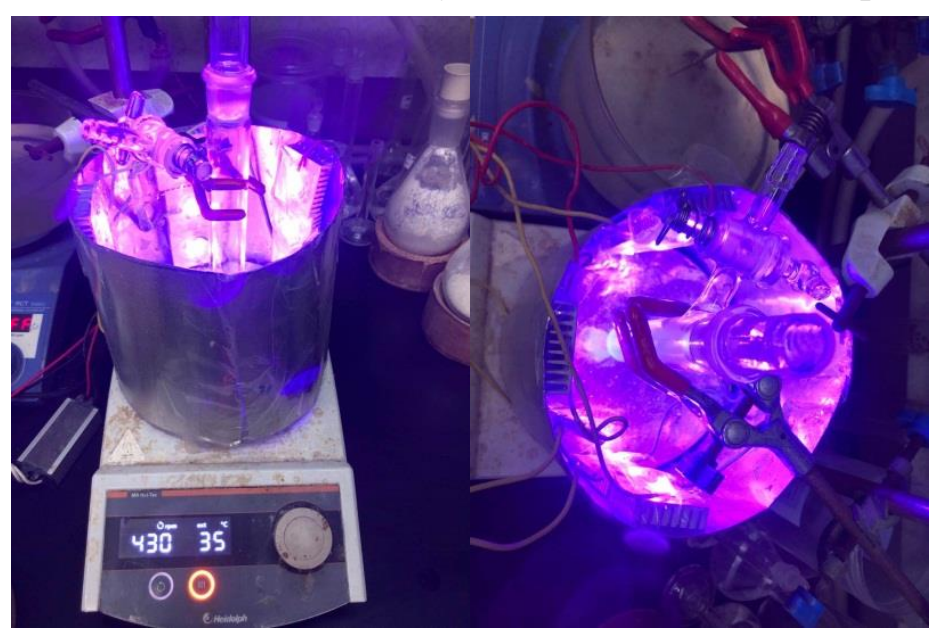




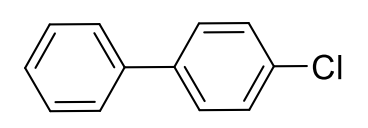

$1 \mathbf{a}$

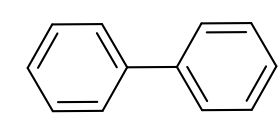

$2 \mathbf{a}$

1a was reduced according to GP3 and purified by flash column chromatography on silica gel (PE/EA 100:1-20:1) to afford 1,1'-biphenyl (2a) as a white solid, 74 mg, 96\%. ${ }^{1} \mathrm{H}$ NMR $\left(400 \mathrm{MHz}, \mathrm{CDCl}_{3}\right) \delta$ 7.78-7.76 (m, 4H), 7.62-7.58 (m, 4H), 7.52-7.48 (m, 2H). ${ }^{13} \mathrm{C}\left\{{ }^{1} \mathrm{H}\right\}$ NMR $\left(100 \mathrm{MHz}, \mathrm{CDCl}_{3}\right) \delta 141.3,128.9,127.4,127.3 .{ }^{7}$<smiles>Clc1ccc2ccccc2c1</smiles>

$1 \mathrm{~b}$<smiles>c1ccc2ccccc2c1</smiles>

2b

1b was reduced according to GP3 and purified by flash column chromatography on silica gel (PE/EA 100:1-20:1) to afford naphthalene (2b) as a white solid, $56.4 \mathrm{mg}$, 88\%. ${ }^{1} \mathrm{H}$ NMR (400 MHz, $\left.\mathrm{CDCl}_{3}\right) \delta 8.01-7.99(\mathrm{~m}, 4 \mathrm{H}), 7.65-7.62(\mathrm{~m}, 4 \mathrm{H}) .{ }^{13} \mathrm{C}\left\{{ }^{1} \mathrm{H}\right\}$ NMR $\left(100 \mathrm{MHz}, \mathrm{CDCl}_{3}\right) \delta 133.6,128.0,125.9 .^{7}$

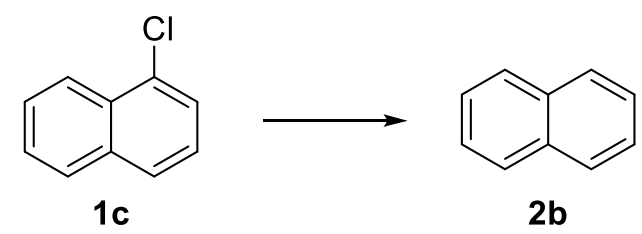

1c was reduced according to GP3 and purified by flash column chromatography on silica gel (PE/EA 100:1-20:1) to afford naphthalene (2b) as a white solid, $55.7 \mathrm{mg}$, 87\%. ${ }^{1} \mathrm{H}$ NMR (400 MHz, $\left.\mathrm{CDCl}_{3}\right) \delta 8.01-7.99(\mathrm{~m}, 4 \mathrm{H}), 7.65-7.62(\mathrm{~m}, 4 \mathrm{H}) .{ }^{13} \mathrm{C}\left\{{ }^{1} \mathrm{H}\right\}$ NMR $\left(100 \mathrm{MHz}, \mathrm{CDCl}_{3}\right) \delta 133.6,128.0,125.9 .^{7}$<smiles>Clc1c2ccccc2cc2ccccc12</smiles>

1d<smiles>c1ccc2cc3ccccc3cc2c1</smiles>

2c

1d was reduced according to GP3 and purified by flash column chromatography on silica gel (PE/EA 100:1-20:1) to afford anthrzcene (2c) as a white solid, $62.4 \mathrm{mg}$, 70\%. ${ }^{1} \mathrm{H}$ NMR (400 MHz, $d$-DMSO) $\delta 8.59$ (s, 2H), $8.10(\mathrm{dd}, J=3.2 \mathrm{~Hz}, 4 \mathrm{H}), 7.52(\mathrm{dd}$, 
$J=3.2 \mathrm{~Hz}, 4 \mathrm{H}) .{ }^{13} \mathrm{C}\left\{{ }^{1} \mathrm{H}\right\} \mathrm{NMR}\left(100 \mathrm{MHz}, d\right.$-DMSO) $\delta 131.3,128.1,126.1,125.6 .{ }^{7}$<smiles>CCCN(C(=O)c1ccccc1)C(=O)c1ccc(Cl)cc1</smiles>

1e was reduced according to GP3 and purified by flash column chromatography on silica gel (PE/EA 100:1-10:1) to afford $N, \boldsymbol{N}$-diisopropylbenzamide (2d) as a white solid, $96.5 \mathrm{mg}, 94 \% .{ }^{1} \mathrm{H}$ NMR $\left(400 \mathrm{MHz}, \mathrm{CDCl}_{3}\right) \delta$ 7.37-7.36 (m, 3H), 7.31-7.29 (m, 2H), 3.82 (brs, 1H), 3.53 (brs, 1H), 1.52 (brs, 6H), 1.15 (brs, 6H). ${ }^{13} \mathrm{C}\left\{{ }^{1} \mathrm{H}\right\}$ NMR $(100$ $\left.\mathrm{MHz}, \mathrm{CDCl}_{3}\right) \delta 171.1,139.0,128.7,128.5,125.6,51.0,20.8 .^{7}$<smiles>CN(C)C(=O)c1ccc(Cl)cc1</smiles>

1f was reduced according to GP3 and purified by flash column chromatography

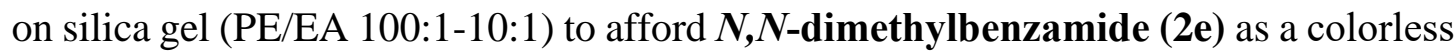
oil, 64.6 mg, 88\%. ${ }^{1} \mathrm{H}$ NMR (400 MHz, $\left.\mathrm{CDCl}_{3}\right) \delta$ 7.39-7.26 (m, 5H), 3.07 (s, 3H), 2.94 (s, 3H). ${ }^{13} \mathrm{C}\left\{{ }^{1} \mathrm{H}\right\}$ NMR $\left(100 \mathrm{MHz}, \mathrm{CDCl}_{3}\right) \delta 171.7,136.4,129.6,128.4,127.1,39.7$, $35.4 .^{8}$<smiles>CCN(CC)C(=O)c1ccccc1</smiles>

$1 \mathrm{~g}$ was reduced according to GP3 and purified by flash column chromatography

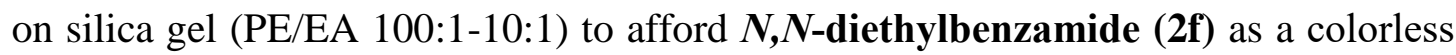
oil, 88.6 mg, 100\%. ${ }^{1} \mathrm{H}$ NMR (400 MHz, $\left.\mathrm{CDCl}_{3}\right) \delta$ 7.36-7.33 (m, 5H), 3.53 (brs, 2H), 3.24 (brs, 2H) 1.22 (s, 3H). 1.09 (s, 3H). ${ }^{13} \mathrm{C}\left\{{ }^{1} \mathrm{H}\right\}$ NMR (100 MHz, CDCl $)_{3} \delta$ 171.4, $137.4,129.1,128.5,126.4,43.4,39.3,14.3,13.0 .^{9}$ 
<smiles>O=C(c1ccccc1)c1ccc(Cl)cc1</smiles>

$1 \mathrm{~h}$<smiles>O=C(c1ccccc1)c1ccccc1</smiles>

$2 \mathrm{~g}$

1h was reduced according to GP3 and purified by flash column chromatography on silica gel (PE/EA 100:1-10:1) to afford benzophenone (2g) as a white solid, 46.5 mg, 51\%. ${ }^{1} \mathrm{H}$ NMR (400 MHz, $\left.\mathrm{CDCl}_{3}\right) \delta 7.80$ (d, $\left.J=7.2 \mathrm{~Hz}, 4 \mathrm{H}\right), 7.59$ (t, $J=7.2 \mathrm{~Hz}$, 2H), $7.49(\mathrm{t}, J=7.6 \mathrm{~Hz}, 4 \mathrm{H}) .{ }^{13} \mathrm{C}\left\{{ }^{1} \mathrm{H}\right\} \mathrm{NMR}\left(100 \mathrm{MHz}, \mathrm{CDCl}_{3}\right) \delta 196.9,137.7,132.6$, $130.2,128.4 .^{10}$<smiles>N#Cc1ccc(Cl)cc1</smiles>

$1 \mathbf{i}$<smiles>N#Cc1ccccc1</smiles>

$2 \mathrm{~h}$

$1 \mathbf{i}$ was reduced according to $\mathbf{G P 3}$ and purified by flash column chromatography on silica gel (PE/EA 100:1-20:1) to afford benzonitrile (2h) as a colorless oil, $51.6 \mathrm{mg}$, 100\%. ${ }^{1} \mathrm{H}$ NMR $\left(400 \mathrm{MHz}, \mathrm{CDCl}_{3}\right) \delta 7.64(\mathrm{~d}, J=8.0 \mathrm{~Hz}, 2 \mathrm{H}), 7.60(\mathrm{t}, J=7.6 \mathrm{~Hz}, 1 \mathrm{H})$, $7.47(\mathrm{t}, J=7.6 \mathrm{~Hz}, 2 \mathrm{H}) .{ }^{13} \mathrm{C}\left\{{ }^{1} \mathrm{H}\right\} \mathrm{NMR}\left(100 \mathrm{MHz}, \mathrm{CDCl}_{3}\right) \delta 132.9,132.2,129.2,118.9$, $112.5 .^{11}$

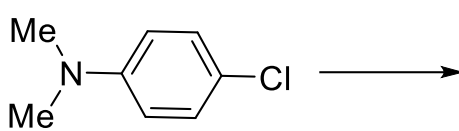

$1 \mathrm{j}$<smiles>CN(C)c1ccccc1</smiles>

$2 \mathbf{i}$

1j was reduced according to GP3 and purified by flash column chromatography on silica gel (PE/EA 100:1-10:1) to afford $\mathbf{N}, \boldsymbol{N}$-dimethylaniline (2i) as a colorless oil, $57.6 \mathrm{mg}, 95 \% .{ }^{1} \mathrm{H}$ NMR (400 MHz, $\left.\mathrm{CDCl}_{3}\right) \delta$ 7.31-7.27 (m, 2H), 6.80-6.75 (m, 3H), $2.98(\mathrm{~s}, 3 \mathrm{H}) .{ }^{13} \mathrm{C}\left\{{ }^{1} \mathrm{H}\right\}$ NMR $\left(100 \mathrm{MHz}, \mathrm{CDCl}_{3}\right) \delta 150.8,129.2,116.7,112.8,40.7 .{ }^{7}$<smiles>Clc1ccc(-n2cccc2)cc1</smiles>

$1 \mathrm{k}$<smiles>c1ccc(-n2cccc2)cc1</smiles>

2j

1k was reduced according to GP3 and purified by flash column chromatography on silica gel (PE/EA 100:1-10:1) to afford 1-phenyl-1H-pyrrole (2j) as a white solid, $44.4 \mathrm{mg}, 62 \% .{ }^{1} \mathrm{H}$ NMR (400 MHz, $\left.\mathrm{CDCl}_{3}\right) \delta$ 7.47-7.41 (m, 4H), 7.31-7.25 (m, 2H), 7.13-7.12 (m, 2H), 6.39-6.38 (m, 2H). ${ }^{13} \mathrm{C}\left\{{ }^{1} \mathrm{H}\right\}$ NMR (100 MHz, $\left.\mathrm{CDCl}_{3}\right) \delta$ 140.9, 


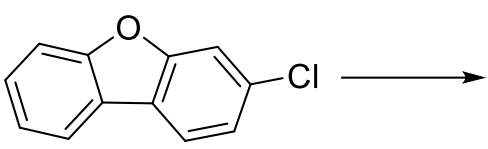

11

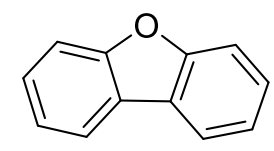

2k

11 was reduced according to GP3 and purified by flash column chromatography on silica gel (PE/EA 100:1-10:1) to afford dibenzo[b,d]furan (2k) as a white solid, $47.1 \mathrm{mg}, 56 \% .{ }^{1} \mathrm{H}$ NMR (400 MHz, $\left.\mathrm{CDCl}_{3}\right) \delta 7.97$ (dt, $\left.J=7.6,0.8 \mathrm{~Hz}, 2 \mathrm{H}\right), 7.59$ (dd, $J=8.4,0.8 \mathrm{~Hz}, 2 \mathrm{H}), 7.49-7.45(\mathrm{~m}, 2 \mathrm{H}), 7.36(\mathrm{t}, J=7.6 \mathrm{~Hz}, 2 \mathrm{H}) .{ }^{13} \mathrm{C}\left\{{ }^{1} \mathrm{H}\right\} \mathrm{NMR}(100$ $\left.\mathrm{MHz}, \mathrm{CDCl}_{3}\right) \delta 156.3,127.2,124.3,122.8,120.8,111.8 .^{12}$

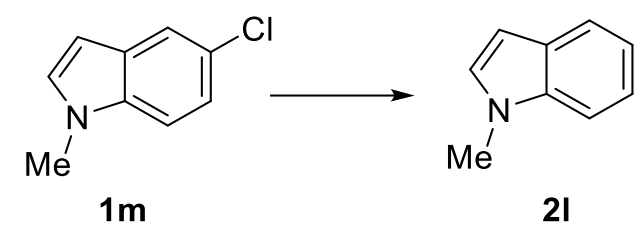

1m was reduced according to GP3 and purified by flash column chromatography on silica gel (PE/EA 100:1-10:1) to afford 1-methyl-1H-indole (2l) as a colorless oil, $63.0 \mathrm{mg}, 96 \% .{ }^{1} \mathrm{H} \mathrm{NMR}\left(400 \mathrm{MHz}, \mathrm{CDCl}_{3}\right) \delta 7.65(\mathrm{dt}, J=8.0,0.8 \mathrm{~Hz}, 1 \mathrm{H}), 7.35(\mathrm{dd}$, $J=8.0,0.8 \mathrm{~Hz}, 1 \mathrm{H}), 7.27-7.23(\mathrm{~m}, 1 \mathrm{H}), 7.15-7.11(\mathrm{~m}, 1 \mathrm{H}), 7.07(\mathrm{~d}, J=7.2 \mathrm{~Hz}, 1 \mathrm{H})$. ${ }^{13} \mathrm{C}\left\{{ }^{1} \mathrm{H}\right\} \mathrm{NMR}\left(100 \mathrm{MHz}, \mathrm{CDCl}_{3}\right) \delta 136.8,128.9,128.5,121.6,120.9,119.3,109.3$, $101.0,32.9 .^{7}$<smiles>Cn1ccc2ccc(Cl)cc21</smiles>

1n was reduced according to GP3 and purified by flash column chromatography on silica gel (PE/EA 100:1-10:1) to afford 1-methyl-1H-indole (2l) as a colorless oil, $41.3 \mathrm{mg}, 63 \% .{ }^{1} \mathrm{H} \mathrm{NMR}\left(400 \mathrm{MHz}, \mathrm{CDCl}_{3}\right) \delta 7.65$ (dt, $\left.J=8.0,0.8 \mathrm{~Hz}, 1 \mathrm{H}\right), 7.35$ (dd, $J=8.0,0.8 \mathrm{~Hz}, 1 \mathrm{H}), 7.27-7.23(\mathrm{~m}, 1 \mathrm{H}), 7.15-7.11(\mathrm{~m}, 1 \mathrm{H}), 7.07$ (d, $J=7.2 \mathrm{~Hz}, 1 \mathrm{H})$. ${ }^{13} \mathrm{C}\left\{{ }^{1} \mathrm{H}\right\}$ NMR $\left(100 \mathrm{MHz}, \mathrm{CDCl}_{3}\right) \delta 136.8,128.9,128.5,121.6,120.9,119.3,109.3$, 101.0, 32.9. 


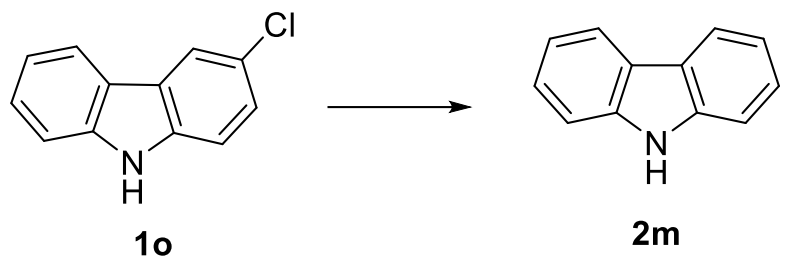

10 was reduced according to GP3 and purified by flash column chromatography on silica gel (PE/EA 100:1-10:1) to afford $\mathbf{9 H}$-carbazole (2m) as a white solid, 83.6 mg, 50\%. ${ }^{1} \mathrm{H}$ NMR (400 MHz, $\left.\mathrm{CDCl}_{3}\right) \delta 11.3(\mathrm{~s}, 1 \mathrm{H}), 8.11(\mathrm{~d}, J=7.6 \mathrm{~Hz}, 2 \mathrm{H}), 7.51(\mathrm{~d}$, $J=8.0 \mathrm{~Hz}, 2 \mathrm{H}), 7.39(\mathrm{t}, J=7.6 \mathrm{~Hz}, 2 \mathrm{H}), 7.16(\mathrm{~d}, J=7.2 \mathrm{~Hz}, 2 \mathrm{H}) .{ }^{13} \mathrm{C}\left\{{ }^{1} \mathrm{H}\right\} \mathrm{NMR}(100$ $\left.\mathrm{MHz}, \mathrm{CDCl}_{3}\right) \delta 140.2,126.0,122.8,120.6,118.9,111.4 .^{13}$

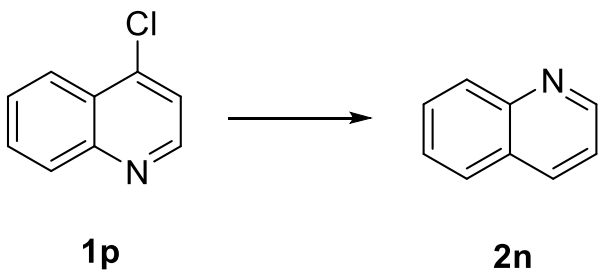

1p was reduced according to GP3 and purified by flash column chromatography on silica gel (PE/EA 100:1-10:1) to afford quinoline (2n) as a white solid, $55.5 \mathrm{mg}$, 86\%. ${ }^{1} \mathrm{H}$ NMR (400 MHz, $\left.\mathrm{CDCl}_{3}\right) \delta 8.93(\mathrm{dd}, J=8.0,2.0 \mathrm{~Hz}, 1 \mathrm{H}), 8.17(\mathrm{~d}, J=8.4 \mathrm{~Hz}$, $1 \mathrm{H}), 8.12(\mathrm{~d}, J=8.4 \mathrm{~Hz}, 1 \mathrm{H}), 7.83(\mathrm{~d}, J=8.0 \mathrm{~Hz}, 1 \mathrm{H}), 7.75-7.71(\mathrm{~m}, 1 \mathrm{H}), 7.56(\mathrm{dt}, J=$ $8.0,1.2 \mathrm{~Hz}, 1 \mathrm{H}), 7.41(\mathrm{dd}, J=8.0,4.0 \mathrm{~Hz}, 1 \mathrm{H}),{ }^{13} \mathrm{C}\left\{{ }^{1} \mathrm{H}\right\} \mathrm{NMR}\left(100 \mathrm{MHz}, \mathrm{CDCl}_{3}\right) \delta$ $150.5,148.3,136.1,129.5,129.5,128.3,127.6,126.6,121.1 .^{14}$

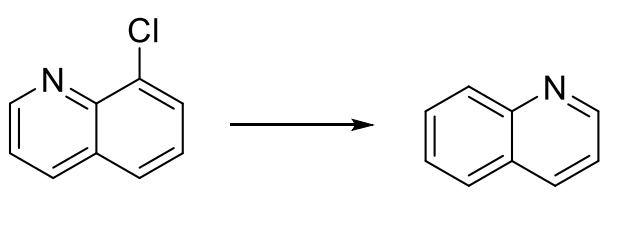

$1 q$

2n

1q was reduced according to GP3 and purified by flash column chromatography on silica gel (PE/EA 100:1-10:1) to afford quinoline (2n) as a white solid, $47.8 \mathrm{mg}$, 74\%. ${ }^{1} \mathrm{H}$ NMR (400 MHz, $\left.\mathrm{CDCl}_{3}\right) \delta 8.93(\mathrm{dd}, J=8.0,2.0 \mathrm{~Hz}, 1 \mathrm{H}), 8.17(\mathrm{~d}, J=8.4 \mathrm{~Hz}$, $1 \mathrm{H}), 8.12(\mathrm{~d}, J=8.4 \mathrm{~Hz}, 1 \mathrm{H}), 7.83(\mathrm{~d}, J=8.0 \mathrm{~Hz}, 1 \mathrm{H}), 7.75-7.71(\mathrm{~m}, 1 \mathrm{H}), 7.56(\mathrm{dt}, J=$ $8.0,1.2 \mathrm{~Hz}, 1 \mathrm{H}), 7.41(\mathrm{dd}, J=8.0,4.0 \mathrm{~Hz}, 1 \mathrm{H}),{ }^{13} \mathrm{C}\left\{{ }^{1} \mathrm{H}\right\} \mathrm{NMR}\left(100 \mathrm{MHz}, \mathrm{CDCl}_{3}\right) \delta$ $150.5,148.3,136.1,129.5,129.5,128.3,127.6,126.6,121.1 .^{14}$ 


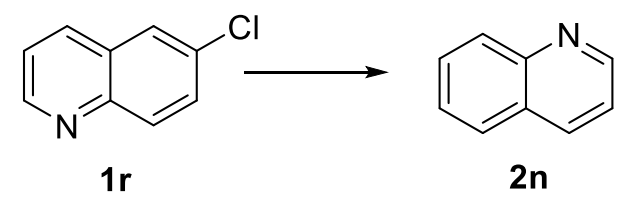

1r was reduced according to GP3 and purified by flash column chromatography on silica gel (PE/EA 100:1-10:1) to afford quinoline (2n) as a white solid, $41.3 \mathrm{mg}$, 64\%. ${ }^{1} \mathrm{H}$ NMR (400 MHz, $\left.\mathrm{CDCl}_{3}\right) \delta 8.93(\mathrm{dd}, J=8.0,2.0 \mathrm{~Hz}, 1 \mathrm{H}), 8.17(\mathrm{~d}, J=8.4 \mathrm{~Hz}$, $1 \mathrm{H}), 8.12(\mathrm{~d}, J=8.4 \mathrm{~Hz}, 1 \mathrm{H}), 7.83(\mathrm{~d}, J=8.0 \mathrm{~Hz}, 1 \mathrm{H}), 7.75-7.71(\mathrm{~m}, 1 \mathrm{H}), 7.56(\mathrm{dt}, J=$ 8.0, 1.2Hz, 1H), $7.41(\mathrm{dd}, J=8.0,4.0 \mathrm{~Hz}, 1 \mathrm{H}),{ }^{13} \mathrm{C}\left\{{ }^{1} \mathrm{H}\right\} \mathrm{NMR}\left(100 \mathrm{MHz}, \mathrm{CDCl}_{3}\right) \delta$ $150.5,148.3,136.1,129.5,129.5,128.3,127.6,126.6,121.1 .^{14}$

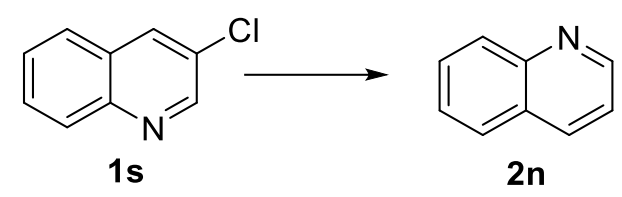

1s was reduced according to GP3 and purified by flash column chromatography on silica gel (PE/EA 100:1-10:1) to afford quinoline (2n) as a white solid, $30.3 \mathrm{mg}$, 47\%. ${ }^{1} \mathrm{H}$ NMR $\left(400 \mathrm{MHz}, \mathrm{CDCl}_{3}\right) \delta 8.93(\mathrm{dd}, J=8.0,2.0 \mathrm{~Hz}, 1 \mathrm{H}), 8.17$ (d, $J=8.4 \mathrm{~Hz}$, $1 \mathrm{H}), 8.12(\mathrm{~d}, J=8.4 \mathrm{~Hz}, 1 \mathrm{H}), 7.83(\mathrm{~d}, J=8.0 \mathrm{~Hz}, 1 \mathrm{H}), 7.75-7.71(\mathrm{~m}, 1 \mathrm{H}), 7.56(\mathrm{dt}, J=$ 8.0, 1.2Hz, 1H), $7.41(\mathrm{dd}, J=8.0,4.0 \mathrm{~Hz}, 1 \mathrm{H}),{ }^{13} \mathrm{C}\left\{{ }^{1} \mathrm{H}\right\} \mathrm{NMR}\left(100 \mathrm{MHz}, \mathrm{CDCl}_{3}\right) \delta$ $150.5,148.3,136.1,129.5,129.5,128.3,127.6,126.6,121.1 .^{14}$

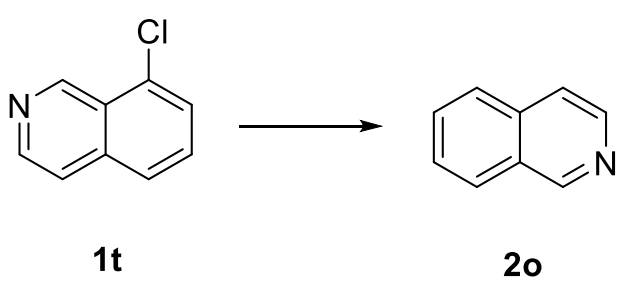

1t was reduced according to GP3 and purified by flash column chromatography on silica gel (PE/EA 100:1-10:1) to afford isouinoline (2o) as a white solid, $48.4 \mathrm{mg}$, 75\%. ${ }^{1} \mathrm{H}$ NMR (400 MHz, $\left.\mathrm{CDCl}_{3}\right) \delta 9.24(\mathrm{~s}, 1 \mathrm{H}), 8.51(\mathrm{dd}, J=6.0,1.2 \mathrm{~Hz}, 1 \mathrm{H}), 7.94$ $(\mathrm{d}, J=7.2 \mathrm{~Hz}, 1 \mathrm{H}), 7.79(\mathrm{~d}, J=7.2 \mathrm{~Hz}, 1 \mathrm{H}), 7.69-7.56(\mathrm{~m}, 3 \mathrm{H}) .{ }^{13} \mathrm{C}\left\{{ }^{1} \mathrm{H}\right\}$ NMR $(100$ $\left.\mathrm{MHz}_{\mathrm{CDCl}}\right) \delta 152.6,143.0,135.8,130.4,128.7,127.7,127.3,126.5,120.5 .^{7}$ 


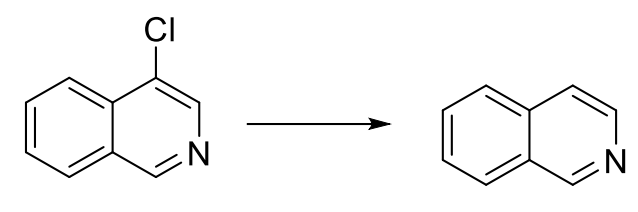

1u

20

1u was reduced according to GP3 and purified by flash column chromatography on silica gel (PE/EA 100:1-10:1) to afford isouinoline (2o) as a white solid, $58.8 \mathrm{mg}$, 91\%. ${ }^{1} \mathrm{H}$ NMR (400 MHz, $\left.\mathrm{CDCl}_{3}\right) \delta 9.24(\mathrm{~s}, 1 \mathrm{H}), 8.51(\mathrm{dd}, J=6.0,1.2 \mathrm{~Hz}, 1 \mathrm{H}), 7.94$ $(\mathrm{d}, J=7.2 \mathrm{~Hz}, 1 \mathrm{H}), 7.79(\mathrm{~d}, J=7.2 \mathrm{~Hz}, 1 \mathrm{H}), 7.69-7.56(\mathrm{~m}, 3 \mathrm{H}) \cdot{ }^{13} \mathrm{C}\left\{{ }^{1} \mathrm{H}\right\}$ NMR $(100$ $\left.\mathrm{MHz}_{2} \mathrm{CDCl}_{3}\right) \delta 152.6,143.0,135.8,130.4,128.7,127.7,127.3,126.5,120.5{ }^{7}$<smiles>Clc1cccc2cnccc12</smiles>

1v
20<smiles>c1ccc2cnccc2c1</smiles>

1v was reduced according to GP3 and purified by flash column chromatography on silica gel (PE/EA 100:1-10:1) to afford isouinoline (2o) as a white solid, $57.5 \mathrm{mg}$, 89\%. ${ }^{1} \mathrm{H}$ NMR (400 MHz, $\left.\mathrm{CDCl}_{3}\right) \delta 9.24(\mathrm{~s}, 1 \mathrm{H}), 8.51(\mathrm{dd}, J=6.0,1.2 \mathrm{~Hz}, 1 \mathrm{H}), 7.94$ $(\mathrm{d}, J=7.2 \mathrm{~Hz}, 1 \mathrm{H}), 7.79(\mathrm{~d}, J=7.2 \mathrm{~Hz}, 1 \mathrm{H}), 7.69-7.56(\mathrm{~m}, 3 \mathrm{H}) \cdot{ }^{13} \mathrm{C}\left\{{ }^{1} \mathrm{H}\right\}$ NMR $(100$ $\left.\mathrm{MHz}_{2} \mathrm{CDCl}_{3}\right) \delta 152.6,143.0,135.8,130.4,128.7,127.7,127.3,126.5,120.5{ }^{7}$<smiles>Cc1ccc2ccc(C)nc2c1</smiles>

1w was reduced according to GP3 and purified by flash column chromatography on silica gel (PE/EA 100:1-10:1) to afford 2-methylquinoline (2p) as a white solid, $39.4 \mathrm{mg}, 55 \% .{ }^{1} \mathrm{H}$ NMR (400 MHz, $\left.\mathrm{CDCl}_{3}\right) \delta 8.00(\mathrm{t}, J=8.0 \mathrm{~Hz}, 2 \mathrm{H}), 7.74-7.72(\mathrm{~m}$, 1H), 7.98-7.63 (m, 1H), 7.47-7.42 (m, 1H), 7.26-7.22 (m, 1H), $2.73(\mathrm{~s}, 3 \mathrm{H}) .{ }^{13} \mathrm{C}\left\{{ }^{1} \mathrm{H}\right\}$ $\operatorname{NMR}\left(100 \mathrm{MHz}, \mathrm{CDCl}_{3}\right) \delta 159.0,147.9,136.2,129.5,128.7,127.6,126.5,125.7,122.1$, $25.4 .^{15}$<smiles>CC=CCCc1ccccc1Cl</smiles> 
1x was reduced according to GP3 and purified by flash column chromatography on silica gel (PE/EA 100:1-20:1) to afford 1-methyl-2,3-dihydro-1H-indene (6) as a colorless oil, $21.8 \mathrm{mg}, 33 \%$. ${ }^{1} \mathrm{H}$ NMR (400 MHz, $\left.\mathrm{CDCl}_{3}\right) \delta$ 7.23-7.13 (m, 4H), 3.23$3.14(\mathrm{~m}, 1 \mathrm{H}), 2.95-2.80(\mathrm{~m}, 2 \mathrm{H}), 2.35-2.27(\mathrm{~m}, 1 \mathrm{H}), 1.65-1.54(\mathrm{~m}, 1 \mathrm{H}), 1.29$ (d, $J=7.8$ $\mathrm{Hz}, 3 \mathrm{H}) .{ }^{13} \mathrm{C}\left\{{ }^{1} \mathrm{H}\right\} \mathrm{NMR}\left(100 \mathrm{MHz}, \mathrm{CDCl}_{3}\right) \delta 148.8,144.0,126.2,124.5,123.3,39.5$, $34.9,31.6,20.0 .^{16}$

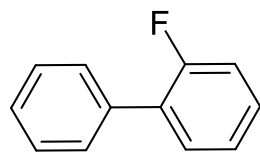

$3 a$

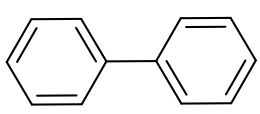

$2 a$

3a was reduced according to GP3 and purified by flash column chromatography on silica gel (PE/EA 100:1-20:1) to afford 1,1'-biphenyl (2a) as a white solid, $29.3 \mathrm{mg}$, 76\%. ${ }^{1} \mathrm{H}$ NMR $\left(400 \mathrm{MHz}, \mathrm{CDCl}_{3}\right) \delta$ 7.78-7.76 (m, 4H), 7.62-7.58 (m, 4H), 7.52-7.48 $(\mathrm{m}, 2 \mathrm{H}) .{ }^{13} \mathrm{C}\left\{{ }^{1} \mathrm{H}\right\}$ NMR $\left(100 \mathrm{MHz}, \mathrm{CDCl}_{3}\right) \delta 141.3,128.9,127.4,127.3 .{ }^{7}$<smiles>Fc1cccc2ccccc12</smiles>

3b<smiles>c1ccc2ccccc2c1</smiles>

2b

3b was reduced according to GP3 and purified by flash column chromatography on silica gel (PE/EA 100:1-20:1) to afford naphthalene (2b) as a white solid, $17.9 \mathrm{mg}$, 56\%. ${ }^{1} \mathrm{H}$ NMR $\left(400 \mathrm{MHz}, \mathrm{CDCl}_{3}\right) \delta 8.01-7.99(\mathrm{~m}, 4 \mathrm{H}), 7.65-7.62(\mathrm{~m}, 4 \mathrm{H}) .{ }^{13} \mathrm{C}\left\{{ }^{1} \mathrm{H}\right\}$ NMR $\left(100 \mathrm{MHz}, \mathrm{CDCl}_{3}\right) \delta 133.6,128.0,125.9^{7}$

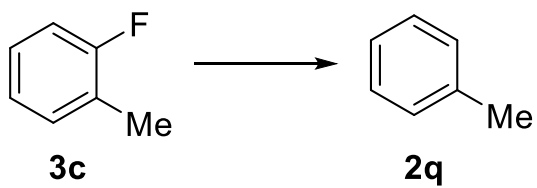

3c was reduced according to GP3 and were determined by GC usin g 1,3,5trimethoxybenzene $(84.1 \mathrm{mg}$ ) as internal standard to afford toluene (2q) as a colorless oil, $87 \%$. The structure was confirmed by comparison with standard toluene sample via GC analysis. ${ }^{17}$ 


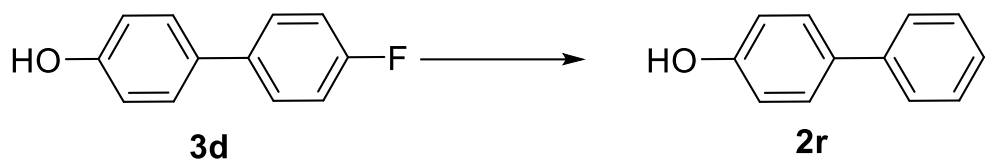

3d was reduced according to GP3 and purified by flash column chromatography on silica gel (PE/EA 100:1-10:1) to afford [1,1'-biphenyl]-4-ol (2r) as a white solid, $37.4 \mathrm{mg}, 88 \%$. ${ }^{1} \mathrm{H}$ NMR (500 MHz, $d$-DMSO) $\delta 9.63$ (s, 1H), 7.58-7.56 (m, 2H), 7. 50$7.48(\mathrm{~m}, 2 \mathrm{H}), 7.40$ (t, $J=8.5 \mathrm{~Hz}, 2 \mathrm{H}), 7.27$ (t, $J=8.5 \mathrm{~Hz}, 1 \mathrm{H}), 6.89(\mathrm{~d}, J=8.5 \mathrm{~Hz}, 2 \mathrm{H})$. ${ }^{13} \mathrm{C}\left\{{ }^{1} \mathrm{H}\right\}$ NMR (125 MHz, $d$-DMSO) $\delta 157.2,140.3,131.0,128.9,127.8,126.5,126.0$, $115.8 .^{18}$

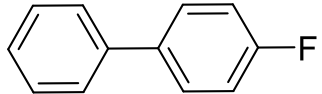

$3 e$

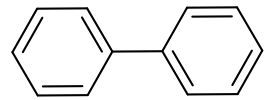

$2 a$

3e was reduced according to GP3 and purified by flash column chromatography on silica gel (PE/EA 100:1-20:1) to afford 1,1'-biphenyl (2a) as a white solid, $31.2 \mathrm{mg}$, 81\%. ${ }^{1} \mathrm{H}$ NMR $\left(400 \mathrm{MHz}, \mathrm{CDCl}_{3}\right) \delta$ 7.78-7.76 (m, 4H), 7.62-7.58 (m, 4H), 7.52-7.48 (m, 2H). ${ }^{13} \mathrm{C}\left\{{ }^{1} \mathrm{H}\right\}$ NMR $\left(100 \mathrm{MHz}, \mathrm{CDCl}_{3}\right) \delta 141.3,128.9,127.4,127.3 .{ }^{7}$

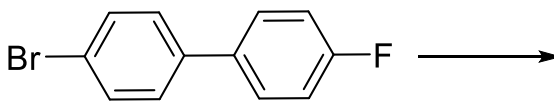

$3 f$

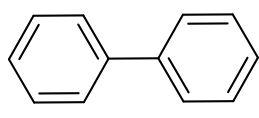

$2 a$

3f was reduced according to GP3 and purified by flash column chromatography on silica gel (PE/EA 100:1-20:1) to afford 1,1'-biphenyl (2a) as a white solid, $24.8 \mathrm{mg}$, 64\%. ${ }^{1} \mathrm{H}$ NMR $\left(400 \mathrm{MHz}, \mathrm{CDCl}_{3}\right) \delta$ 7.78-7.76 (m, 4H), 7.62-7.58 (m, 4H), 7.52-7.48 (m, 2H). ${ }^{13} \mathrm{C}\left\{{ }^{1} \mathrm{H}\right\}$ NMR (100 MHz, $\left.\mathrm{CDCl}_{3}\right) \delta 141.3,128.9,127.4,127.3 .{ }^{7}$

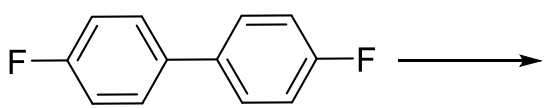

$3 \mathbf{g}$

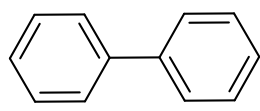

2a

$\mathbf{3 g}$ was reduced according to GP3 and purified by flash column chromatography on silica gel (PE/EA 100:1-20:1) to afford 1,1'-biphenyl (2a) as a white solid, $30.1 \mathrm{mg}$, 78\%. ${ }^{1} \mathrm{H}$ NMR $\left(400 \mathrm{MHz}, \mathrm{CDCl}_{3}\right) \delta$ 7.78-7.76 (m, 4H), 7.62-7.58 (m, 4H), 7.52-7.48 
(m, 2H). ${ }^{13} \mathrm{C}\left\{{ }^{1} \mathrm{H}\right\}$ NMR $\left(100 \mathrm{MHz}, \mathrm{CDCl}_{3}\right) \delta 141.3,128.9,127.4,127.3 .{ }^{7}$

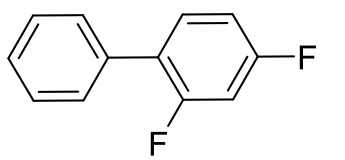

$3 h$

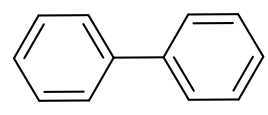

$2 a$

3h was reduced according to GP3 and purified by flash column chromatography on silica gel (PE/EA 100:1-20:1) to afford 1,1'-biphenyl (2a) as a white solid, $19.3 \mathrm{mg}$, 50\%. ${ }^{1} \mathrm{H}$ NMR (400 MHz, $\left.\mathrm{CDCl}_{3}\right) \delta$ 7.78-7.76 (m, 4H), 7.62-7.58 (m, 4H), 7.52-7.48 (m, $2 \mathrm{H}) .{ }^{13} \mathrm{C}\left\{{ }^{1} \mathrm{H}\right\}$ NMR $\left(100 \mathrm{MHz}, \mathrm{CDCl}_{3}\right) \delta 141.3,128.9,127.4,127.3 .{ }^{7}$

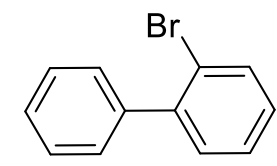

$4 a$

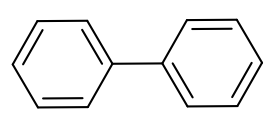

$2 a$

4a was reduced according to GP3 and purified by flash column chromatography on silica gel (PE/EA 100:1-20:1) to afford 1,1'-biphenyl (2a) as a white solid, $64.8 \mathrm{mg}$, 84\%. ${ }^{1} \mathrm{H}$ NMR (400 MHz, $\left.\mathrm{CDCl}_{3}\right) \delta$ 7.78-7.76 (m, 4H), 7.62-7.58 (m, 4H), 7.52-7.48 (m, $2 \mathrm{H}) .{ }^{13} \mathrm{C}\left\{{ }^{1} \mathrm{H}\right\}$ NMR $\left(100 \mathrm{MHz}, \mathrm{CDCl}_{3}\right) \delta 141.3,128.9,127.4,127.3 .{ }^{7}$<smiles>Brc1c2ccccc2cc2ccccc12</smiles>

4b<smiles>c1ccc2cc3ccccc3cc2c1</smiles>

2c

4b was reduced according to GP3 and purified by flash column chromatography on silica gel (PE/EA 100:1-20:1) to afford anthrzcene (2c) as a white solid, $78.4 \mathrm{mg}$, 88\%. ${ }^{1} \mathrm{H}$ NMR (400 MHz, $d$-DMSO) $\delta 8.59(\mathrm{~s}, 2 \mathrm{H}), 8.10(\mathrm{dd}, J=3.2 \mathrm{~Hz}, 4 \mathrm{H}), 7.52(\mathrm{dd}$, $J=3.2 \mathrm{~Hz}, 4 \mathrm{H}) .{ }^{13} \mathrm{C}\left\{{ }^{1} \mathrm{H}\right\}$ NMR $\left(100 \mathrm{MHz}, d\right.$-DMSO) $\delta 131.3,128.1,126.1,125.6 .{ }^{7}$ 


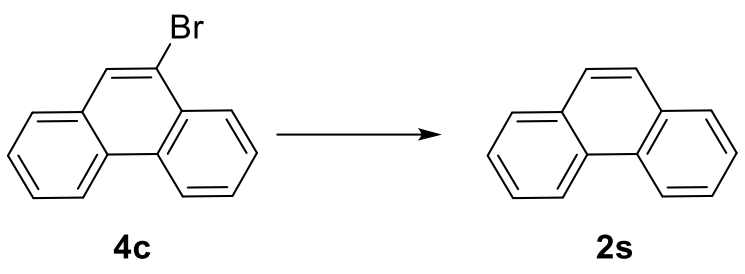

4c was reduced according to GP3 and purified by flash column chromatography on silica gel (PE/EA 100:1-20:1) to afford phenanthrene (2s) as a white solid, 55.3 mg, 62\%. ${ }^{1} \mathrm{H}$ NMR (400 MHz, $\left.\mathrm{CDCl}_{3}\right) \delta 8.71(\mathrm{~d}, J=8.0 \mathrm{~Hz}, 2 \mathrm{H}), 7.91$ (dd, $J=7.6,1.6$ $\mathrm{Hz}, 2 \mathrm{H}), 7.76(\mathrm{~s}, 2 \mathrm{H}), 7.67(\mathrm{dt}, J=6.8,1.6 \mathrm{~Hz}, 2 \mathrm{H}), 7.63-7.59(\mathrm{~m}, 2 \mathrm{H}) .{ }^{13} \mathrm{C}\left\{{ }^{1} \mathrm{H}\right\} \mathrm{NMR}$ $\left(100 \mathrm{MHz}, \mathrm{CDCl}_{3}\right) \delta 132.2,130.4,128.7,127.0,126.7,122.8 .^{7}$<smiles>CCCN1CCOc2ccccc21</smiles>

4d was reduced according to $\mathbf{G P 3}$ and were determined by GC using 1,3,5trimethoxybenzene $(84.1 \mathrm{mg})$ as an internal standard to afford anisole (2t) as a colorless oil, $100 \%$. The structure was confirmed by comparison with standard anisole sample via GC analysis. ${ }^{7}$

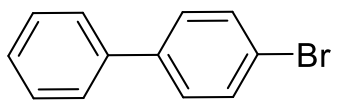

$4 e$

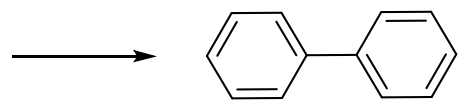

$2 \mathbf{a}$

4e was reduced according to GP3 and purified by flash column chromatography on silica gel (PE/EA 100:1-20:1) to afford 1,1'-biphenyl (2a) as a white solid, $57.1 \mathrm{mg}$, 74\%. ${ }^{1} \mathrm{H}$ NMR (400 MHz, $\left.\mathrm{CDCl}_{3}\right) \delta$ 7.78-7.76 (m, 4H), 7.62-7.58 (m, 4H), 7.52-7.48 $(\mathrm{m}, 2 \mathrm{H}) .{ }^{13} \mathrm{C}\left\{{ }^{1} \mathrm{H}\right\} \mathrm{NMR}\left(100 \mathrm{MHz}, \mathrm{CDCl}_{3}\right) \delta 141.3,128.9,127.4,127.3 .{ }^{7}$

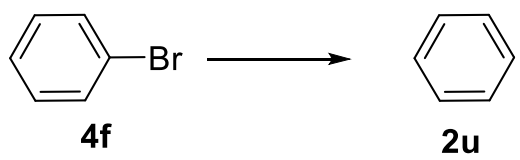

4f was reduced according to GP3 and were determined by GC using 1,3,5trimethoxybenzene $(84.1 \mathrm{mg})$ as an internal standard to afford benzene (2u) as a colorless oil, $82 \%$. The structure was confirmed by comparison with standard benzene 
sample via GC analysis. ${ }^{7}$

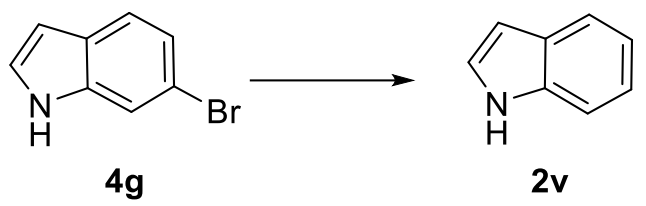

4g was reduced according to GP3 and purified by flash column chromatography on silica gel (PE/EA 100:1-10:1) to afford $\mathbf{1 H}$-indole (2v) as a colorless oil, $34.0 \mathrm{mg}$, $58 \%$, the starting materials have recovered $29 \%(28.4 \mathrm{mg}) .{ }^{1} \mathrm{H} \mathrm{NMR}\left(400 \mathrm{MHz}, \mathrm{CDCl}_{3}\right)$ $\delta 8.09$ (s, 1H), 7.69 (d, $J=8.0 \mathrm{~Hz}, 2 \mathrm{H}), 7.40(\mathrm{dd}, J=8.0,0.8 \mathrm{~Hz}, 1 \mathrm{H}), 7.24-7.14(\mathrm{~m}$, $3 \mathrm{H}), 6.59(\mathrm{~s}, 1 \mathrm{H}) .{ }^{13} \mathrm{C}\left\{{ }^{1} \mathrm{H}\right\} \mathrm{NMR}\left(100 \mathrm{MHz}, \mathrm{CDCl}_{3}\right) \delta 136.0,128.1,124.6,122.3,121.0$, $120.1,111.5,102.7 .^{19}$

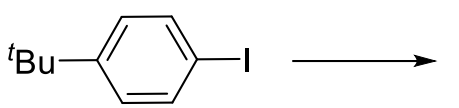

$5 a$<smiles>CC(C)(C)c1ccccc1</smiles>

2w

5a was reduced according to GP3 and were determined by GC using 1,3,5trimethoxybenzene $(84.1 \mathrm{mg})$ as an internal standard to afford tert-butylbenzene (2w) as a colorless oil, $91 \%$. The structure was confirmed by comparison with standard tertbutylbenzene sample via GC analysis. $^{20}$

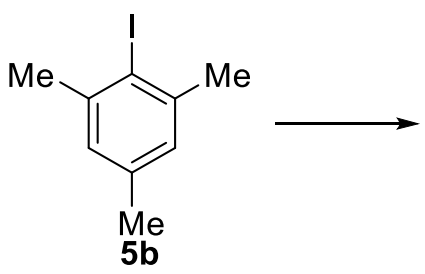<smiles>Cc1cc(C)cc(C)c1</smiles>

5b was reduced according to GP3 and were determined by GC using 1,3,5trimethoxybenzene $(84.1 \mathrm{mg})$ as an internal standard to afford mesitylene (2x) as a colorless oil, 96\%. The structure was confirmed by comparison with standard mesitylene sample via GC analysis. ${ }^{20}$<smiles>Ic1cccc2ccccc12</smiles>

$5 \mathrm{c}$<smiles>c1ccc2ccccc2c1</smiles>

$2 b$ 
5c was reduced according to GP3 and purified by flash column chromatography on silica gel (PE/EA 100:1-20:1) to afford naphthalene (2b) as a white solid, $50.0 \mathrm{mg}$, 78\%. ${ }^{1} \mathrm{H}$ NMR $\left(400 \mathrm{MHz}, \mathrm{CDCl}_{3}\right) \delta 8.01-7.99(\mathrm{~m}, 4 \mathrm{H}), 7.65-7.62(\mathrm{~m}, 4 \mathrm{H}) .{ }^{13} \mathrm{C}\left\{{ }^{1} \mathrm{H}\right\}$ NMR $\left(100 \mathrm{MHz}, \mathrm{CDCl}_{3}\right) \delta 133.6,128.0,125.9^{7}$

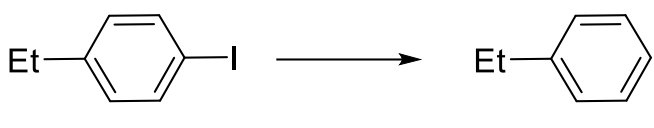

5d

5d was reduced according to GP3 and were determined by GC using 1,3,5trimethoxybenzene $(84.1 \mathrm{mg})$ as an internal standard to afford ethylbenzene (2y) as a colorless oil, 91\%. The structure was confirmed by comparison with standard ethylbenzene sample via GC analysis. $^{21}$<smiles>Cc1cccc(C)c1</smiles>

5e was reduced according to $\mathbf{G P 3}$ and were determined by GC using 1,3,5trimethoxybenzene $(84.1 \mathrm{mg})$ as an internal standard to afford $\boldsymbol{m}$-xylene (2y) as a colorless oil, $63 \%$. The structure was confirmed by comparison with standard $m$-xylene sample via GC analysis. ${ }^{22}$<smiles>Cc1cccc(C)c1</smiles>

5f was reduced according to $\mathbf{G P 3}$ and were determined by GC using 1,3,5trimethoxybenzene $(84.1 \mathrm{mg})$ as an internal standard to afford $m$-xylene (2y) as a colorless oil, $100 \%$. The structure was confirmed by comparison with standard $m$ xylene sample via GC analysis. ${ }^{22}$ 


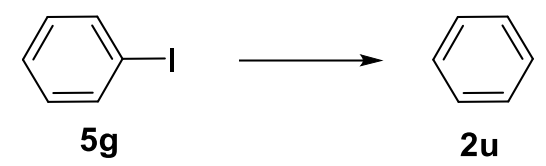

5g was reduced according to $\mathbf{G P 3}$ and were determined by GC using 1,3,5trimethoxybenzene $(84.1 \mathrm{mg})$ as an internal standard to afford benzene (2u) as a colorless oil, $100 \%$. The structure was confirmed by comparison with standard benzene sample via GC analysis. ${ }^{7}$

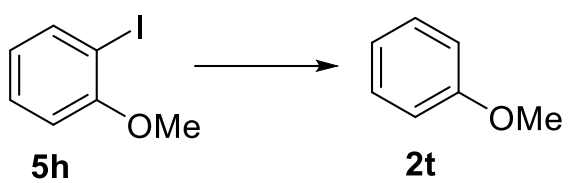

5h was reduced according to GP3 and were determined by GC using 1,3,5trimethoxybenzene $(84.1 \mathrm{mg})$ as an internal standard to afford anisole (2t) as a colorless oil, $100 \%$. The structure was confirmed by comparison with standard anisole sample via GC analysis. ${ }^{7}$

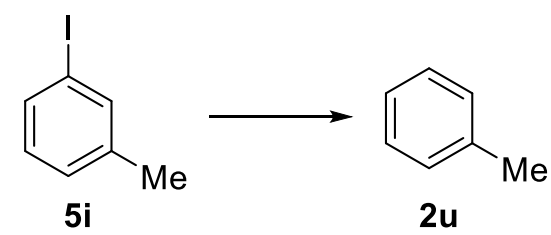

5i was reduced according to GP3 and were determined by GC usin g 1,3,5trimethoxybenzene $(84.1 \mathrm{mg}$ ) as internal standard to afford toulene (2u) as a colorless oil, $70 \%$. The structure was confirmed by comparison with standard toulene sample via GC analysis. ${ }^{17}$

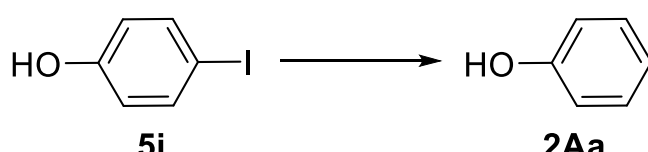

5j was reduced according to GP3 and purified by flash column chromatography on silica gel (PE/EA 100:1-10:1) to afford phenol (2Aa) as a colorless oil, $45.2 \mathrm{mg}$, 96\%. ${ }^{1} \mathrm{H}$ NMR (400 MHz, $\left.\mathrm{CDCl}_{3}\right) \delta$ 7.27-7.23 (m, 2H), $6.94(\mathrm{dt}, J=7.6,0.8 \mathrm{~Hz}, 1 \mathrm{H})$, $6.84(\mathrm{dd}, J=6.8,1.2 \mathrm{~Hz}, 2 \mathrm{H}), 4.73(\mathrm{~s}, 1 \mathrm{H}) .{ }^{13} \mathrm{C}\left\{{ }^{1} \mathrm{H}\right\} \mathrm{NMR}\left(100 \mathrm{MHz}, \mathrm{CDCl}_{3}\right) \delta 155.5$, $129.8,121.0,115.4 .^{23}$ 


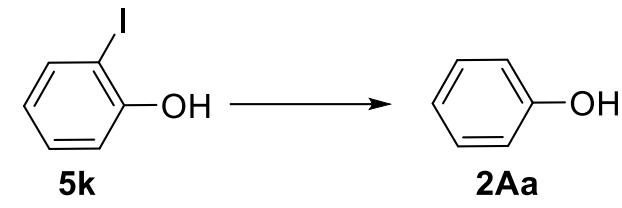

5k was reduced according to GP3 and purified by flash column chromatography on silica gel (PE/EA 100:1-10:1) to afford phenol (2Aa) as a colorless oil, $47.1 \mathrm{mg}$, 100\%. ${ }^{1} \mathrm{H}$ NMR (400 MHz, $\left.\mathrm{CDCl}_{3}\right) \delta$ 7.27-7.23 (m, 2H), $6.94(\mathrm{dt}, J=7.6,0.8 \mathrm{~Hz}, 1 \mathrm{H})$, $6.84(\mathrm{dd}, J=6.8,1.2 \mathrm{~Hz}, 2 \mathrm{H}), 4.73(\mathrm{~s}, 1 \mathrm{H}) .{ }^{13} \mathrm{C}\left\{{ }^{1} \mathrm{H}\right\} \mathrm{NMR}\left(100 \mathrm{MHz}, \mathrm{CDCl}_{3}\right) \delta 155.5$, $129.8,121.0,115.4 .^{23}$ 


\section{Deuterium Labeling Experiments}

1a (0.5 mmol, 1 equiv) and ${ }^{t} \mathrm{BuOK}(280.3 \mathrm{mg}, 2.5 \mathrm{mmol}, 5$ equiv) was weighed directly into a Schlenk tube and dried under high vacuum for 15 min. Then the DMF$d_{7}(4 \mathrm{~mL})$ and was added. Then the tube irradiated by a $27 \mathrm{~W}$ Blue LED and the reaction was monitored by TLC. Upon completion, $20 \mathrm{~mL}$ of water and $10 \mathrm{~mL}$ of ethyl acetate was added. After extarction of the aqueous phase with ethyl acetate, the combined organic extracts were washed with brine, dried over $\mathrm{Na}_{2} \mathrm{SO}_{4}$, and concentrated. The crude product was purified on flash column chromatography on silica gel to afford the desired product $2 \mathrm{a}$ as a white solid, $30.1 \mathrm{mg}, 78 \% .{ }^{1} \mathrm{H}$ NMR $\left(400 \mathrm{MHz}, \mathrm{CDCl}_{3}\right) \delta$ 7.63-7.60 (m, 4H), 7.48-7.44 (m, 3.1H), 7.39-7.34 (m, 1.2H). ${ }^{13} \mathrm{C}\left\{{ }^{1} \mathrm{H}\right\} \mathrm{NMR}(100 \mathrm{MHz}$, $\left.\mathrm{CDCl}_{3}\right) \delta 141.4,128.9,128.8,127.4,127.3,127.2$. 


\section{References}

1. Bisz, E.; Szostak, M. Iron-Catalyzed C(sp2)-C(sp3) Cross-Coupling of Chlorobenzamides with Alkyl Grignard Reagents: Development of Catalyst System, Synthetic Scope, and Application. Adv. Synth. Catal. 2019, 361, 85.

2. Zhang, J.; Huang, X.; Zhang, R. K;Arnold, F. H. Enantiodivergent $\alpha$-Amino C-H Fluoroalkylation Catalyzed by Engineered Cytochrome P450s. J. Am. Chem. Soc. 2019, 141, 9798.

3. Singh, K.; Kabadwal, L. M.; Bera, S.; Alanthadka A.; Banerjee, D. Nickel-Catalyzed Synthesis of N-Substituted Pyrroles Using Diols with Aryl- and Alkylamines. J. Org. Chem. 2018, 83, 15406.

4. Gehrtz, P. H.; Geiger, V.; Schmidt, T.; Sršan L.; Fleischer, I. Cross-Coupling of Chloro(hetero)arenes with Thiolates Employing a Ni(0)-Precatalyst. Org. Lett. 2018, 21,50 .

5. Lang, R.; Shi, L.; Li, D.; Xia C.; Li, F. A General Method for Palladium-Catalyzed Direct Carbonylation of Indole with Alcohol and Phenol. Org. Lett. 2012, 14, 4130.

6. Zhu, D. H.; Lv, L. Y.; Li, C. C.; Ung, S.; Gao, J.; Li, C. J. Umpolung of Carbonyl Groups as Alkyl Organometallic Reagent Surrogates for Palladium-Catalyzed Allylic Alkylation. Angew. Chem. Int. Ed. 2018, 130, 16.

7. Zheng, H.-X.; Shan, X.-H.; Qu, J.-P.; Kang, Y.-B. Transition-Metal-Free Hydrogenation of Aryl Halides: From Alcohol to Aldehyde. Org. Lett. 2017, 19, 5114.

8. Xia, Q.; Liu, X.; Zhang, Y.; Chen C.; Chen, W.; Copper-Catalyzed N-Methylation of Amides and O-Methylation of Carboxylic Acids by Using Peroxides as the Methylating Reagents. Org. Lett. 2013, 15, 3326.

9. Li, G.; Ji, C. L.; Hong X.; Szostak, M.; Highly Chemoselective, Transition-MetalFree Transamidation of Unactivated Amides and Direct Amidation of Alkyl Esters by N-C/O-C Cleavage. J. Am. Chem. Soc. 2019, 141, 11161.

10. Hurst, T. E.; Deichert, J. A.; Kapeniak, L.; Lee, R.; Harris, J.; Jesso P. G.; Snieckus, V. Sodium Methyl Carbonate as an Effective C1 Synthon. Synthesis of Carboxylic Acids, Benzophenones, and Unsymmetrical Ketones. Org. Lett. 2019, 21, 3882.

11. Zheng, S.; Yu C.; Shen, Z. Ethyl Cyanoacetate: A New Cyanating Agent for the Palladium-Catalyzed Cyanation of Aryl Halides. Org. Lett. 2012, 14, 3644.

12. Guo, D. D.; Li, B.; Wang, D. Y.; Gao, Y. R.; Guo, S. H.; Pan G. F.; Wang, Y. Q. Synthesis of $6 H$-Benzo[c]chromenes via Palladium-Catalyzed Intramolecular Dehydrogenative Coupling of Two Aryl C-H Bonds. Org. Lett. 2017, 19, 798.

13. Wu, Y.; Zhang, Y.; Jiang, M.; Dong, X.; Jalani, H. B.; Li, G.; Lu, H. Synergistic combination of visible-light photo-catalytic electron and energy transfer facilitating multicomponent synthesis of b-functionalized a,a-diarylethylamines. Chem. Commun. 2019, 55, 6405.

14. Shi, Z.; Boultadakis-Arapinis M.; Glorius, F. Rh(III)-catalyzed dehydrogenative alkylation of (hetero)arenes with allylic alcohols, allowing aldol condensation to indenes. Chem. Commun. 2013, 49, 6489. 
15. Shao, T.; Yin, Y.; Lee, R.; Zhao, X.; Chai G.; Jiang, Z. Sequential Photoredox Catalysis for Cascade Aerobic Decarboxylative Povarov and Oxidative Dehydrogenation Reactions of N-Aryl a-Amino Acids. Adv. Synth. Catal. 2018, 360 , 1754.

16. Léonard, N. G.; Chirik, P. J. Air-Stable $\alpha$-Diimine Nickel Precatalysts for the hydrogenation of Hindered, Unactivated Alkenes. ACS. Catal. 2018, 8, 342.

17. Liu, W.; Hou, F. Y. Transition-metal-free dehalogenation of aryl halides promoted by phenanthroline/potassium tert-butoxide. Tetrahedron 2017, 73, 931.

18. Cai, Y. M.; Xu, Y. T.; Zhang, X.; Gao, W. X.; Huang, X. B.; Zhou, Y. B.; Liu, M. C.; $\mathrm{Wu}$ H. Y. Photoinduced Hydroxylation of Organic Halides under Mild Conditions. Org. Lett. 2019, $21,8479$.

19. Lizza, J. R.; Bremerich, M.; McCab S. R.; Wipf, P. 2,2,6,6-Tetramethylpiperidin-1yloxycarbonyl: A Protecting Group for Primary, Secondary, and Heterocyclic Amines. Org. Lett. 2018, 20, 6760.

20. Cao, D. W.; Yan, C. X.; Zhou, P. P.; Zeng, H. Y.; Li, C. J. Hydrogen bonding promoted simple and clean photo-induced reduction of $\mathrm{C}-\mathrm{X}$ bond with isopropanol. Chem. Commun. 2019, 55, 767.

21. Gieshoff, T. N.; Villa, M.; Welther, A.; Plois, M.; Chakraborty, U.; Wolf, R.; von Wanglin, A. J. Iron-catalyzed olefin hydrogenation at 1 bar $\mathrm{H}_{2}$ with a $\mathrm{FeCl}_{3}-\mathrm{LiAlH}_{4}$ catalyst. Green. Chem. 2015, 17, 1408.

22. Dai, T.; Li, C. Z.; Li, L.; Kent Zhao, Z. B.; Zhang, B.; Cong, Y.; Wang, A. Q. Selective Production of Renewable para-Xylene by Tungsten Carbide Catalyzed Atom-Economic Cascade Reactions. Angew. Chem. Int. Ed. 2018, 57, 1808.

23. Shirai, T.; Sugimoto, K.; Iwasaki, M.; Sumida, R.; Fujita H.; Yamamoto, Y. Decarbonylation through Aldehydic $\mathrm{C}-\mathrm{H}$ Bond Cleavage by a Cationic Iridium Catalyst. Synlett. 2019, 30, 972. 
6. NMR Spectra
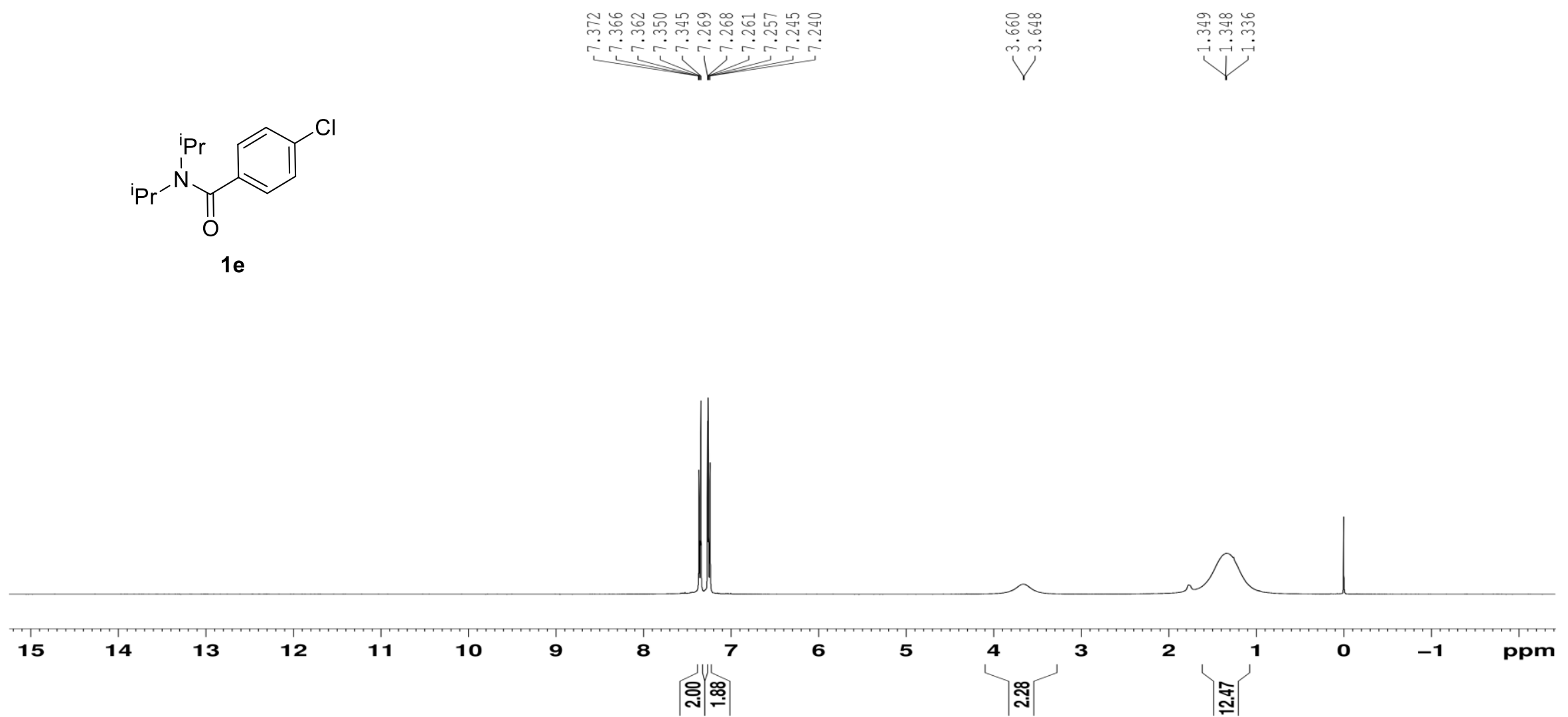

Figure S1. ${ }^{1} \mathrm{H}$ NMR spectrum of 1 e $\left(\mathrm{CDCl}_{3}, 400 \mathrm{MHz}\right)$. 


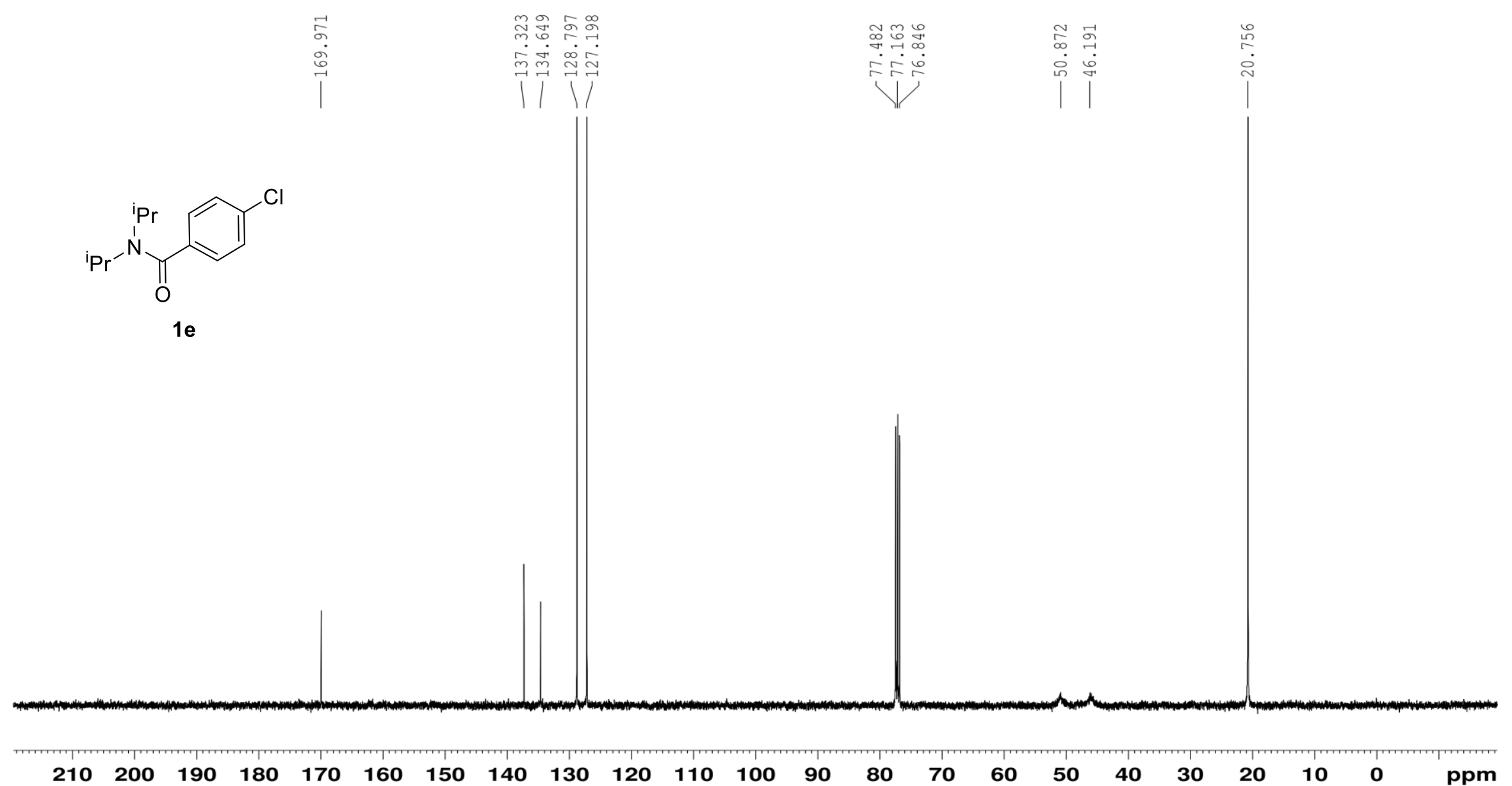

Figure S2. ${ }^{13} \mathrm{C}$ NMR spectrum of $1 \mathbf{e}\left(\mathrm{CDCl}_{3}, 100 \mathrm{MHz}\right)$. 


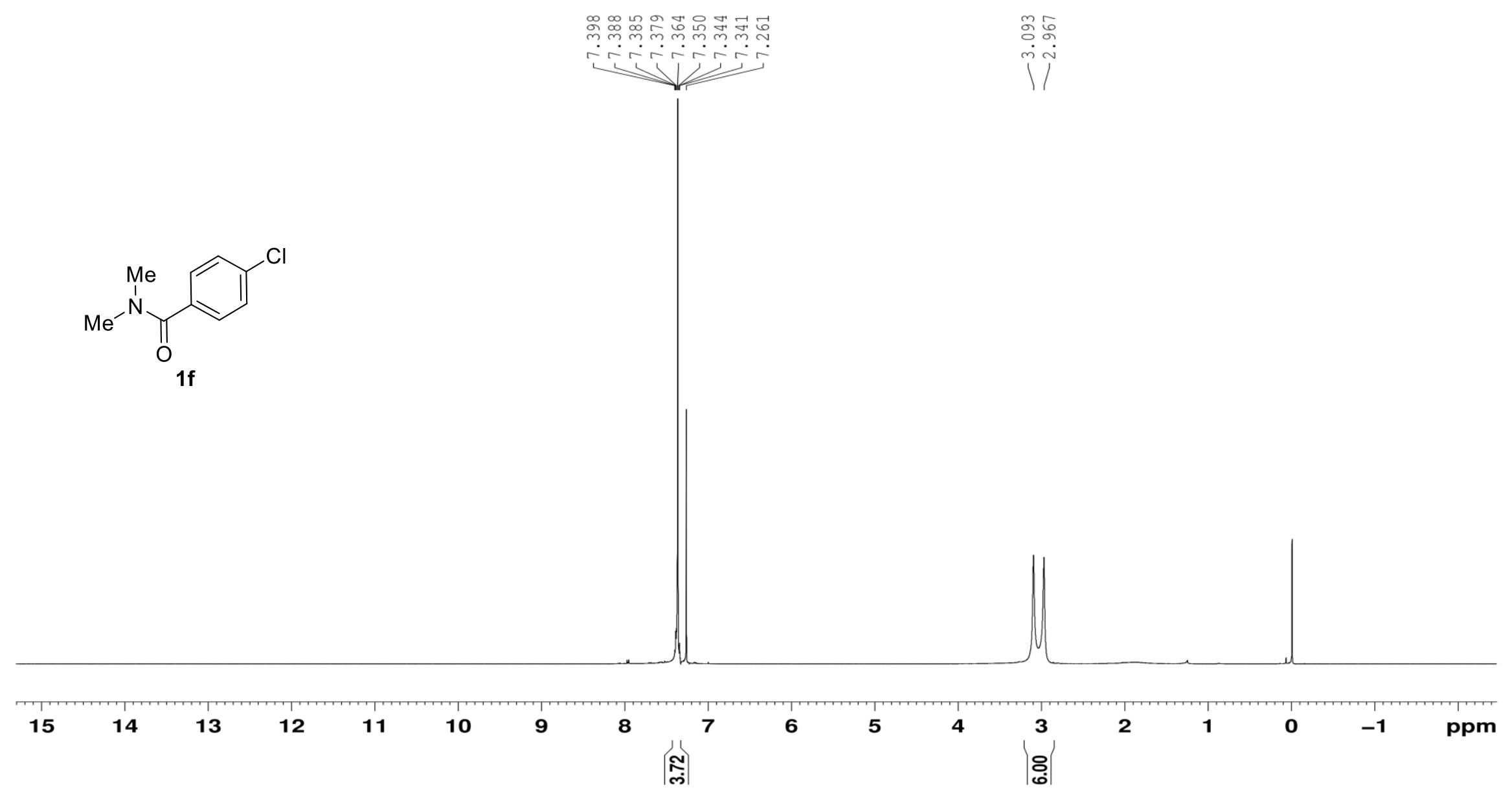

Figure S3. ${ }^{1} \mathrm{H}$ NMR spectrum of $\mathbf{1 f}\left(\mathrm{CDCl}_{3}, 400 \mathrm{MHz}\right)$. 


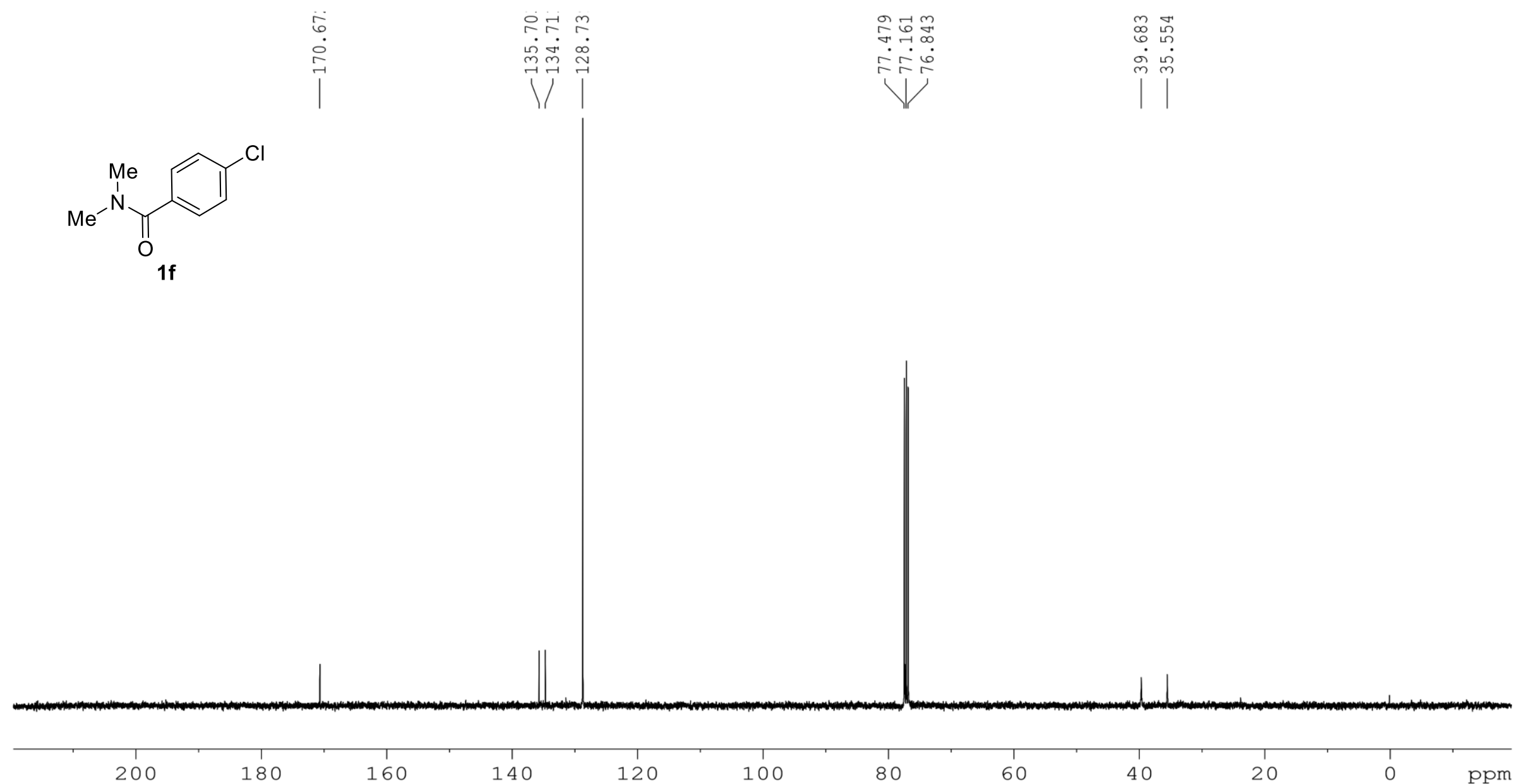

Figure S4. ${ }^{13} \mathrm{C}$ NMR spectrum of $\mathbf{1 f}\left(\mathrm{CDCl}_{3}, 100 \mathrm{MHz}\right)$. 

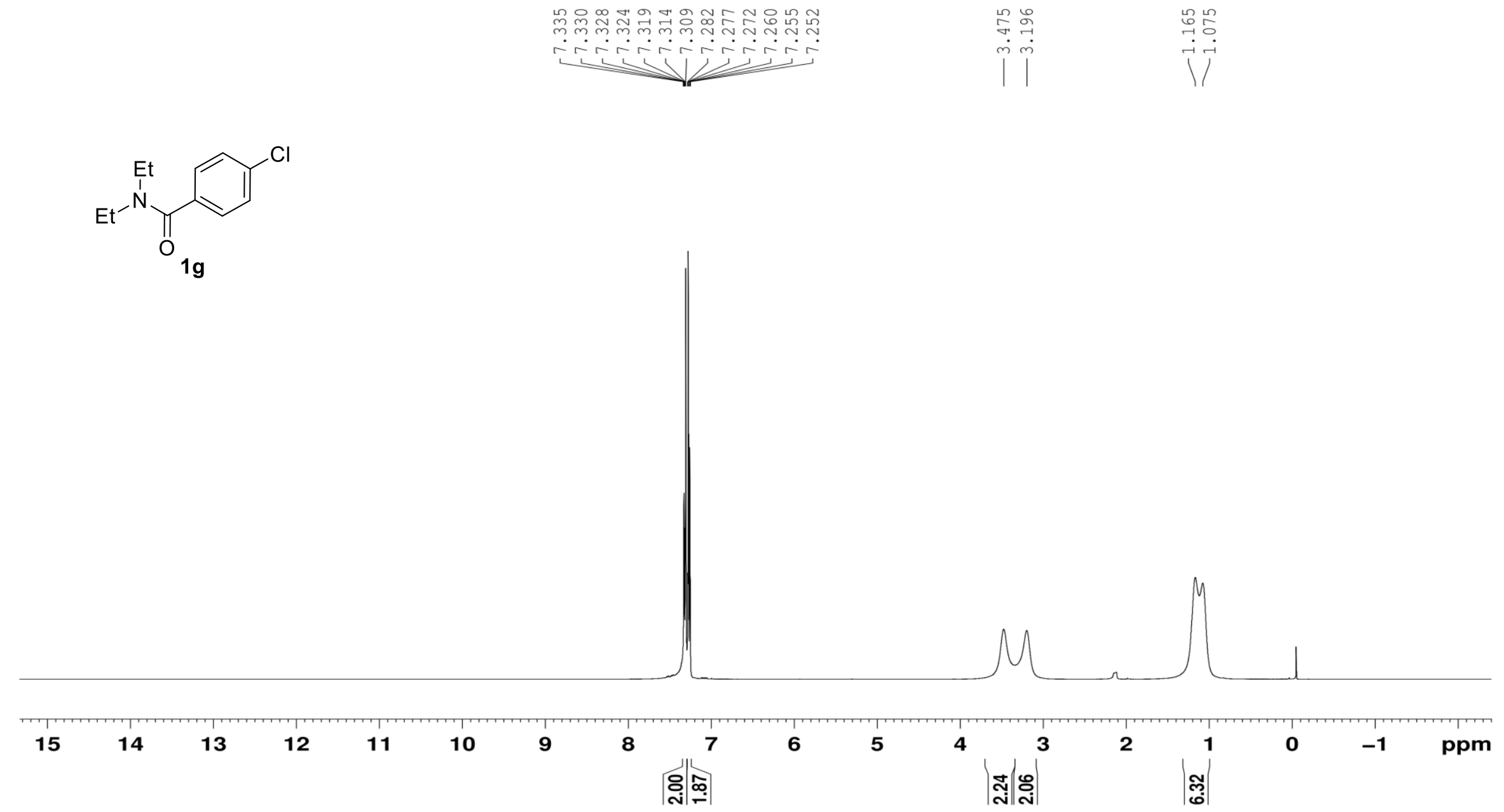

Figure S5. ${ }^{1} \mathrm{H}$ NMR spectrum of $\mathbf{1 g}\left(\mathrm{CDCl}_{3}, 400 \mathrm{MHz}\right)$. 

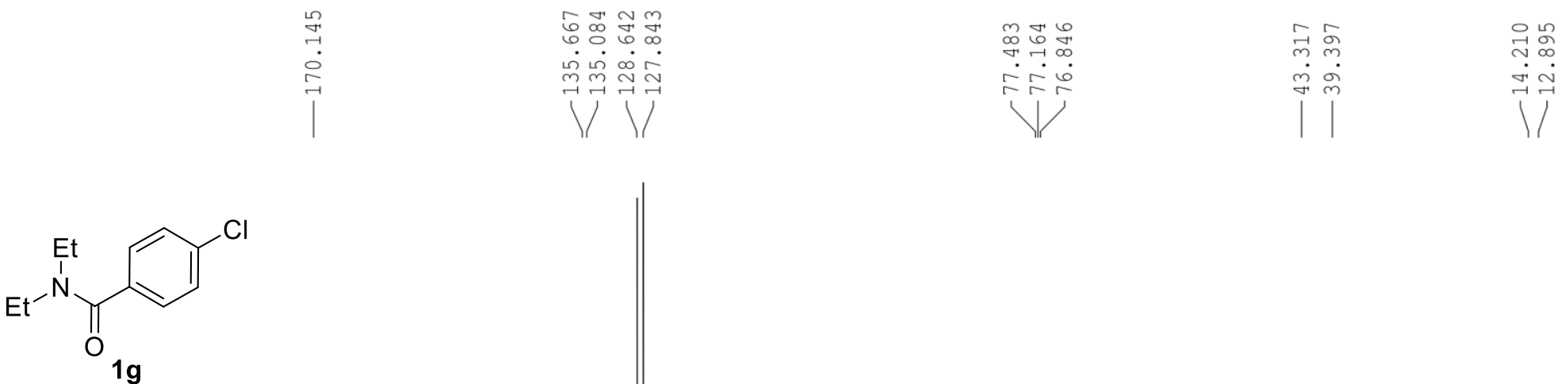

(1)

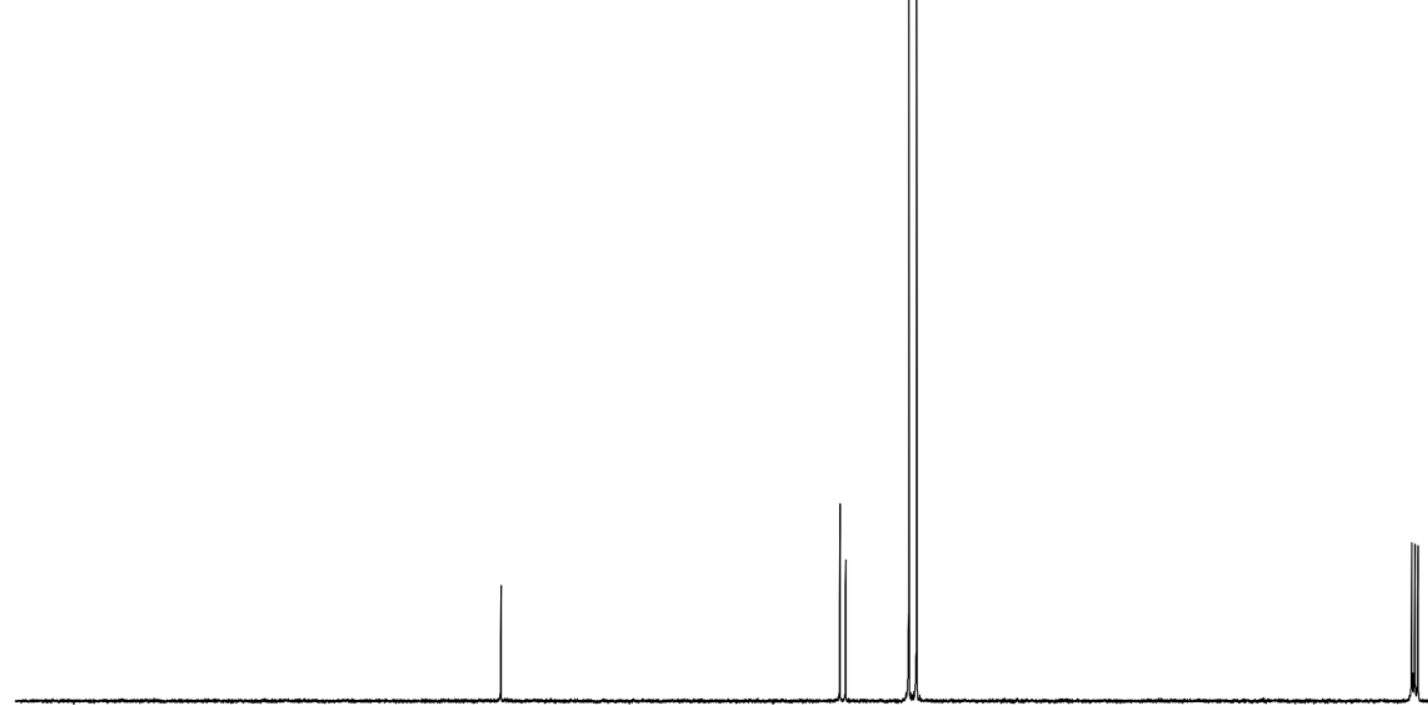

$\begin{array}{lllllllllllllllllllllll}210 & 200 & 190 & 180 & 170 & 160 & 150 & 140 & 130 & 120 & 110 & 100 & 90 & 80 & 70 & 60 & 50 & 40 & 30 & 20 & 10 & 0 & \mathrm{ppm}\end{array}$ Figure S6. ${ }^{13} \mathrm{C}$ NMR spectrum of $\mathbf{1 g}\left(\mathrm{CDCl}_{3}, 100 \mathrm{MHz}\right)$. 

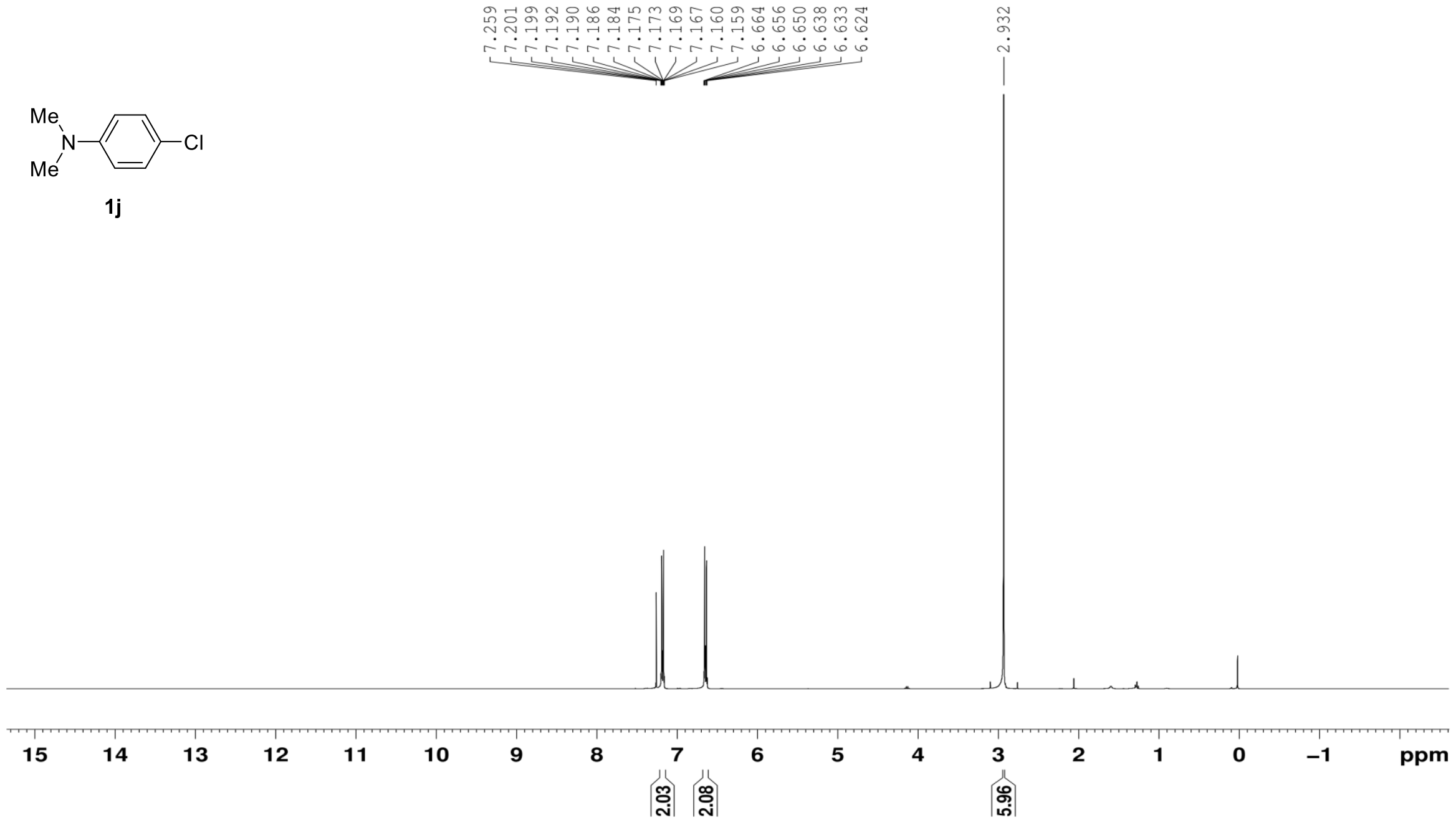

Figure S7. ${ }^{1} \mathrm{H}$ NMR spectrum of $\mathbf{1 j}\left(\mathrm{CDCl}_{3}, 400 \mathrm{MHz}\right)$. 

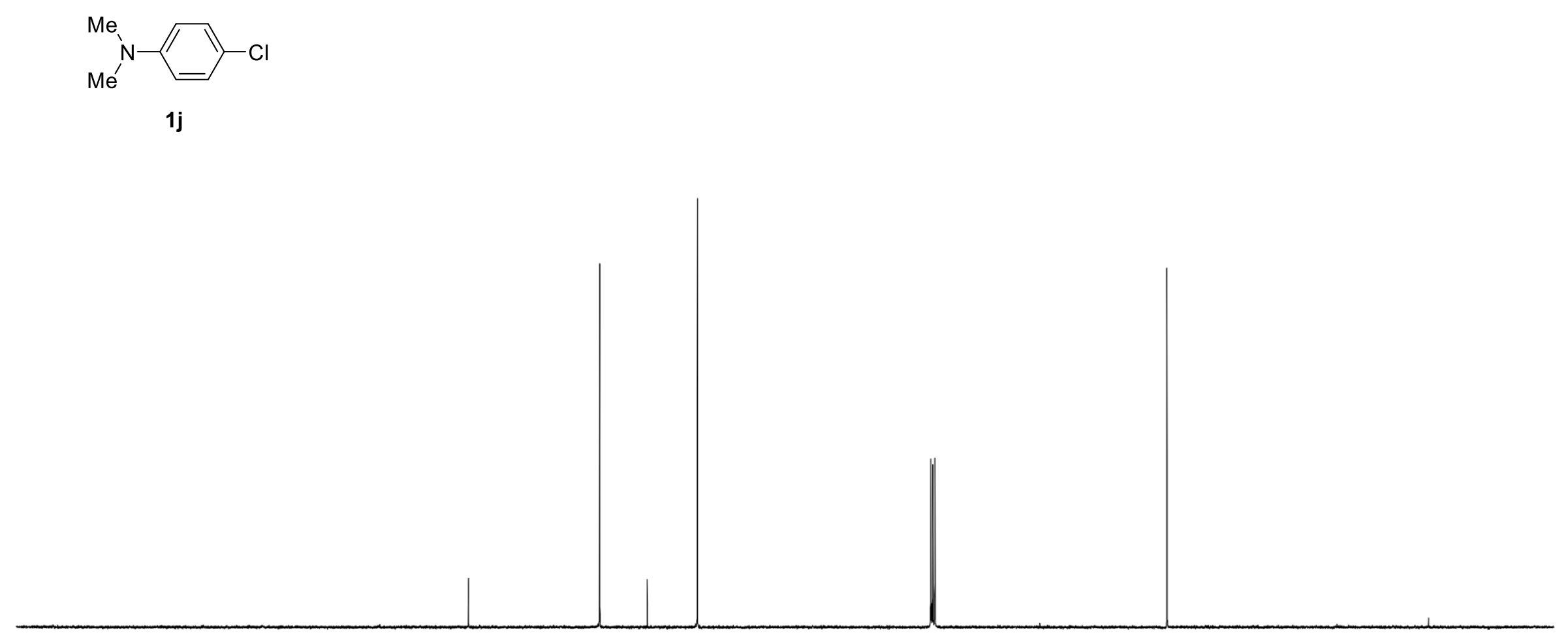

$\begin{array}{lllllllllllllllllllllll}210 & 200 & 190 & 180 & 170 & 160 & 150 & 140 & 130 & 120 & 110 & 100 & 90 & 80 & 70 & 60 & 50 & 40 & 30 & 20 & 10 & 0 & \text { ppm }\end{array}$

Figure S8. ${ }^{13} \mathrm{C}$ NMR spectrum of $\mathbf{1} \mathbf{j}\left(\mathrm{CDCl}_{3}, 100 \mathrm{MHz}\right)$. 


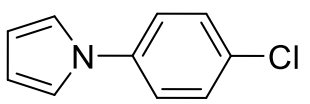

$1 \mathrm{k}$

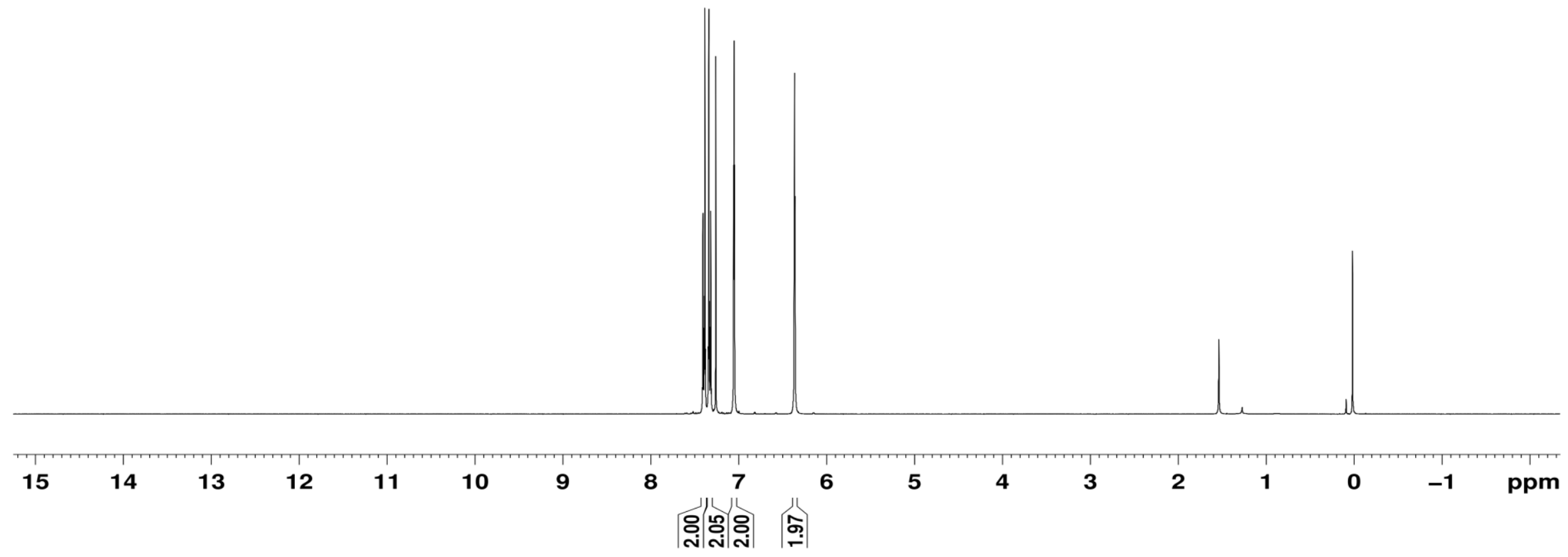

Figure S9. ${ }^{1} \mathrm{H}$ NMR spectrum of $\mathbf{1 k}\left(\mathrm{CDCl}_{3}, 400 \mathrm{MHz}\right)$. 


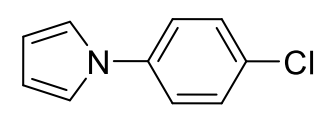

$1 \mathrm{k}$

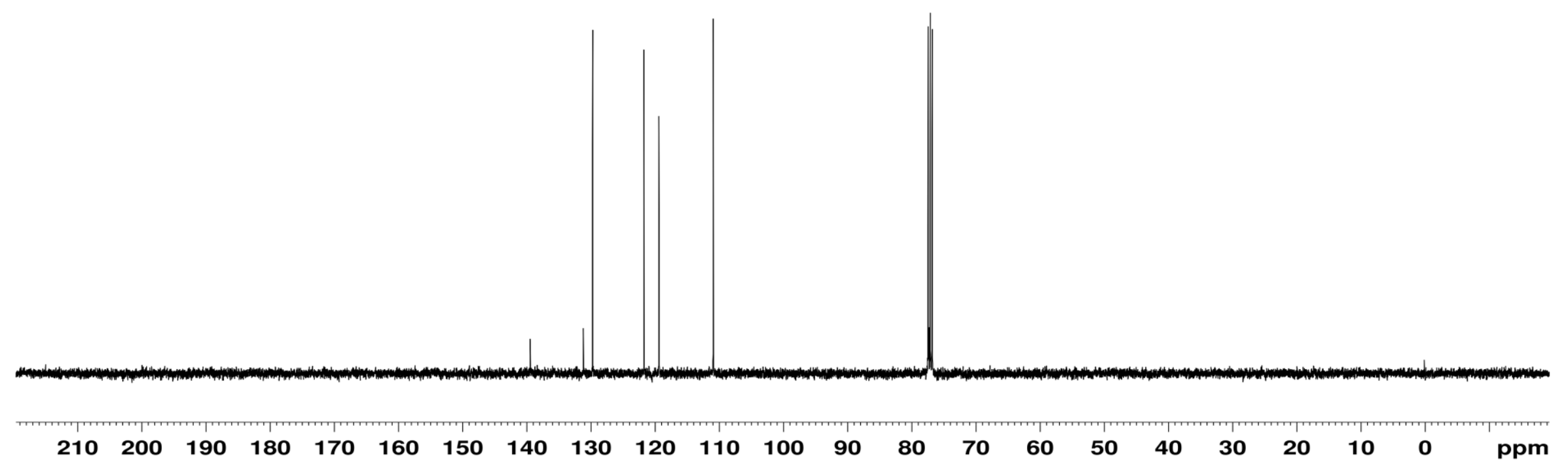

Figure S10. ${ }^{13} \mathrm{C}$ NMR spectrum of $\mathbf{1 k}\left(\mathrm{CDCl}_{3}, 100 \mathrm{MHz}\right)$. 


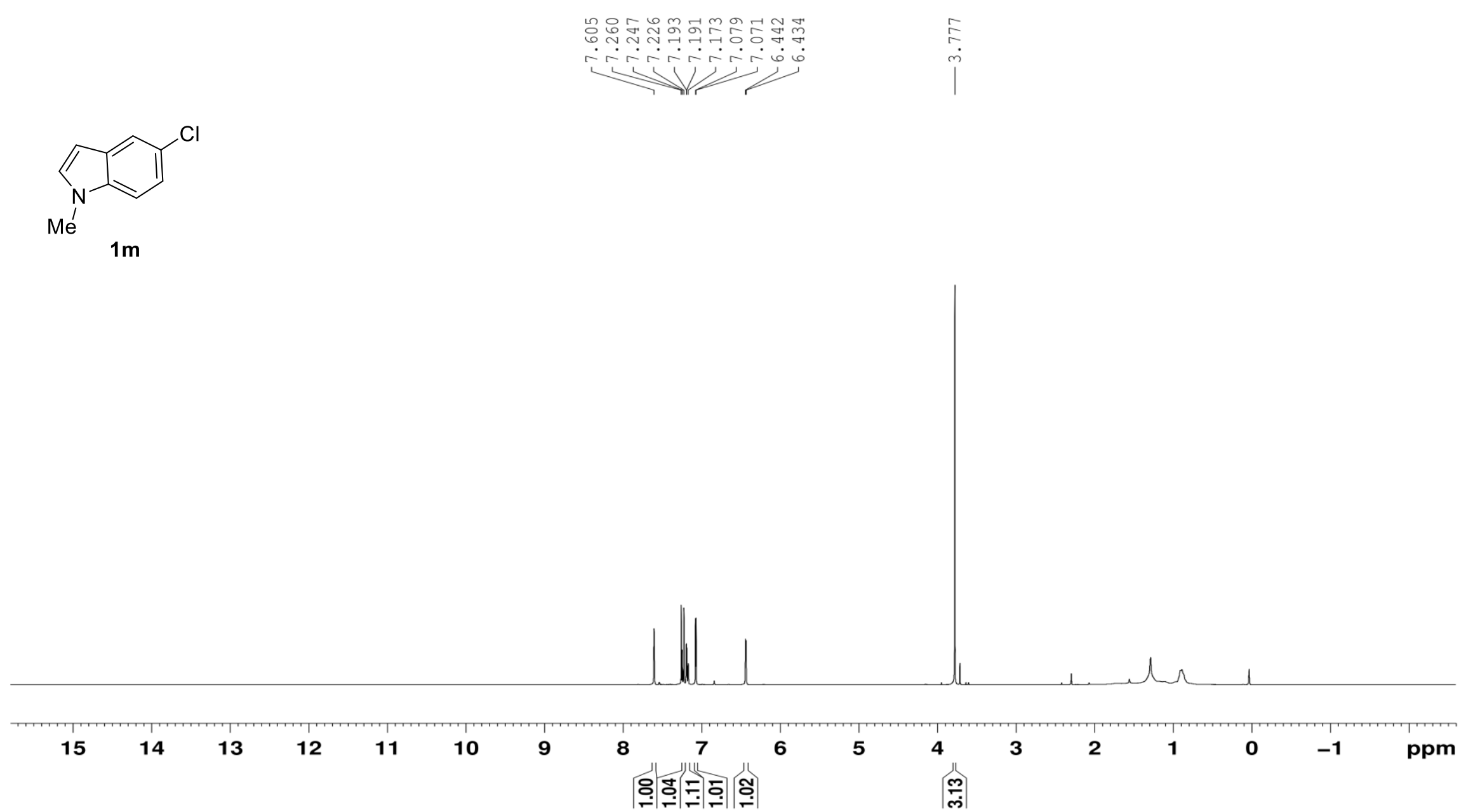

Figure S11. ${ }^{1} \mathrm{H}$ NMR spectrum of $\mathbf{1} \mathbf{m}\left(\mathrm{CDCl}_{3}, 400 \mathrm{MHz}\right)$. 

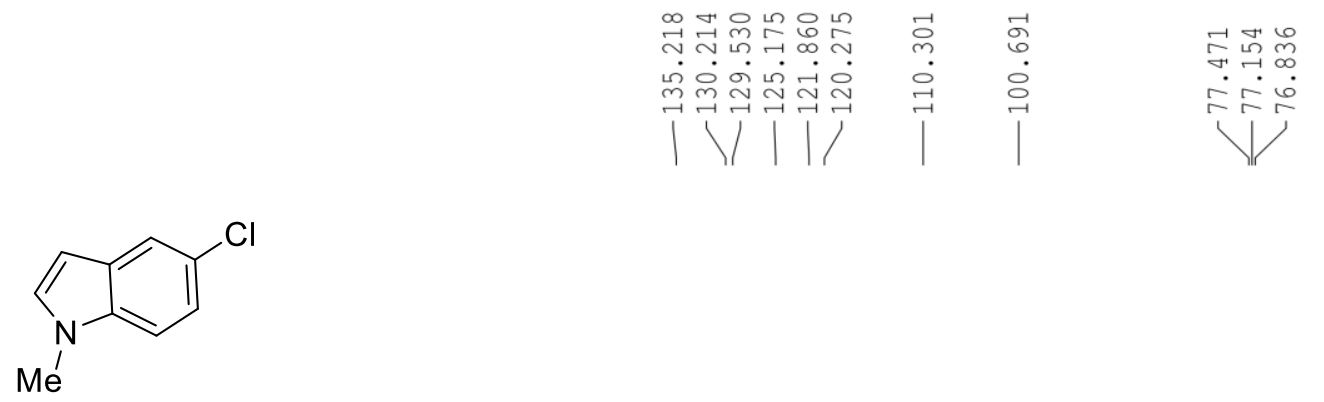

$1 \mathrm{~m}$

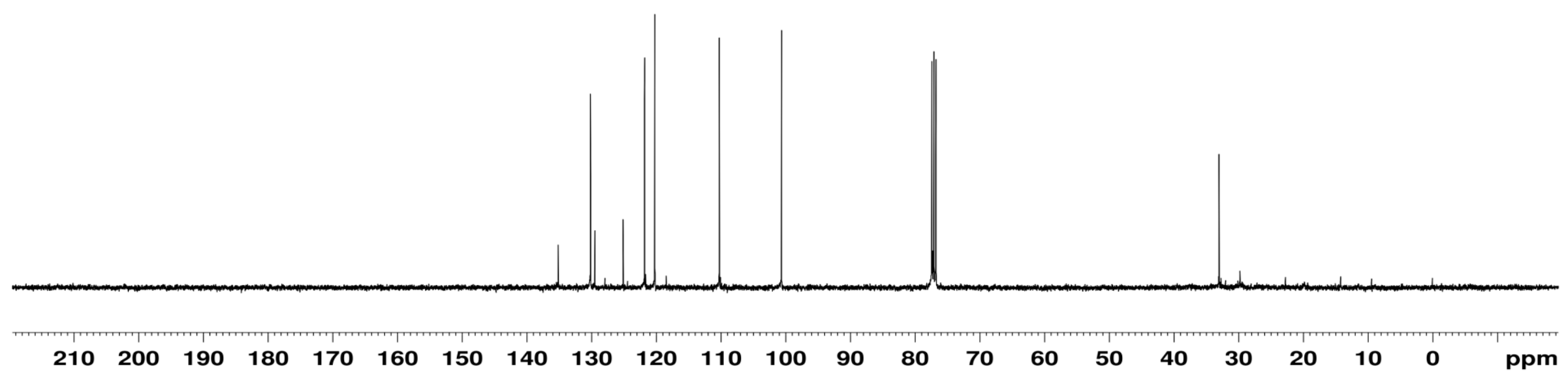

Figure S12. ${ }^{13} \mathrm{C}$ NMR spectrum of $\mathbf{1 m}\left(\mathrm{CDCl}_{3}, 100 \mathrm{MHz}\right)$. 


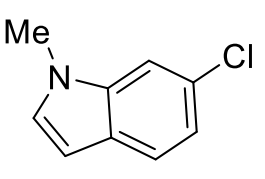

1n

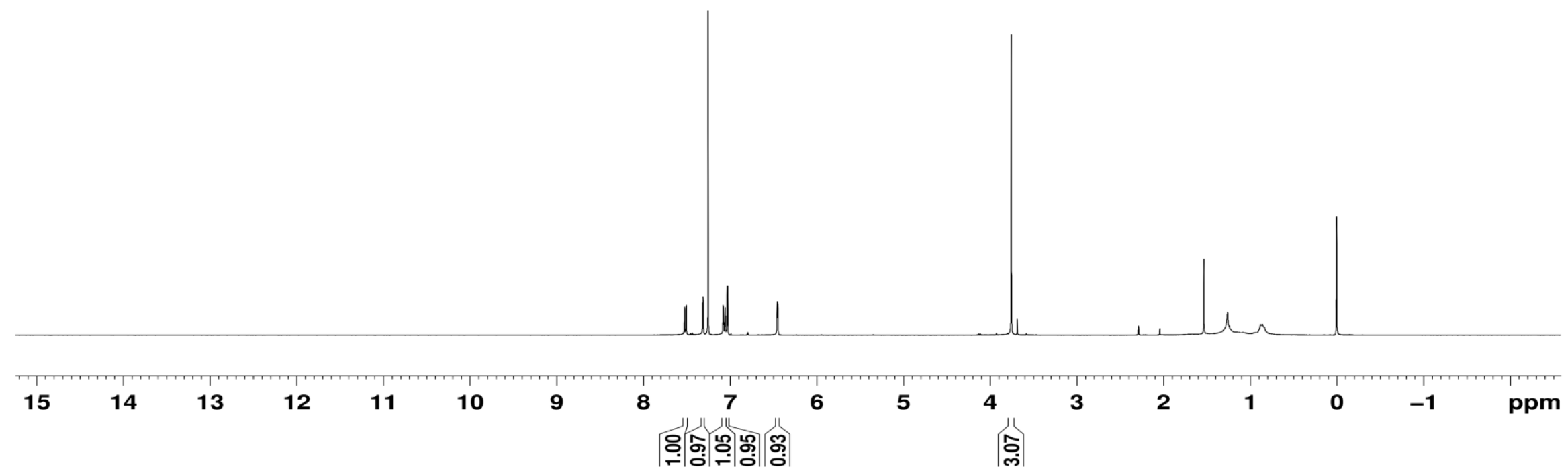

Figure S13. ${ }^{1} \mathrm{H}$ NMR spectrum of $\mathbf{1 n}\left(\mathrm{CDCl}_{3}, 400 \mathrm{MHz}\right)$. 


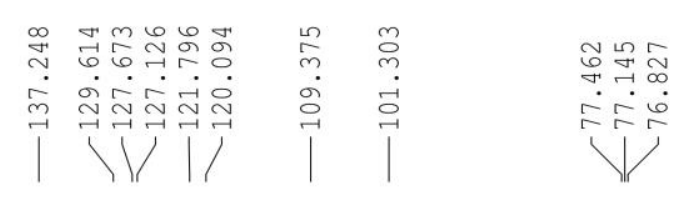

Me

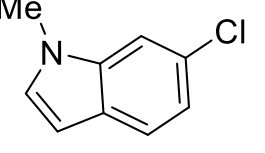

$1 \mathrm{n}$

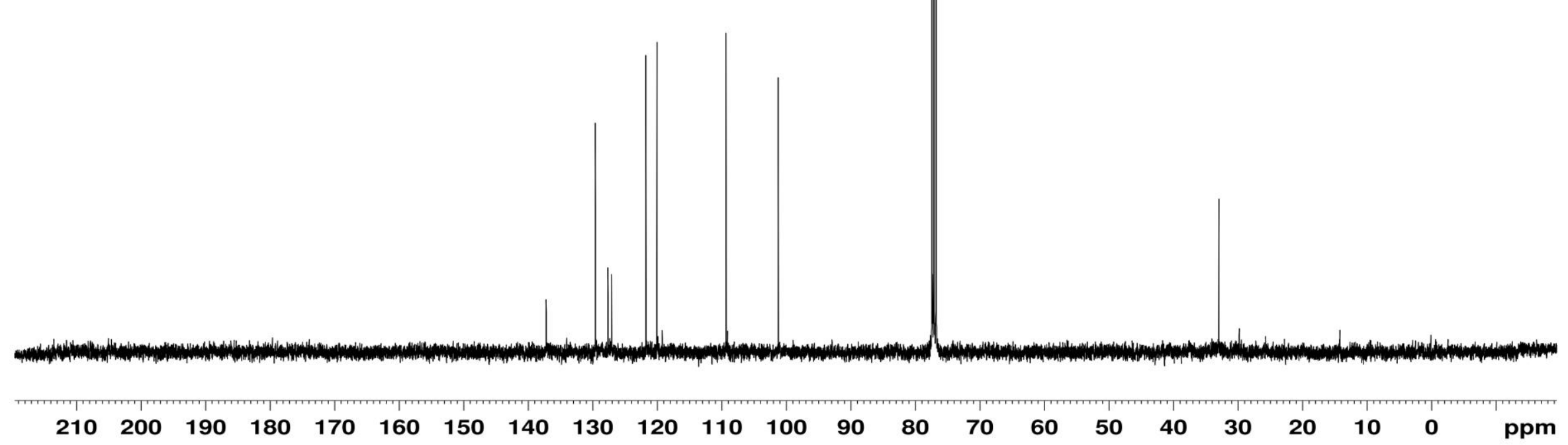

Figure S14. ${ }^{13} \mathrm{C}$ NMR spectrum of $\mathbf{1 n}\left(\mathrm{CDCl}_{3}, 100 \mathrm{MHz}\right)$. 

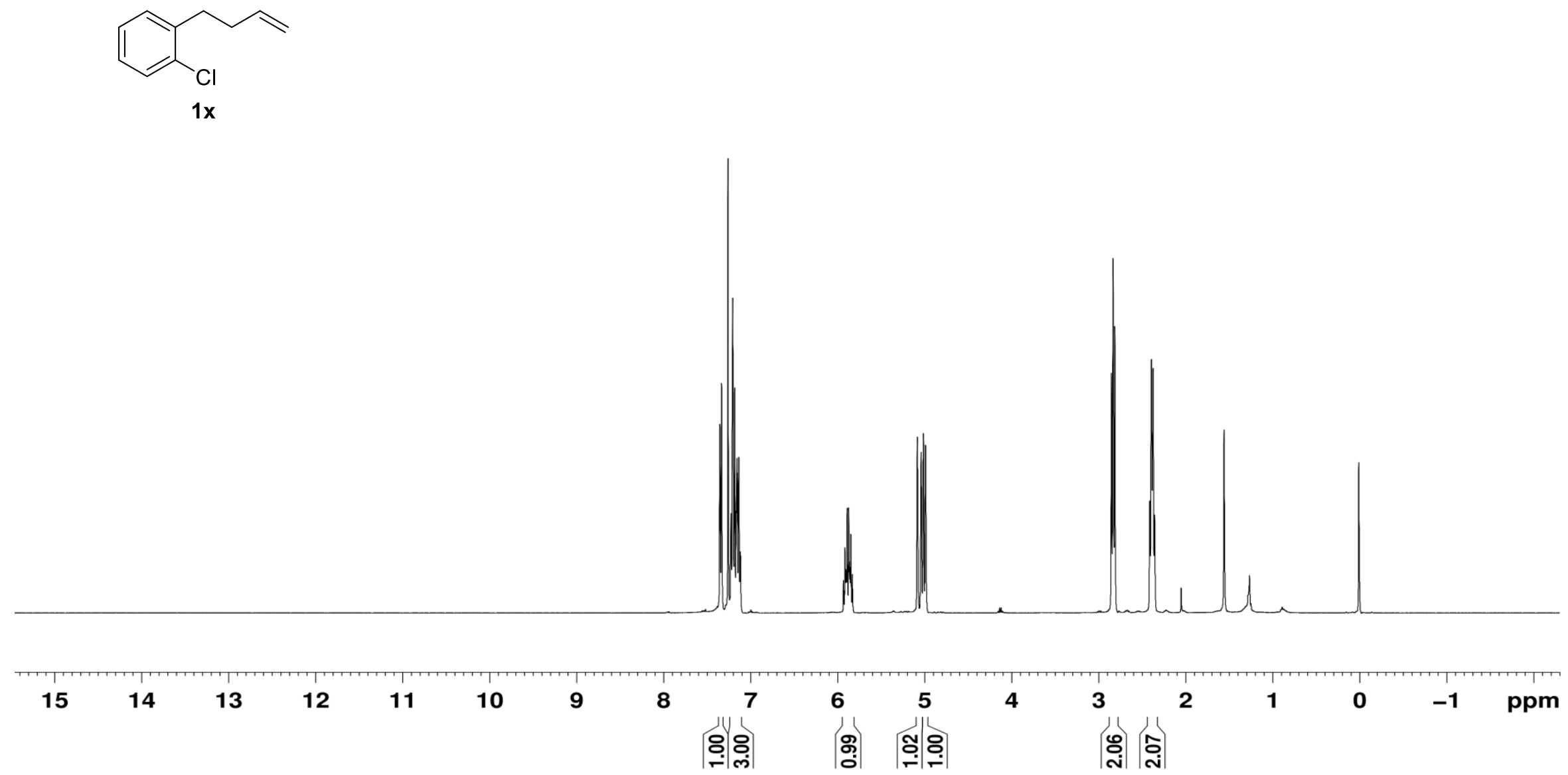

Figure S15. ${ }^{1} \mathrm{H}$ NMR spectrum of $\mathbf{1 x}\left(\mathrm{CDCl}_{3}, 400 \mathrm{MHz}\right)$. 

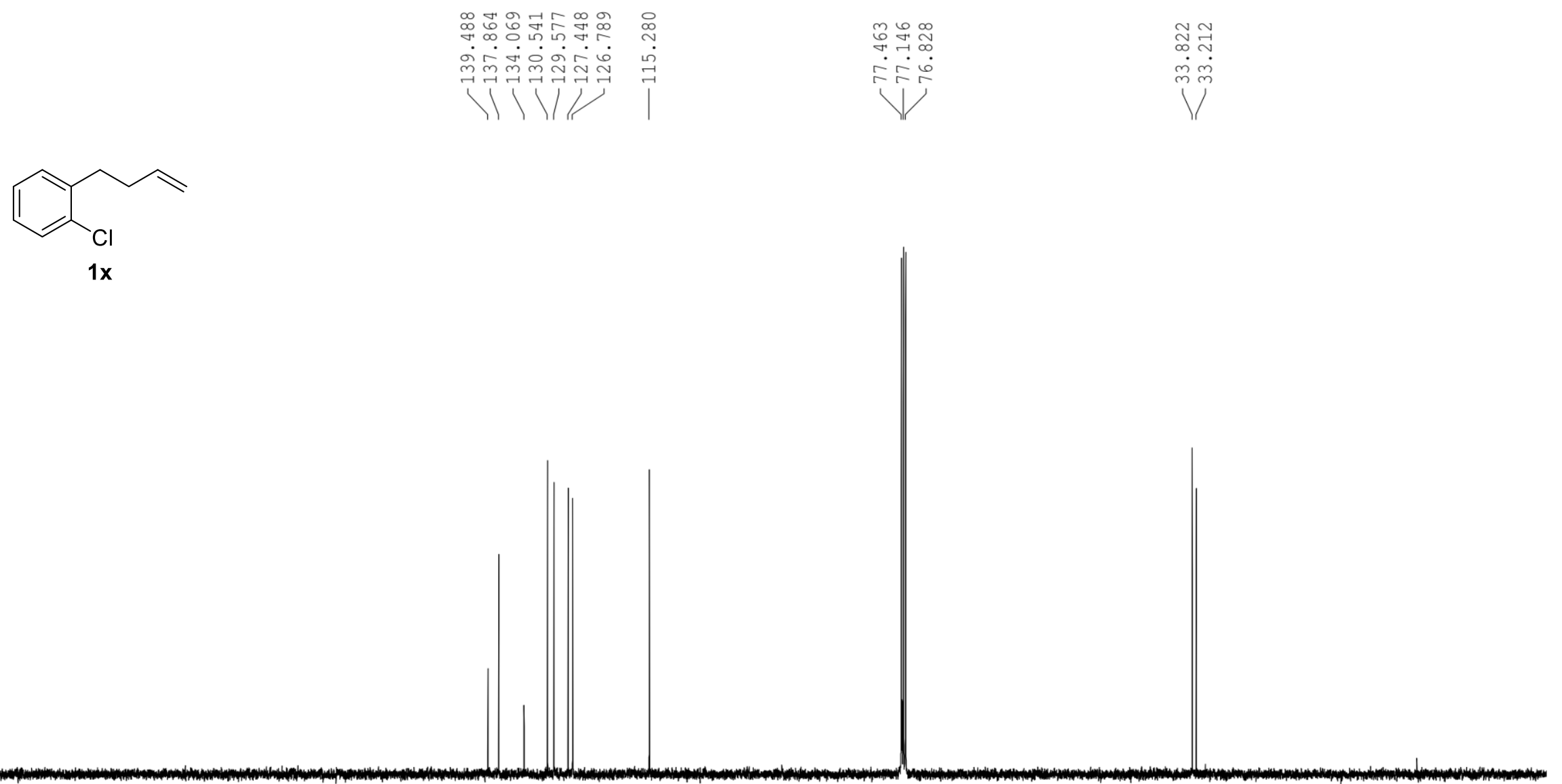

$\begin{array}{llllllllll}70 & 60 & 50 & 40 & 30 & 20 & 10 & 0 & \text { ppm }\end{array}$

Figure S16. ${ }^{13} \mathrm{C}$ NMR spectrum of $\mathbf{1 x}\left(\mathrm{CDCl}_{3}, 100 \mathrm{MHz}\right)$. 


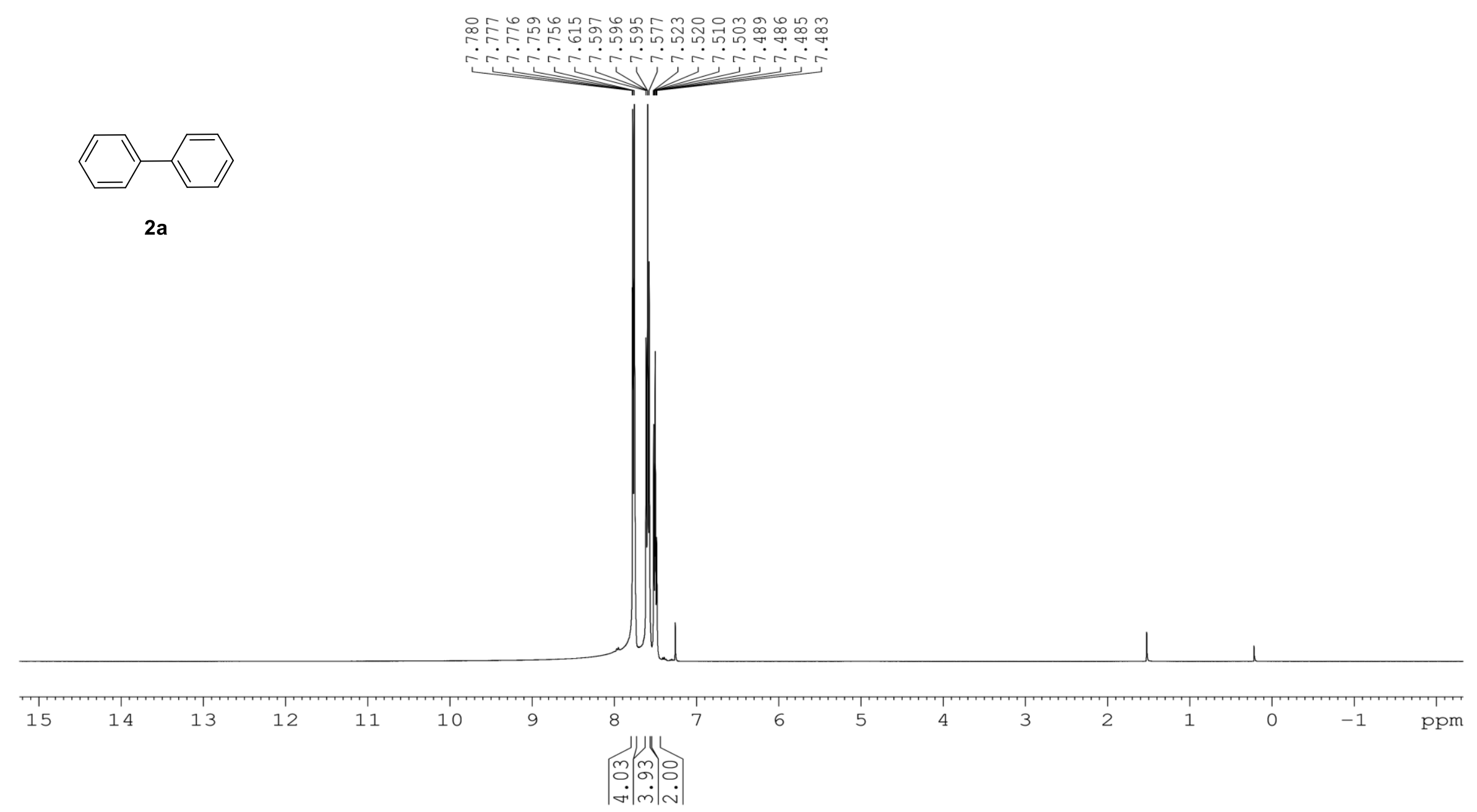

Figure S17. ${ }^{1} \mathrm{H}$ NMR spectrum of $\mathbf{2 a}\left(\mathrm{CDCl}_{3}, 400 \mathrm{MHz}\right)$. 


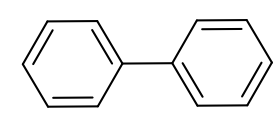

$2 \mathbf{a}$
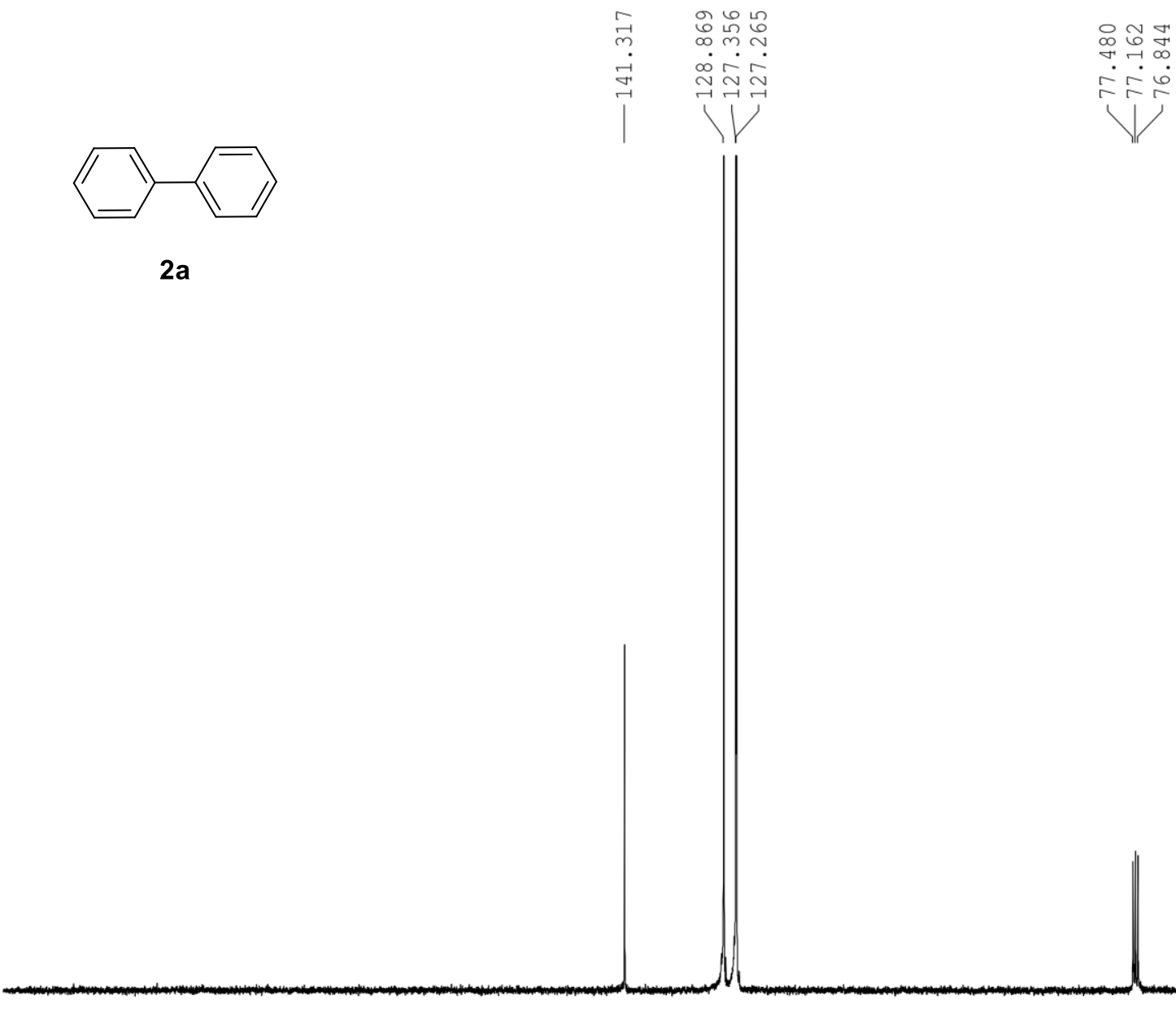

$\begin{array}{lllllllllllllllllllllll}210 & 200 & 190 & 180 & 170 & 160 & 150 & 140 & 130 & 120 & 110 & 100 & 90 & 80 & 70 & 60 & 50 & 40 & 30 & 20 & 10 & 0 & \mathrm{ppm}\end{array}$ Figure S18. ${ }^{13} \mathrm{C}$ NMR spectrum of $\mathbf{2 a}\left(\mathrm{CDCl}_{3}, 100 \mathrm{MHz}\right)$. 


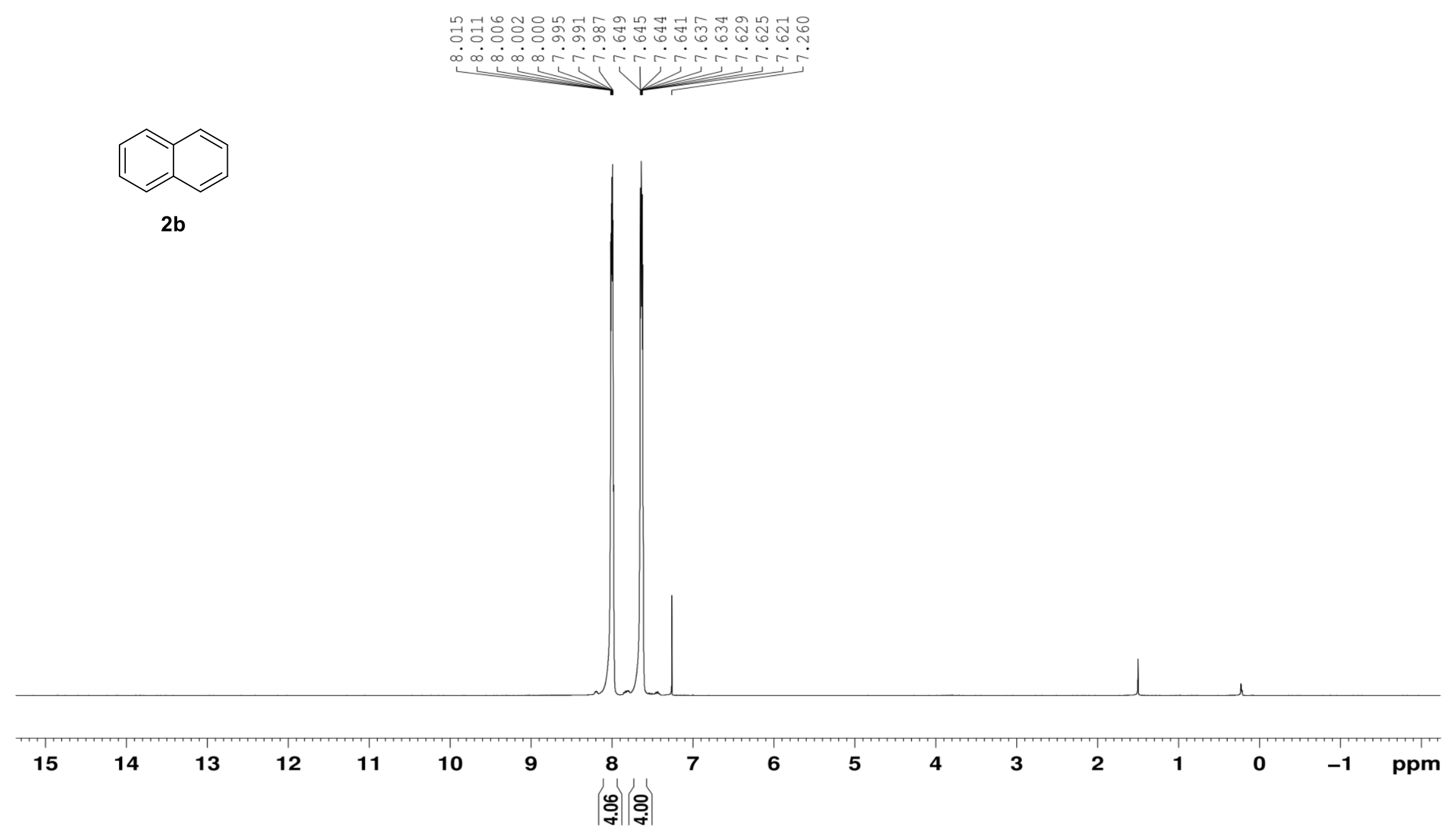

Figure S19. ${ }^{1} \mathrm{H}$ NMR spectrum of $\mathbf{2 b}\left(\mathrm{CDCl}_{3}, 400 \mathrm{MHz}\right)$. 


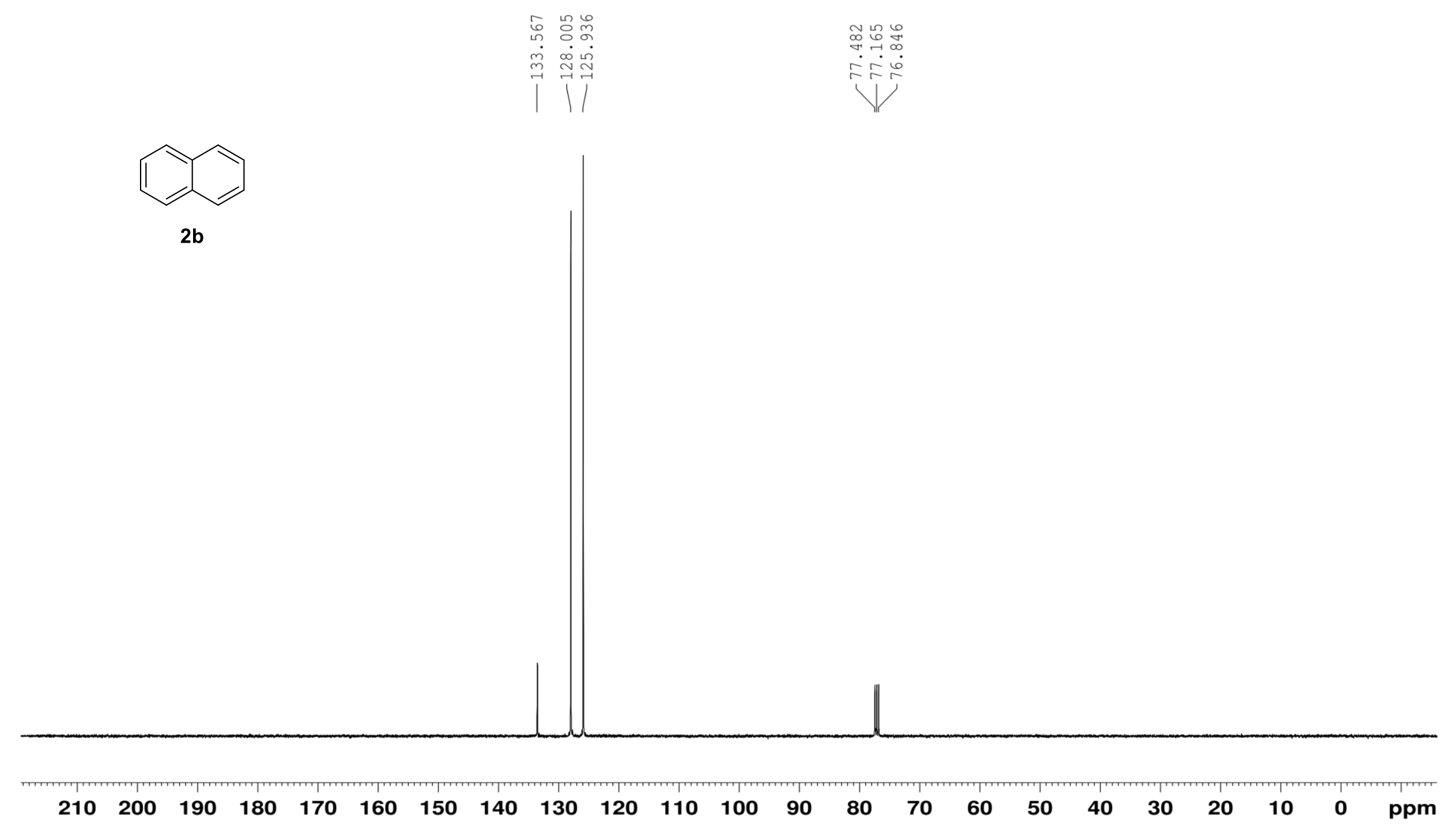

Figure S20. ${ }^{13} \mathrm{C}$ NMR spectrum of $\mathbf{2 b}\left(\mathrm{CDCl}_{3}, 100 \mathrm{MHz}\right)$. 


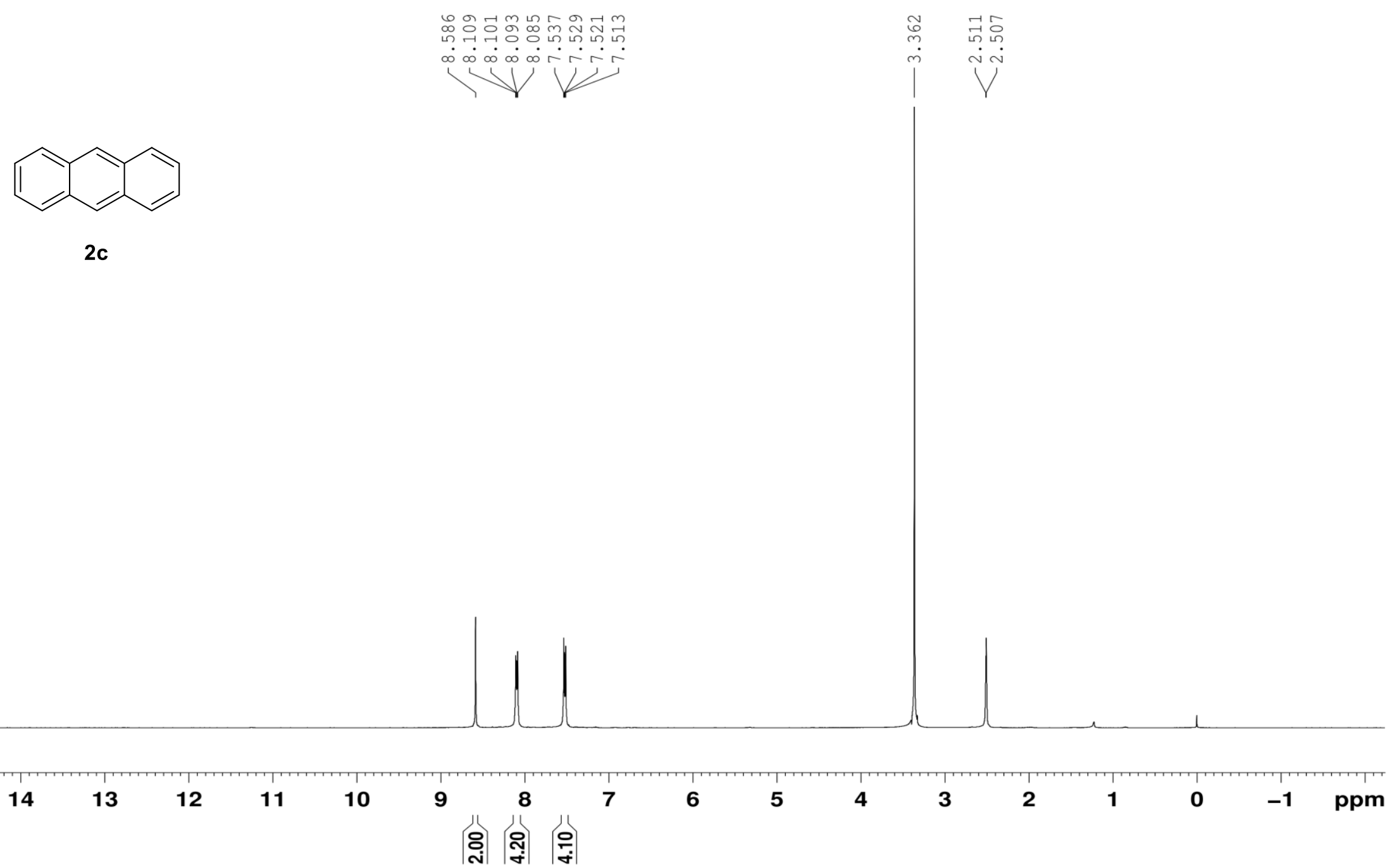

Figure S21. ${ }^{1} \mathrm{H}$ NMR spectrum of $2 \mathbf{c}(d$-DMSO, $400 \mathrm{MHz})$. 

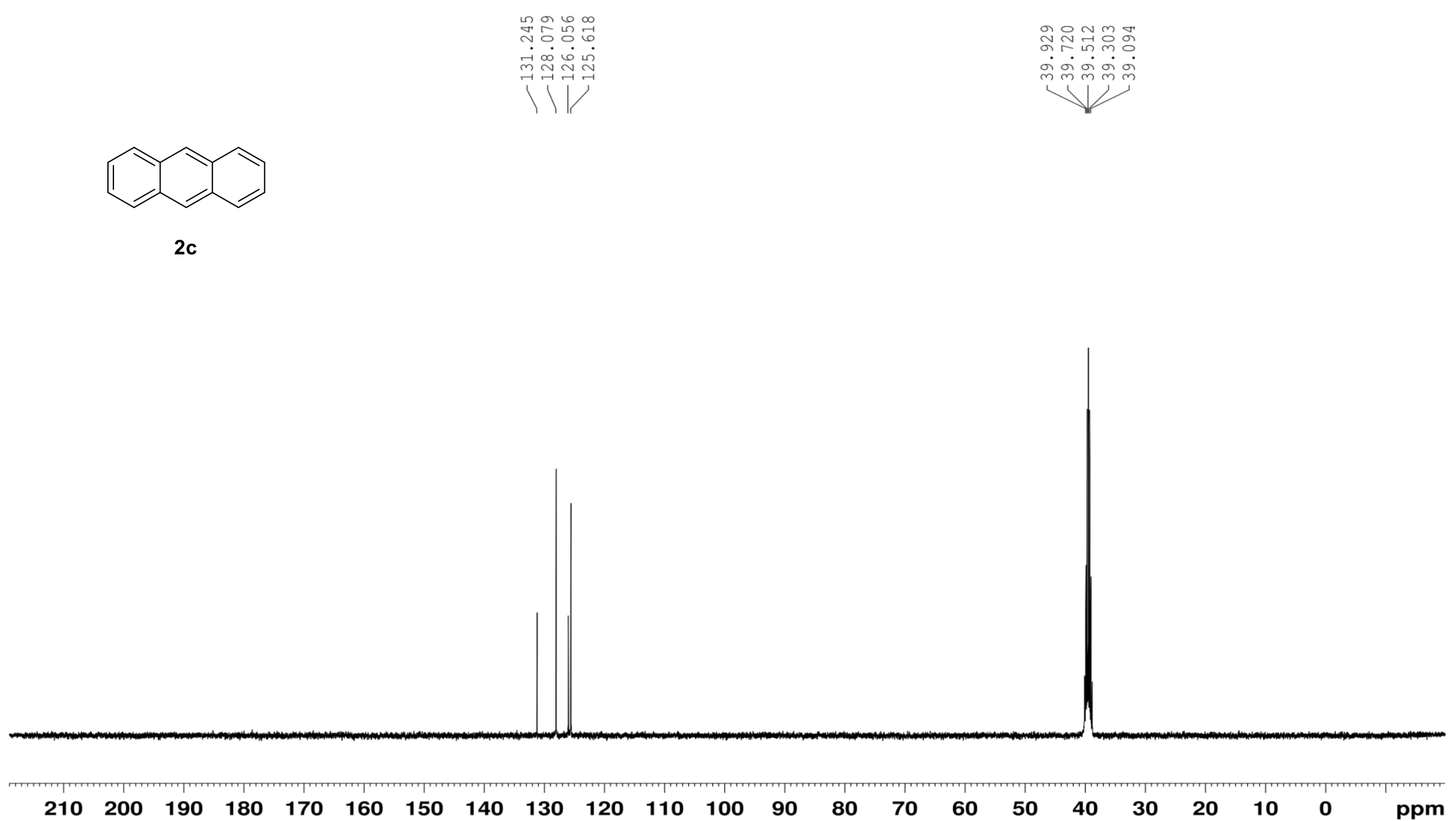

Figure $\mathbf{S 2 2} .{ }^{13} \mathrm{C}$ NMR spectrum of $\mathbf{2 c}(d$-DMSO, $100 \mathrm{MHz})$. 

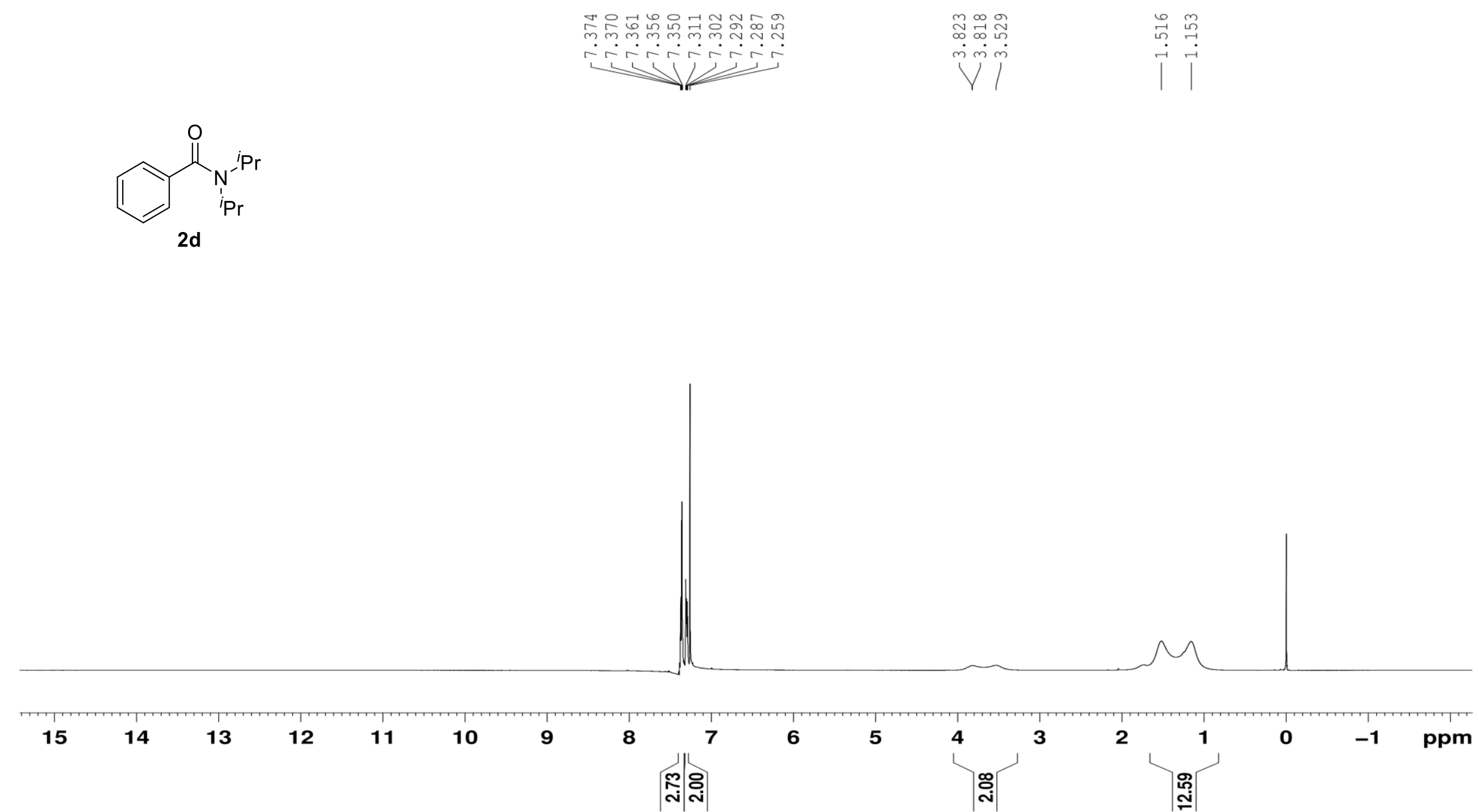

Figure S23. ${ }^{1} \mathrm{H}$ NMR spectrum of $\mathbf{2 d}\left(\mathrm{CDCl}_{3}, 400 \mathrm{MHz}\right)$. 


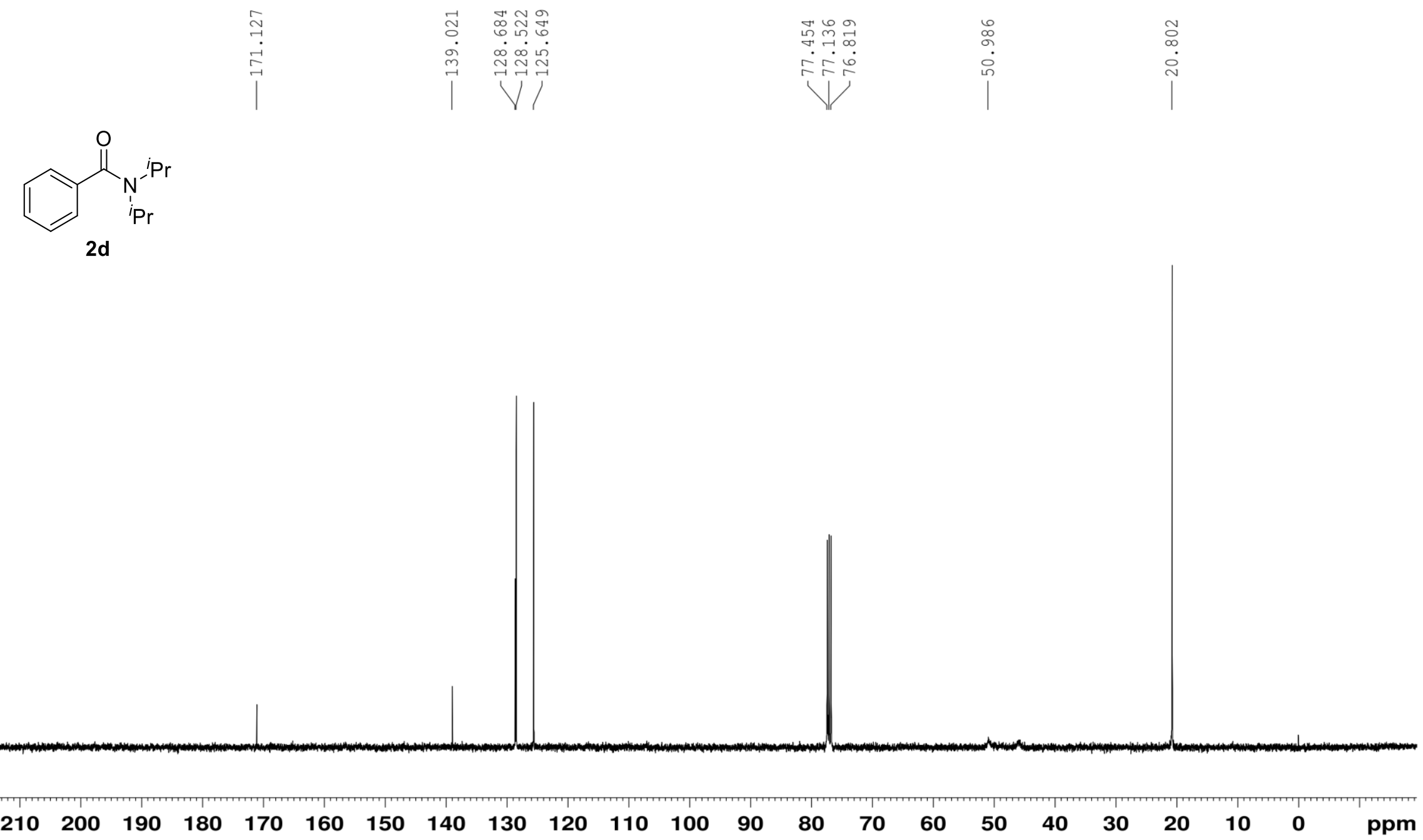

Figure S24. ${ }^{13} \mathrm{C}$ NMR spectrum of $\mathbf{2 d}\left(\mathrm{CDCl}_{3}, 100 \mathrm{MHz}\right)$. 


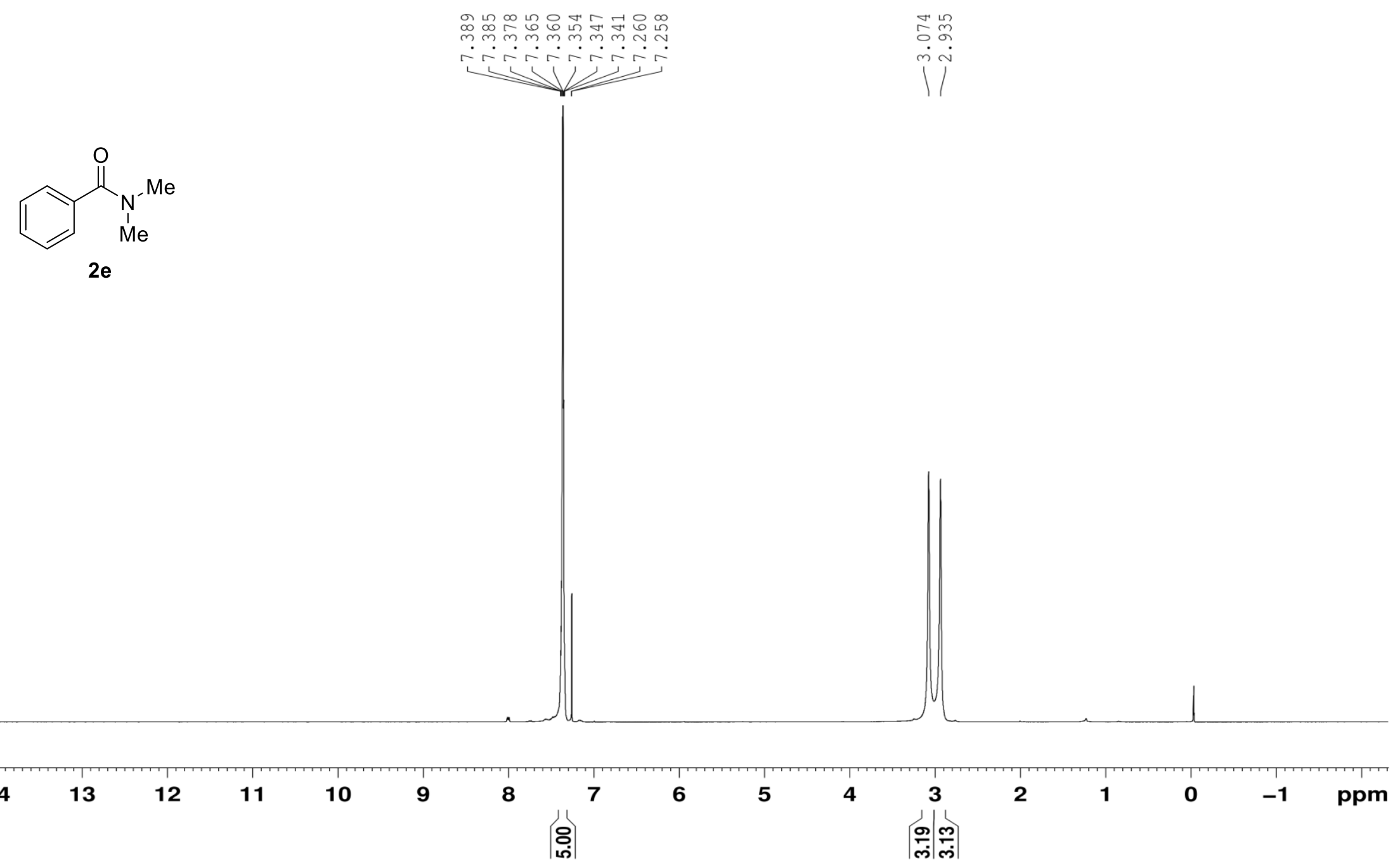

Figure S25. ${ }^{1} \mathrm{H}$ NMR spectrum of $\mathbf{2 e}\left(\mathrm{CDCl}_{3}, 400 \mathrm{MHz}\right)$. 


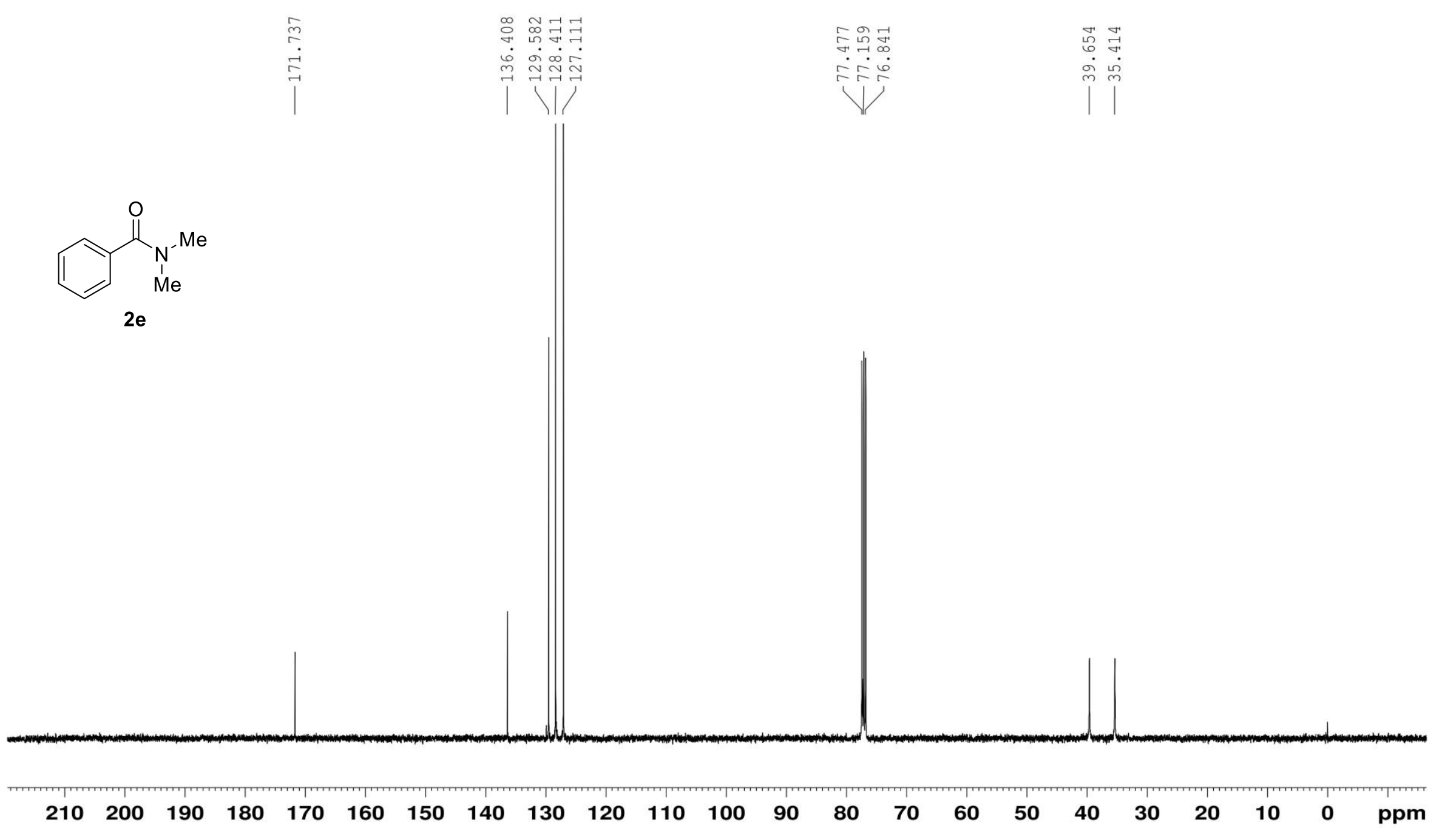

Figure S26. ${ }^{13} \mathrm{C}$ NMR spectrum of $\mathbf{2 e}\left(\mathrm{CDCl}_{3}, 100 \mathrm{MHz}\right)$. 


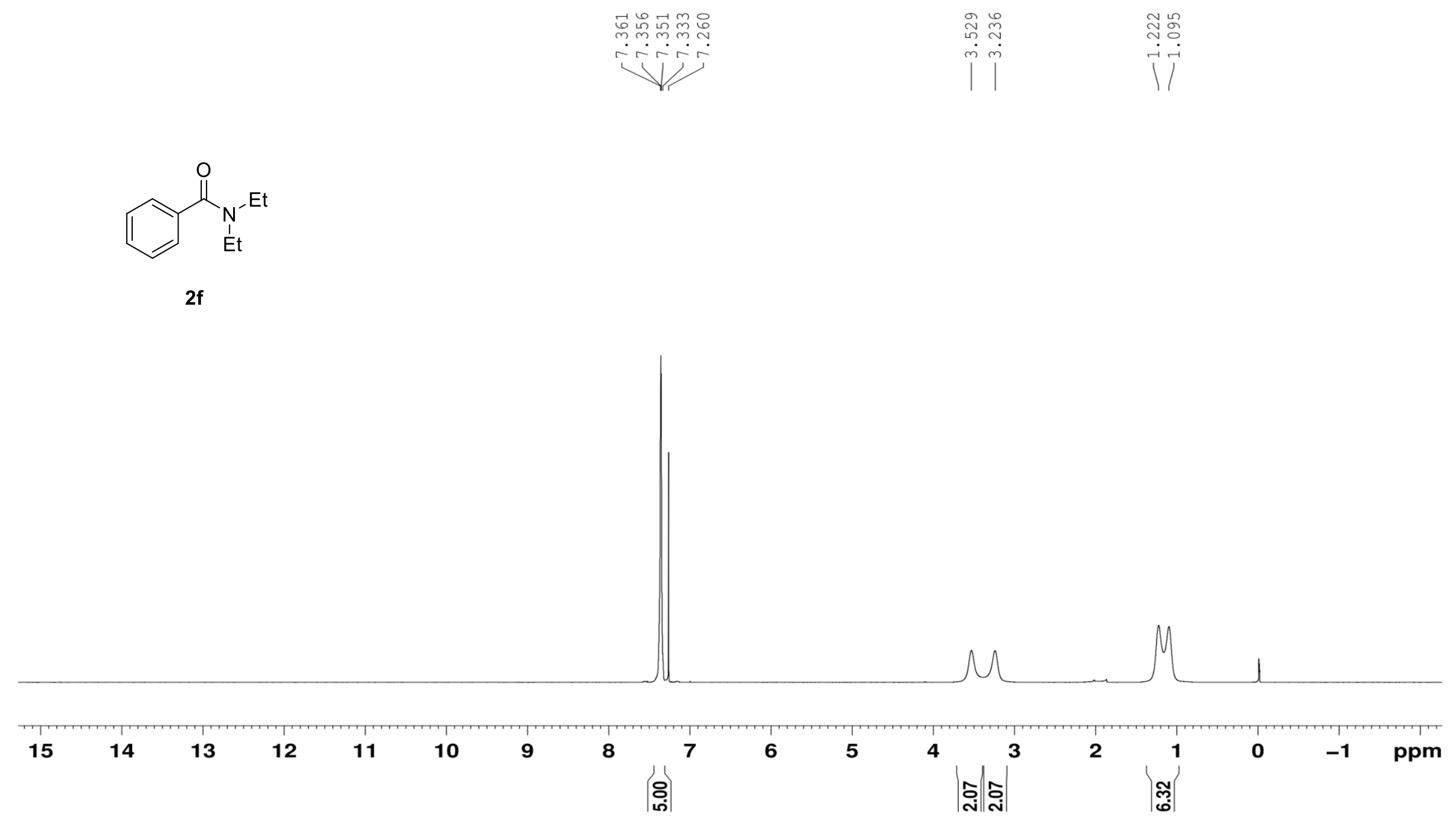

Figure S27. ${ }^{1} \mathrm{H}$ NMR spectrum of $\mathbf{2} \mathbf{f}\left(\mathrm{CDCl}_{3}, 400 \mathrm{MHz}\right)$. 


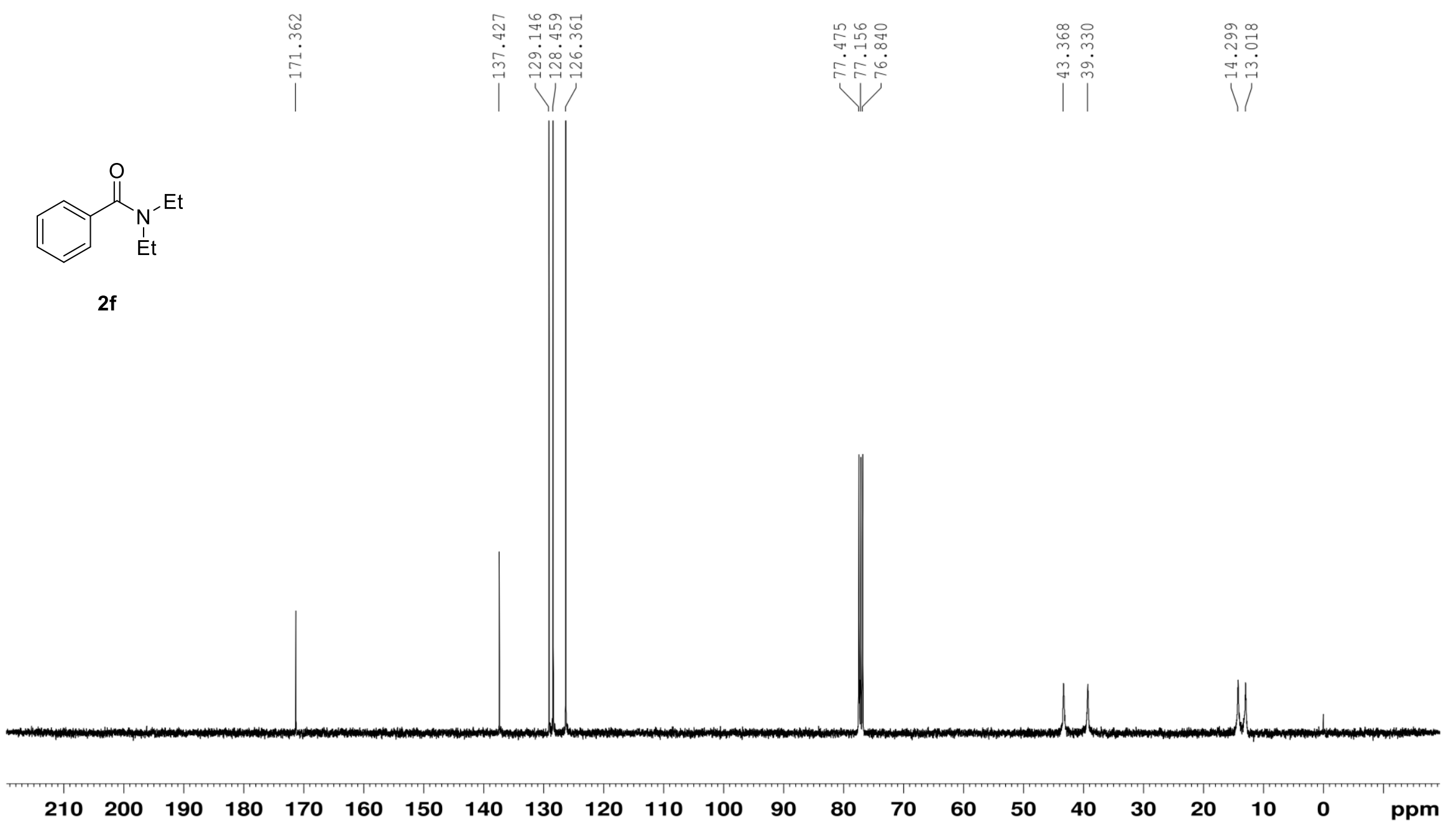

Figure S28. ${ }^{13} \mathrm{C}$ NMR spectrum of $\mathbf{2} \mathbf{f}\left(\mathrm{CDCl}_{3}, 100 \mathrm{MHz}\right)$. 


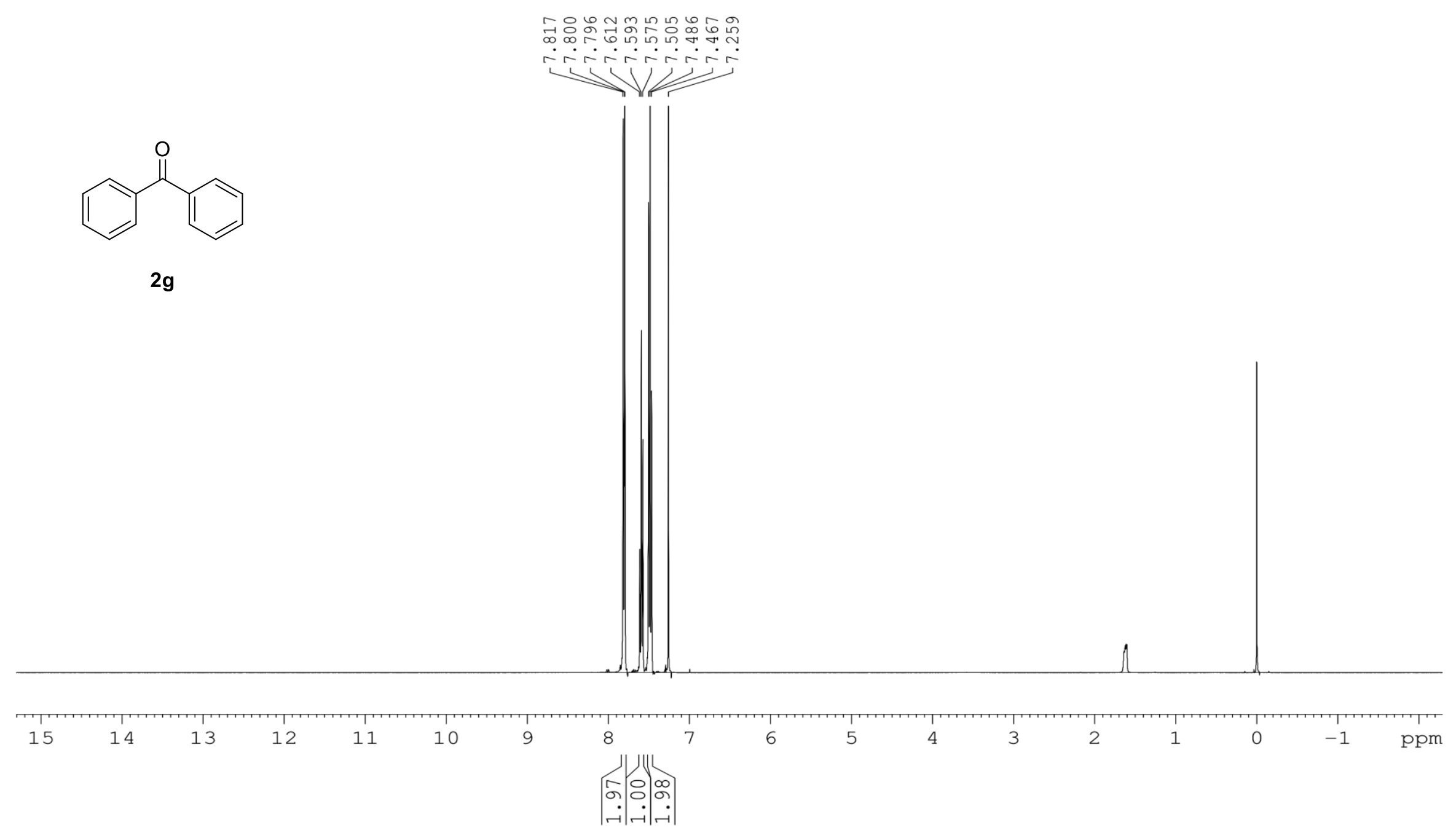

Figure S29. ${ }^{1} \mathrm{H}$ NMR spectrum of $\mathbf{2 g}\left(\mathrm{CDCl}_{3}, 400 \mathrm{MHz}\right)$. 


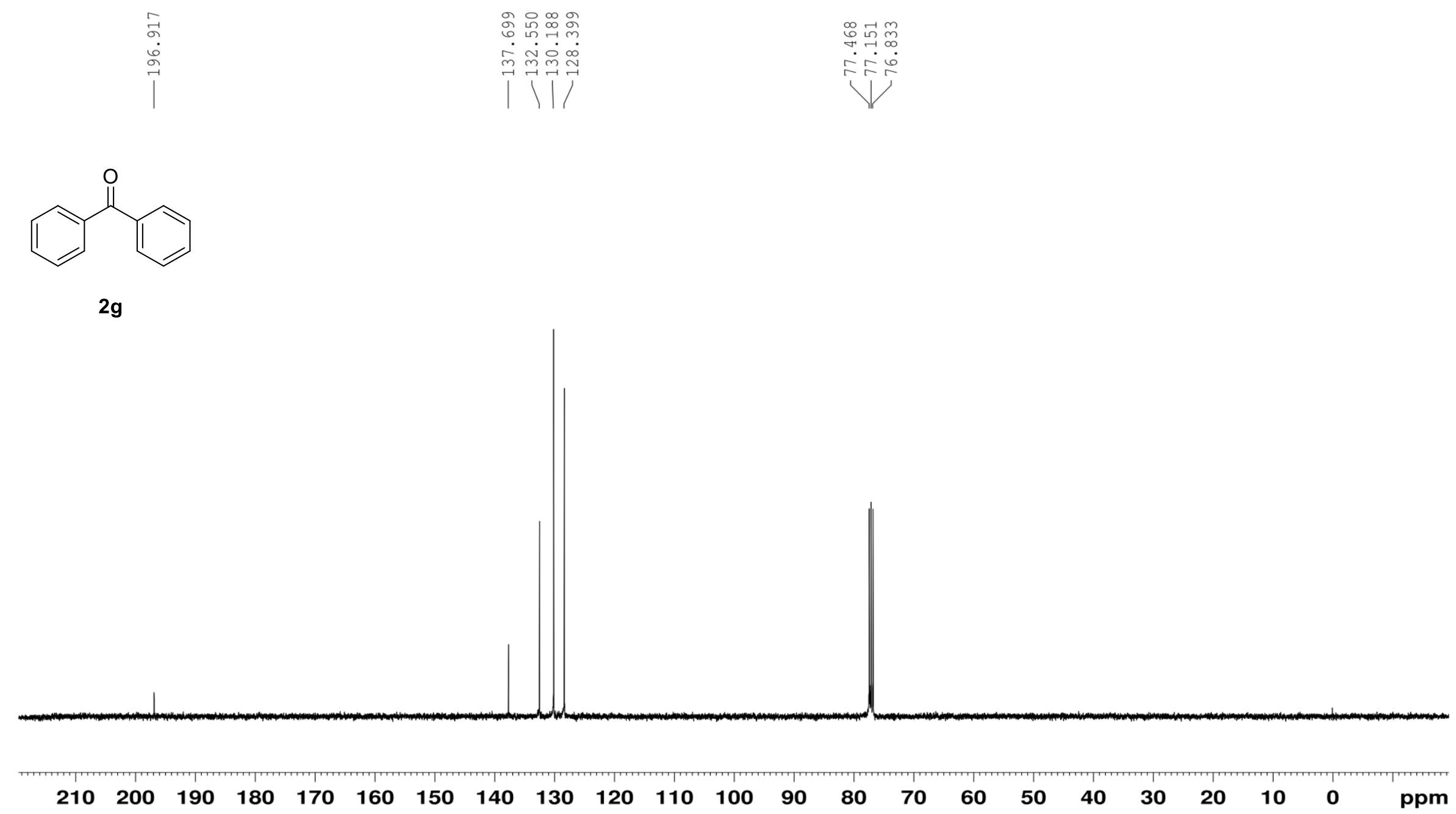

Figure S30 ${ }^{13} \mathrm{C}$ NMR spectrum of $\mathbf{2 g}\left(\mathrm{CDCl}_{3}, 100 \mathrm{MHz}\right)$. 


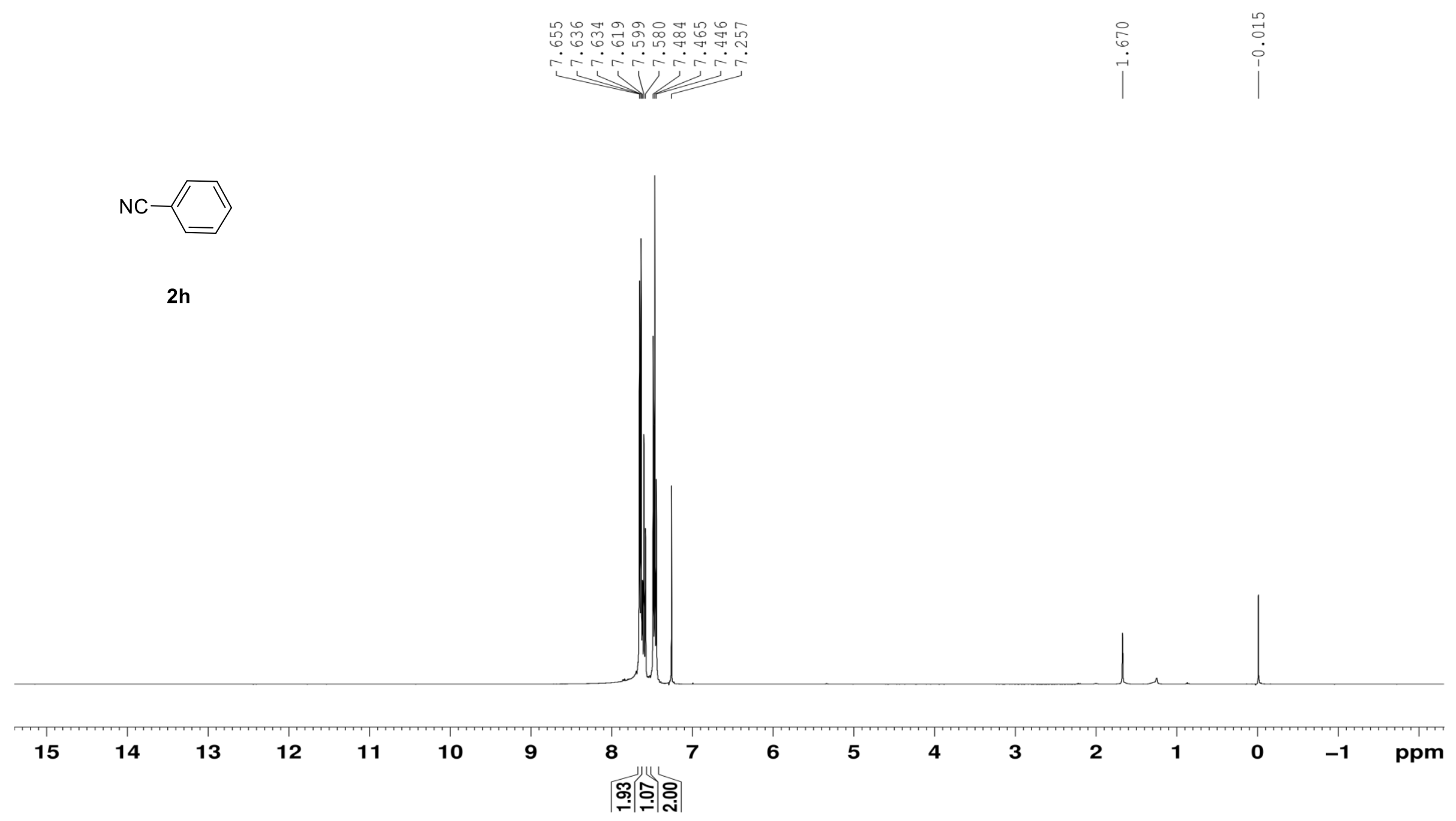

Figure S31. ${ }^{1} \mathrm{H}$ NMR spectrum of $\mathbf{2} \mathbf{h}\left(\mathrm{CDCl}_{3}, 400 \mathrm{MHz}\right)$. 


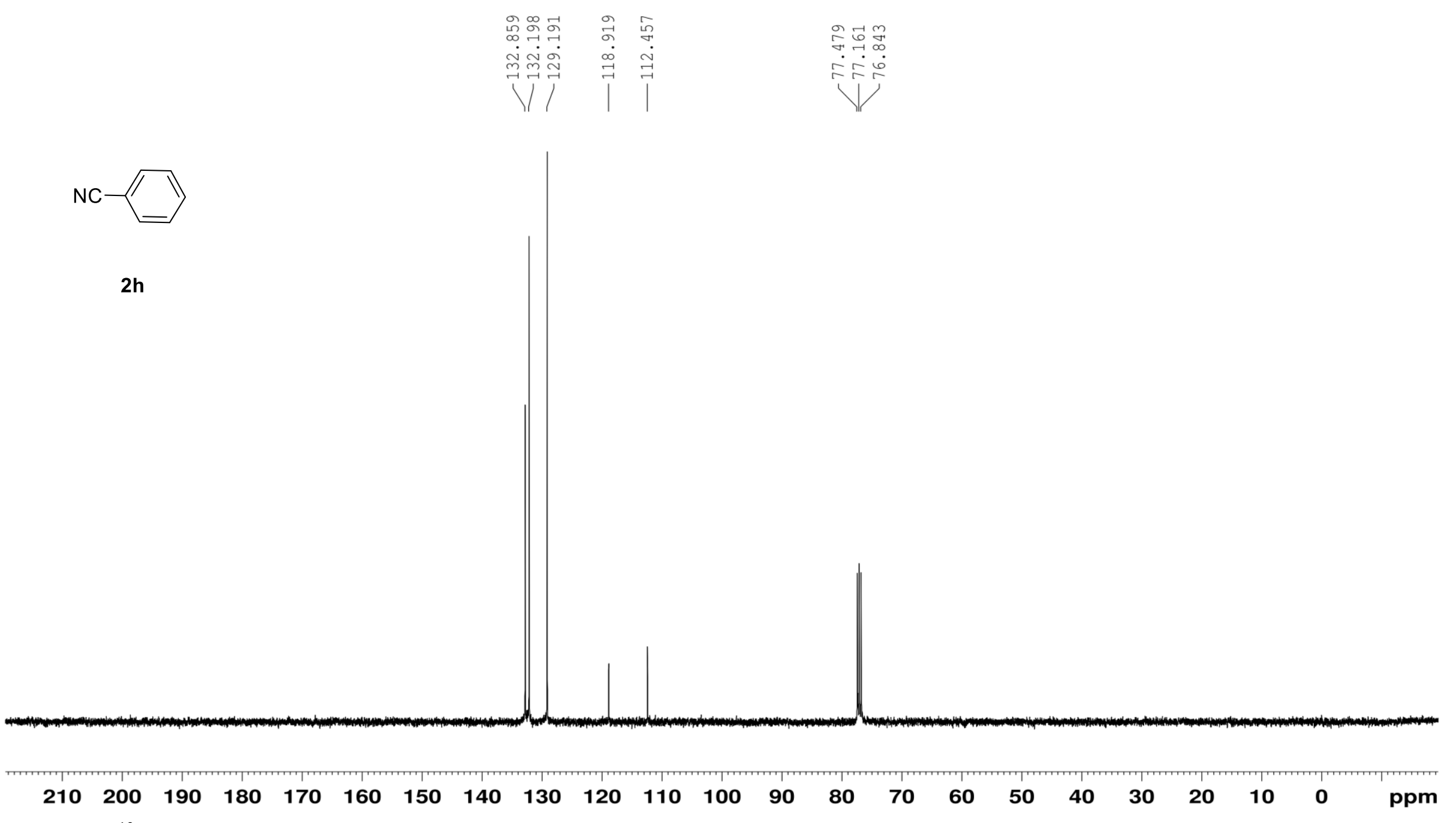

Figure S32. ${ }^{13} \mathrm{C}$ NMR spectrum of $\mathbf{2 h}\left(\mathrm{CDCl}_{3}, 100 \mathrm{MHz}\right)$. 


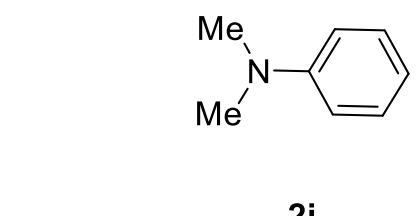

$2 i$

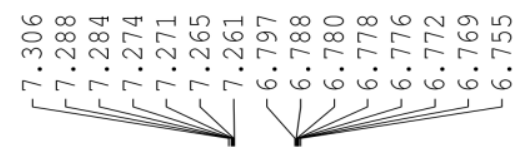

. 


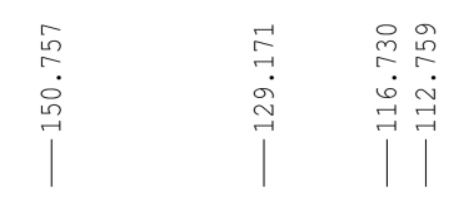

$\mathrm{Me}^{\mathrm{Me}}$

$2 \mathbf{i}$

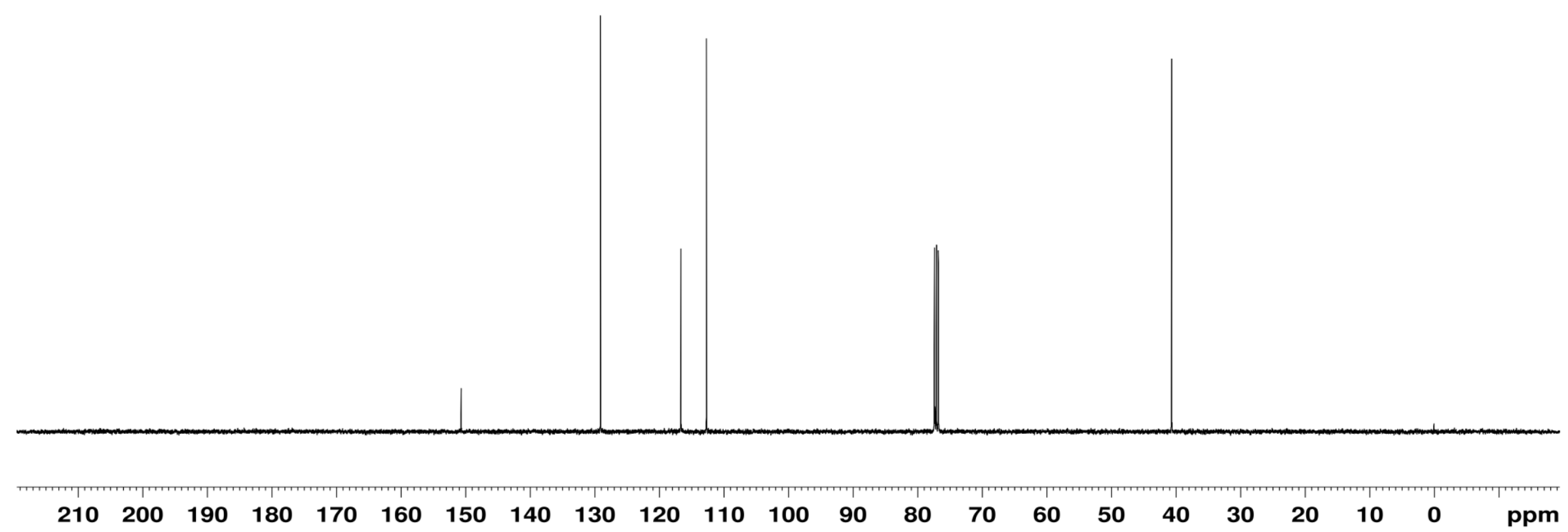

Figure S34. ${ }^{13} \mathrm{C}$ NMR spectrum of $\mathbf{2 i}\left(\mathrm{CDCl}_{3}, 100 \mathrm{MHz}\right)$. 


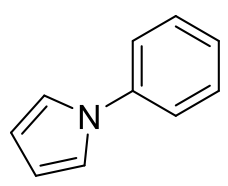

2j

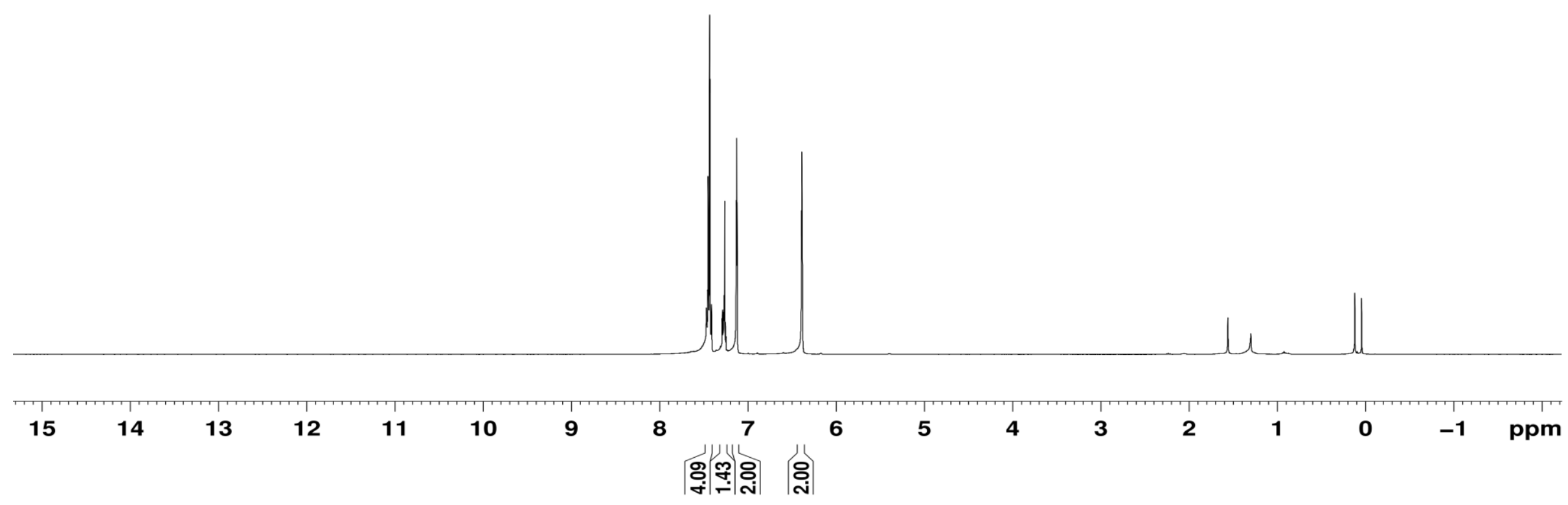

Figure S35. ${ }^{1} \mathrm{H}$ NMR spectrum of $\mathbf{2} \mathbf{j}\left(\mathrm{CDCl}_{3}, 400 \mathrm{MHz}\right)$. 


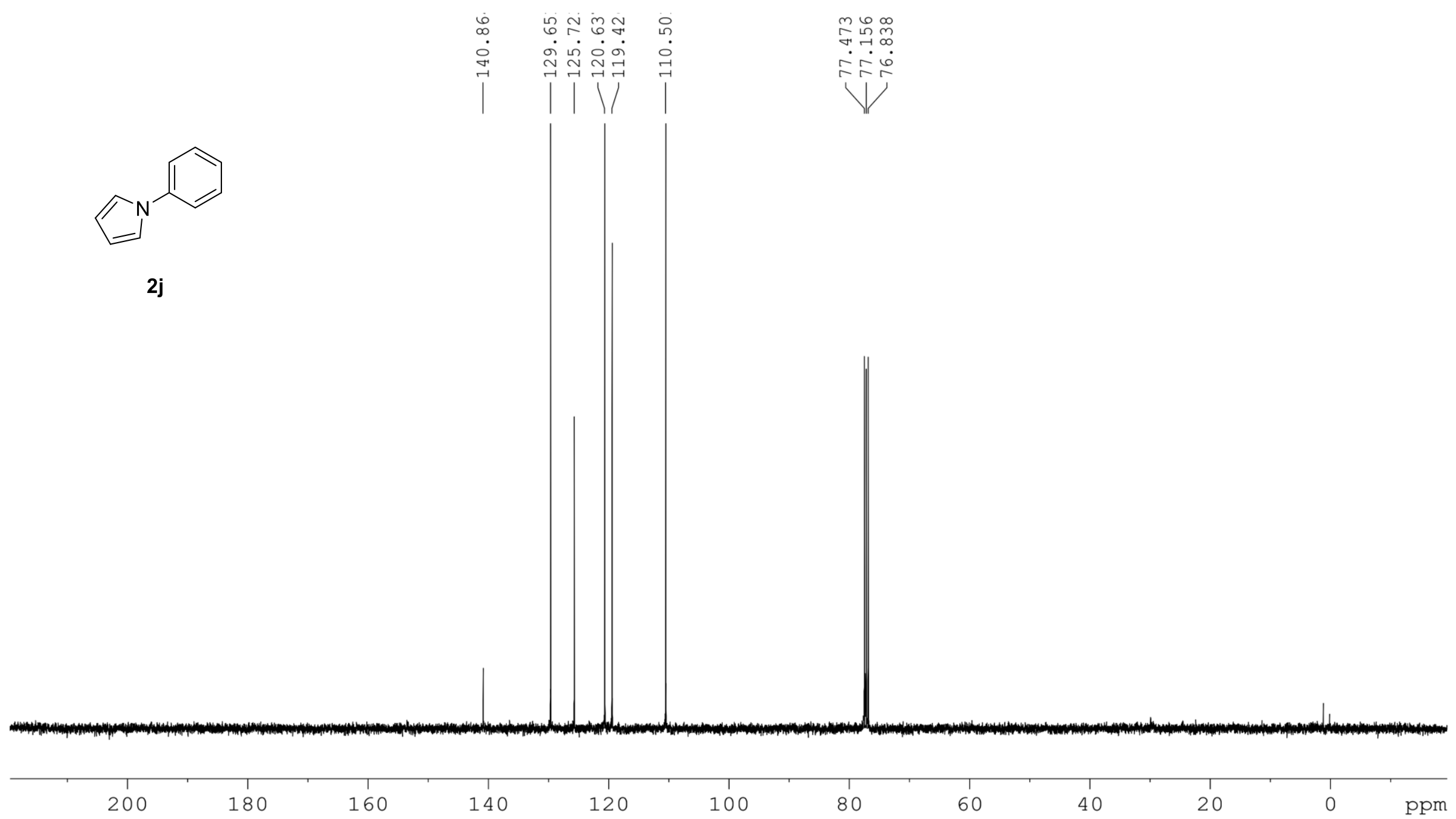

Figure S36. ${ }^{13} \mathrm{C}$ NMR spectrum of $\mathbf{2} \mathbf{j}\left(\mathrm{CDCl}_{3}, 100 \mathrm{MHz}\right)$. 

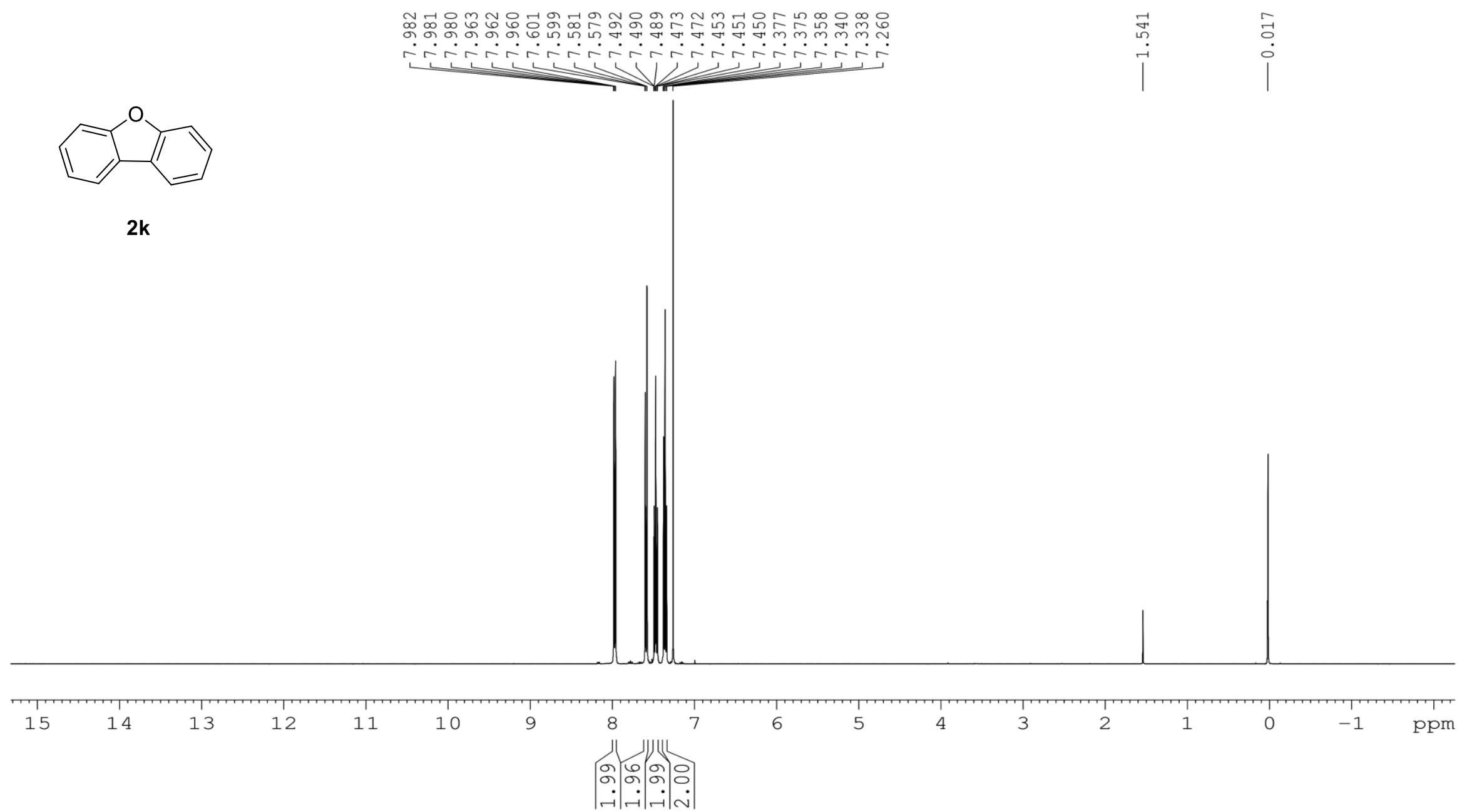

Figure S37. ${ }^{1} \mathrm{H}$ NMR spectrum of $\mathbf{2 k}\left(\mathrm{CDCl}_{3}, 400 \mathrm{MHz}\right)$. 


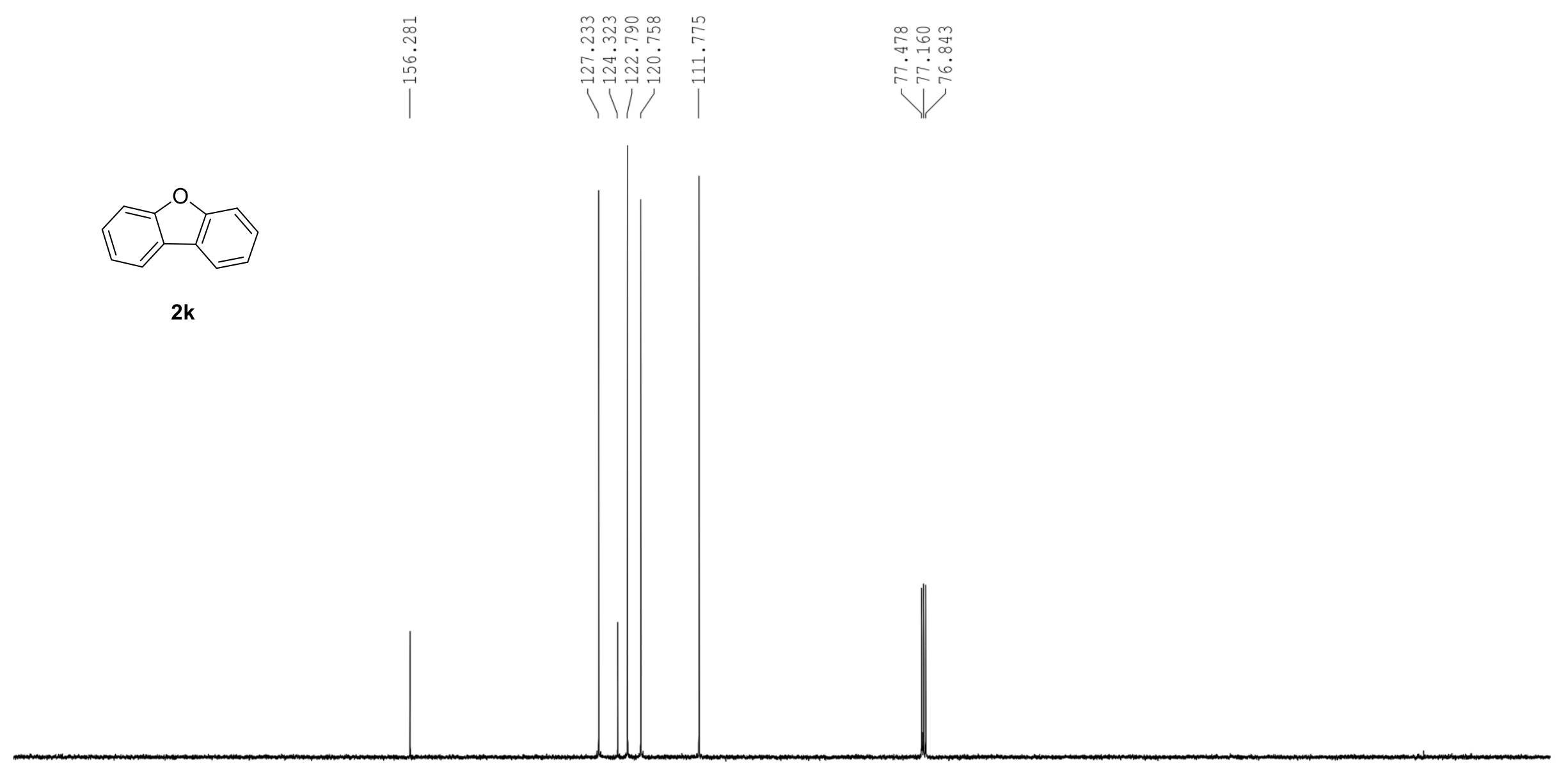

$\begin{array}{llllllllllllllllllllllll}210 & 200 & 190 & 180 & 170 & 160 & 150 & 140 & 130 & 120 & 110 & 100 & 90 & 80 & 70 & 60 & 50 & 40 & 30 & 20 & 10 & 0 & p 0 & 0\end{array}$

Figure S38. ${ }^{13} \mathrm{C}$ NMR spectrum of $\mathbf{2 k}\left(\mathrm{CDCl}_{3}, 100 \mathrm{MHz}\right)$. 


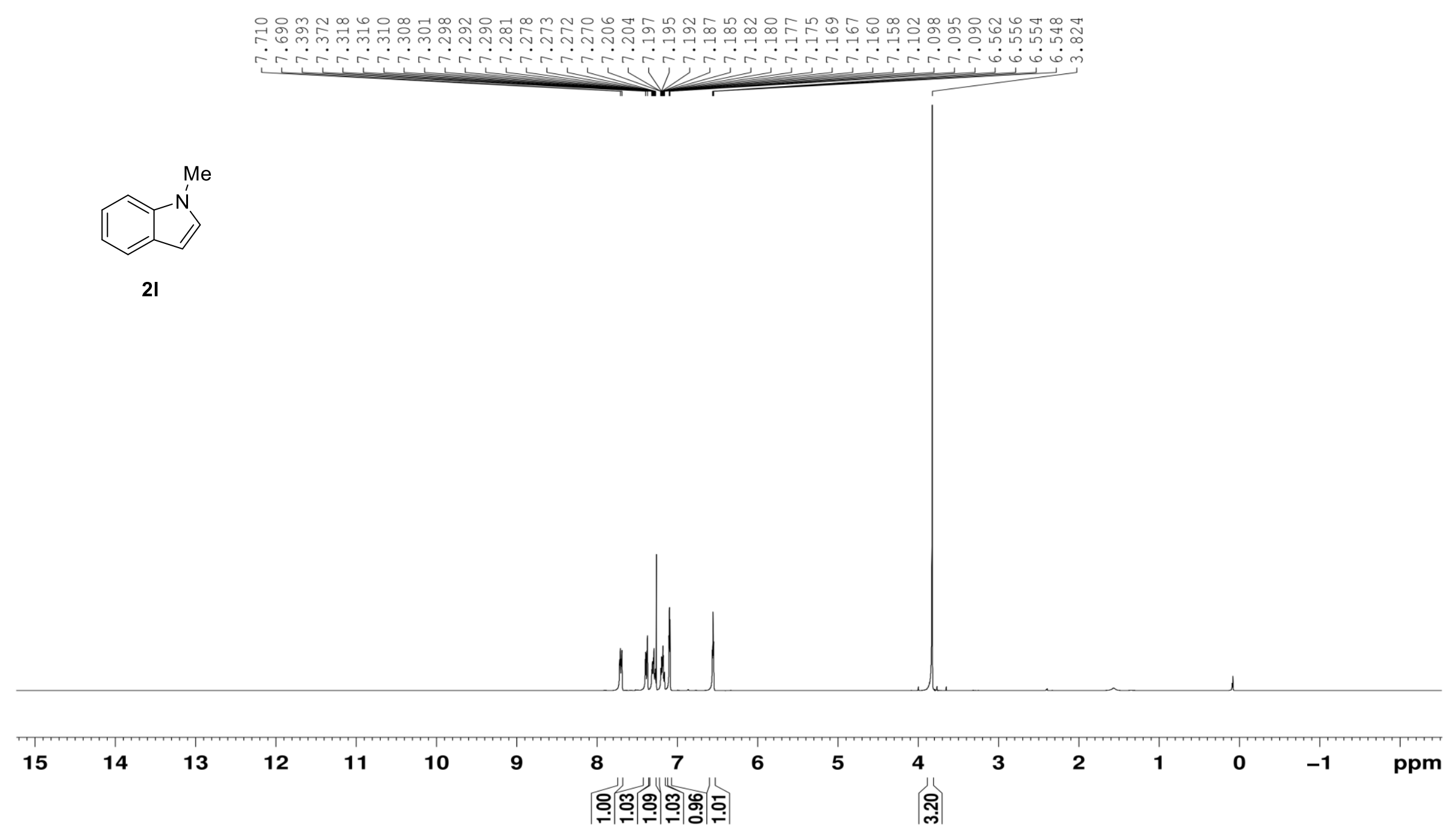

Figure S39. ${ }^{1} \mathrm{H}$ NMR spectrum of $\mathbf{2 l}\left(\mathrm{CDCl}_{3}, 400 \mathrm{MHz}\right)$. 

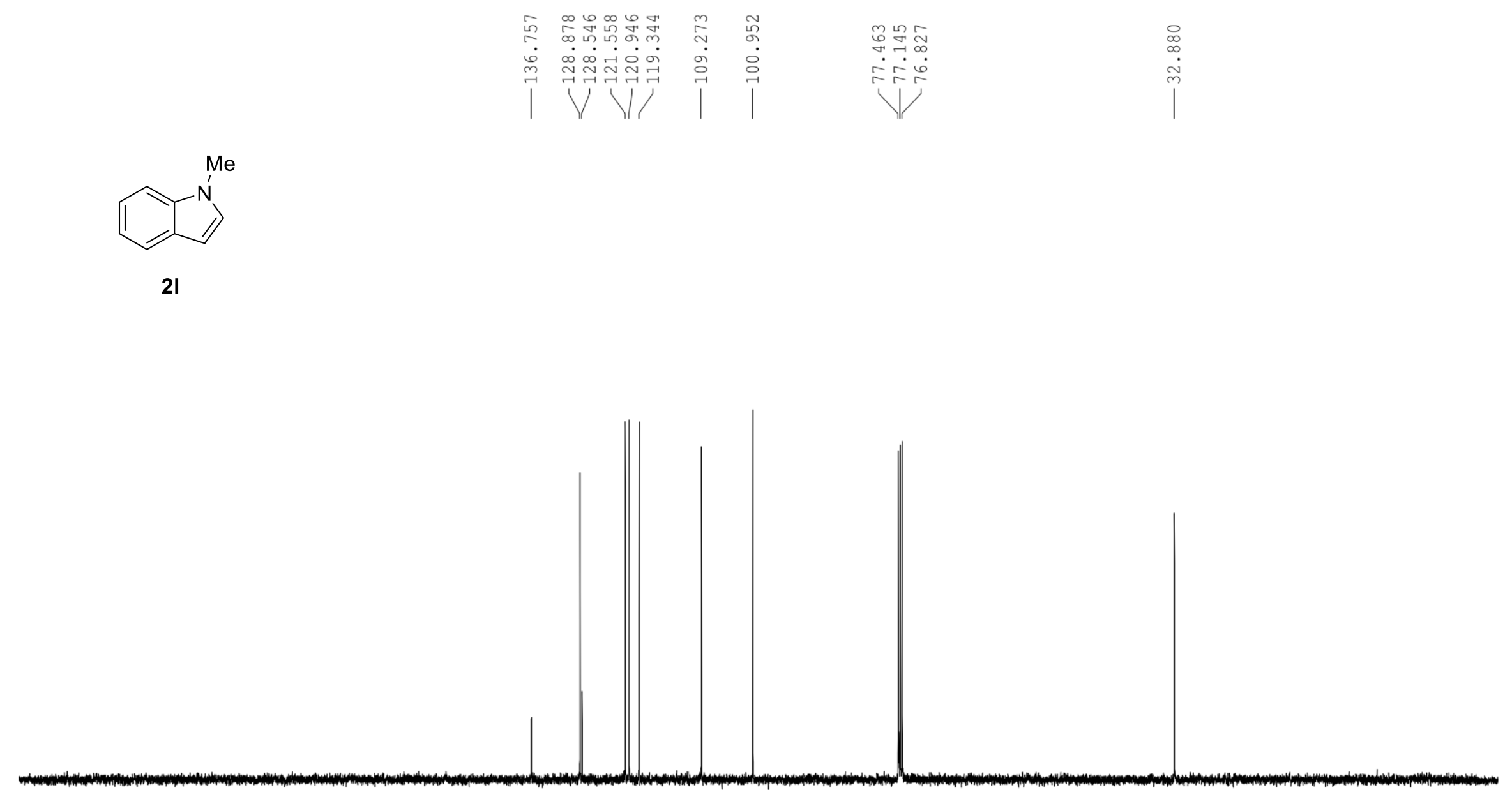

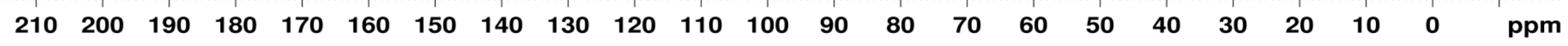

Figure S40. ${ }^{13} \mathrm{C}$ NMR spectrum of $\mathbf{2 l}\left(\mathrm{CDCl}_{3}, 100 \mathrm{MHz}\right)$. 


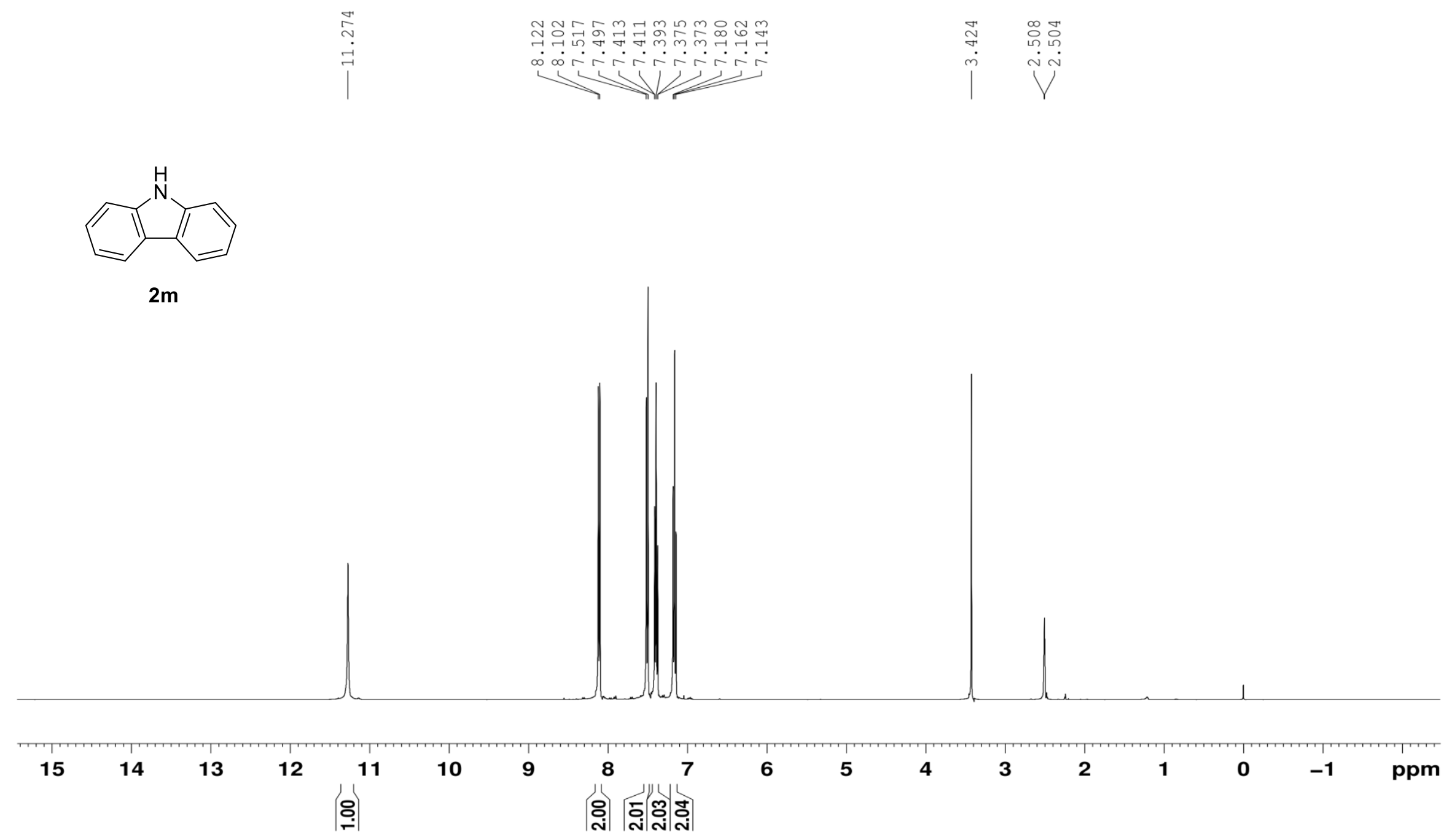

Figure S41. ${ }^{1} \mathrm{H}$ NMR spectrum of $\mathbf{2 m}(d$-DMSO, $400 \mathrm{MHz})$. 

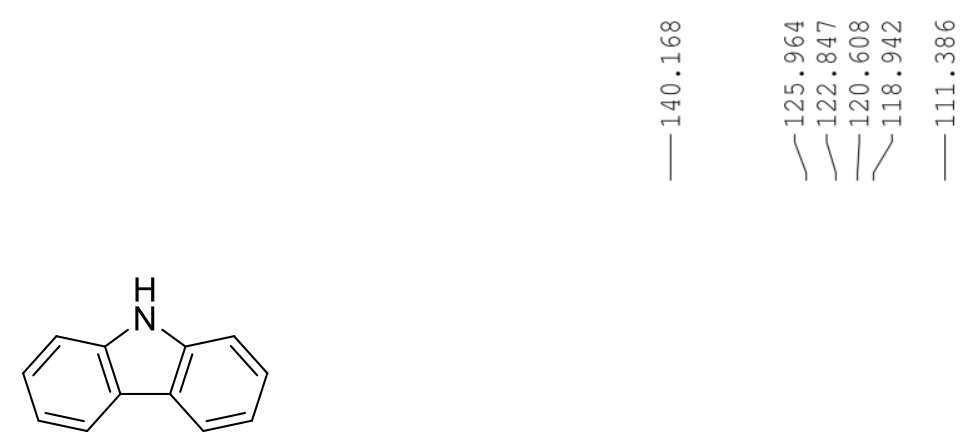

$2 \mathrm{~m}$

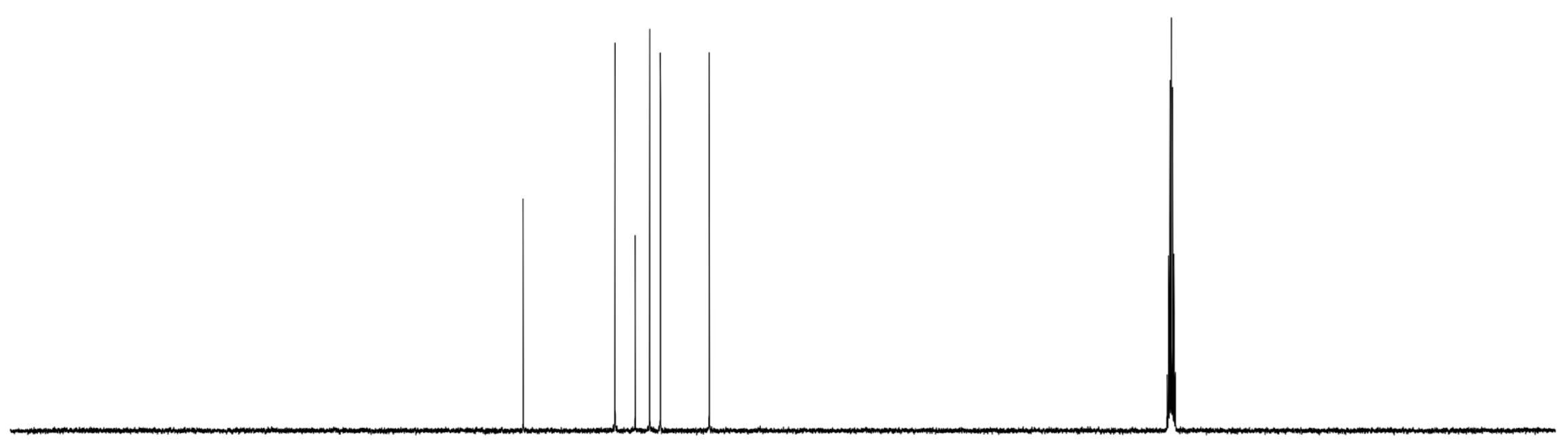

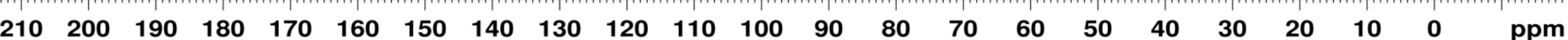

Figure $\mathbf{S 4 2} \cdot{ }^{13} \mathrm{C}$ NMR spectrum of $\mathbf{2 m}(d$-DMSO, $100 \mathrm{MHz})$. 


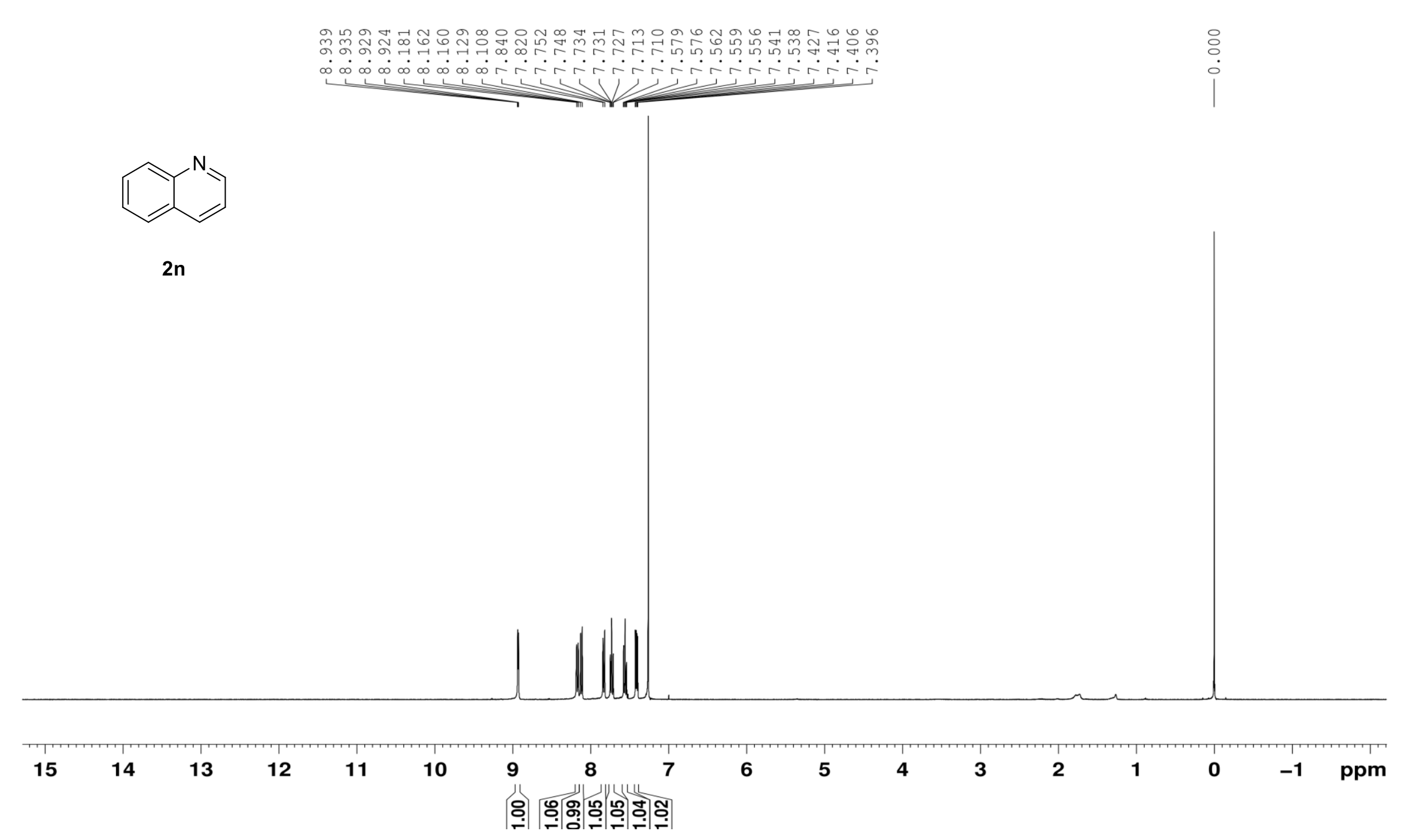

Figure S43. ${ }^{1} \mathrm{H}$ NMR spectrum of $\mathbf{2 n}\left(\mathrm{CDCl}_{3}, 400 \mathrm{MHz}\right)$. 

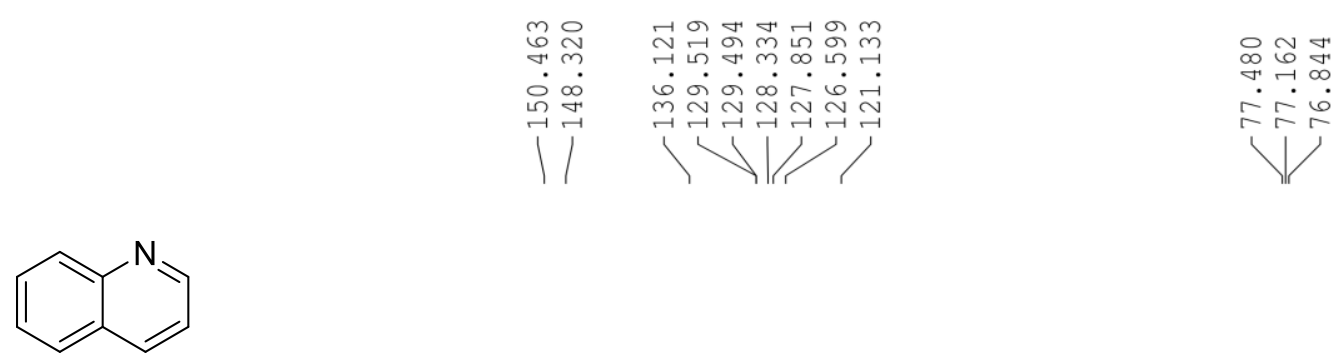

$2 n$

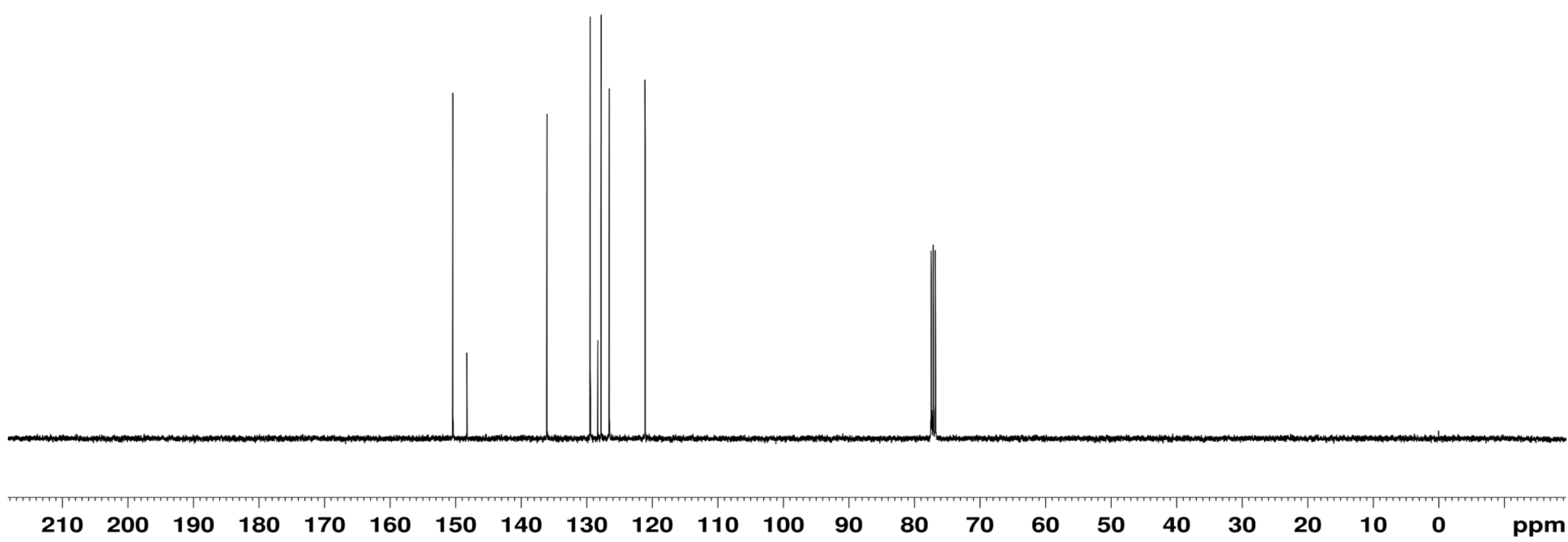

Figure S44. ${ }^{13} \mathrm{C}$ NMR spectrum of $2 \mathrm{n}\left(\mathrm{CDCl}_{3}, 100 \mathrm{MHz}\right)$. 


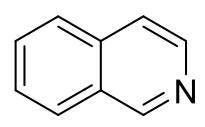

20

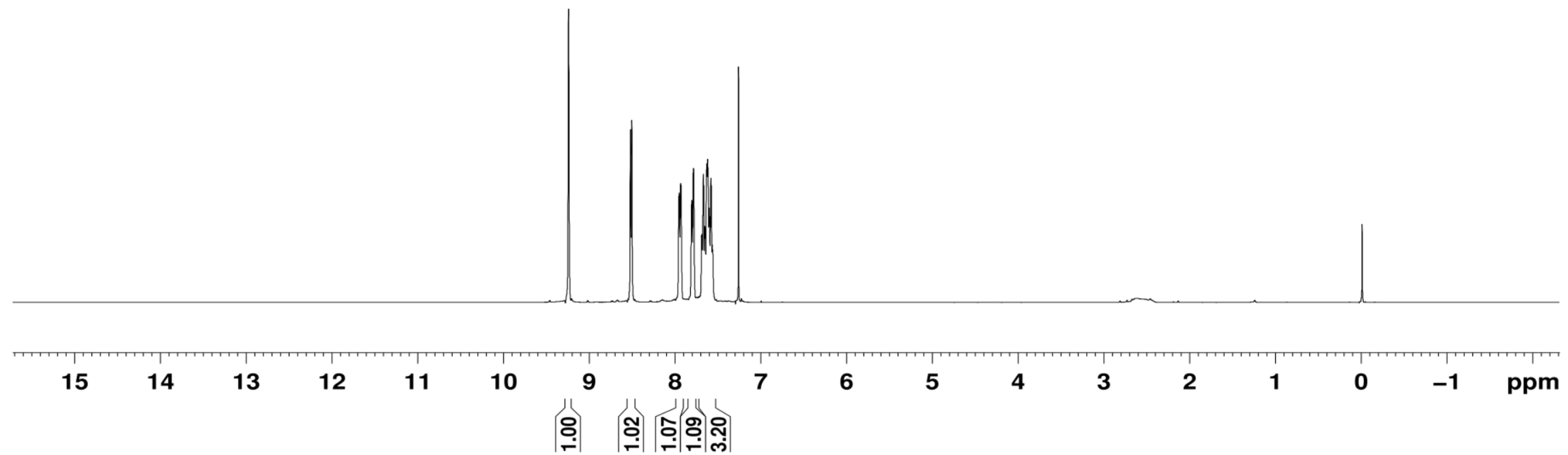

Figure $\mathbf{S 4 5} .{ }^{1} \mathrm{H}$ NMR spectrum of $\mathbf{2 0}\left(\mathrm{CDCl}_{3}, 400 \mathrm{MHz}\right)$. 

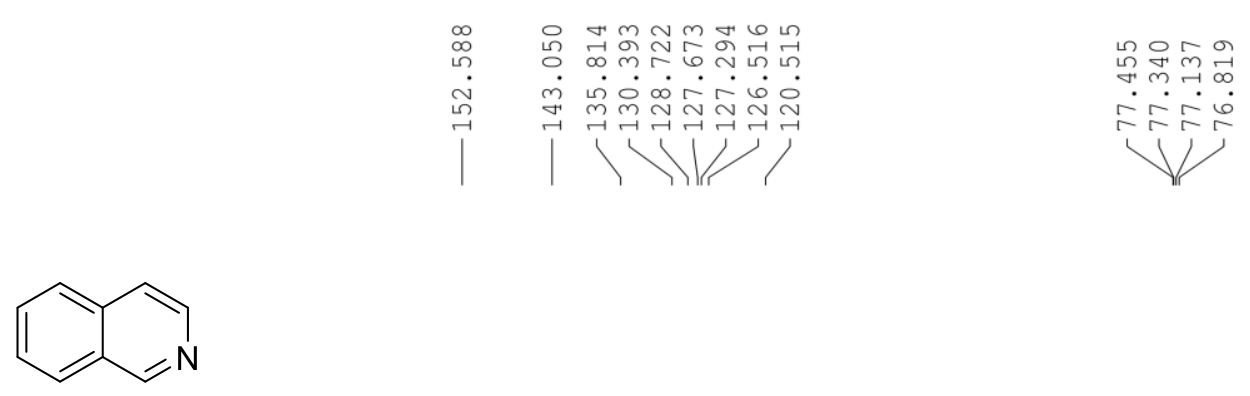

20

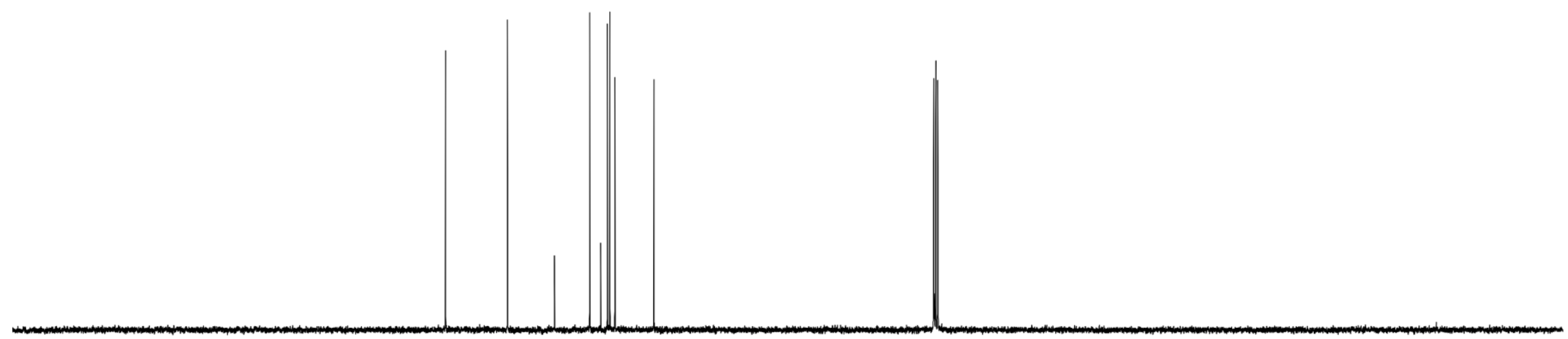

ग

5

$40 \quad 30$

20

ppm

Figure S46. ${ }^{13} \mathrm{C}$ NMR spectrum of $\mathbf{2 0}\left(\mathrm{CDCl}_{3}, 100 \mathrm{MHz}\right)$. 

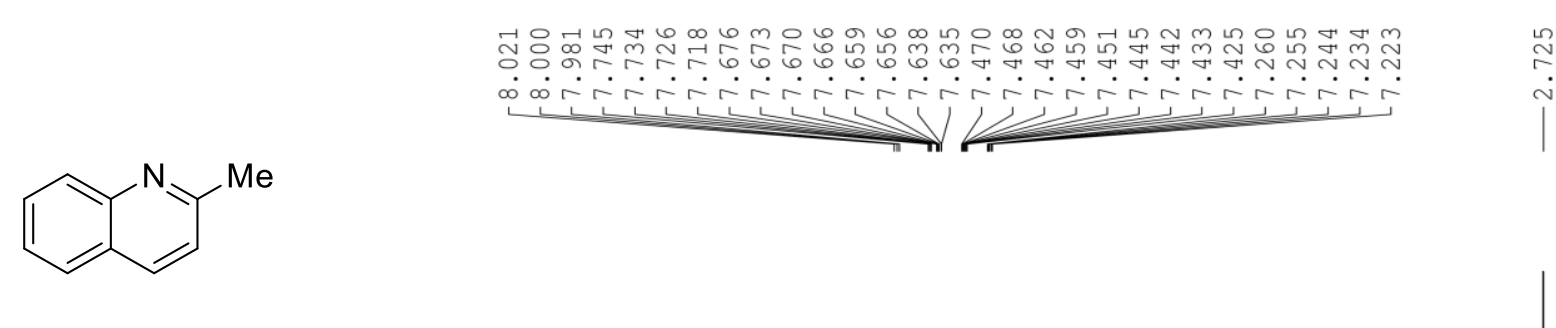

$2 p$

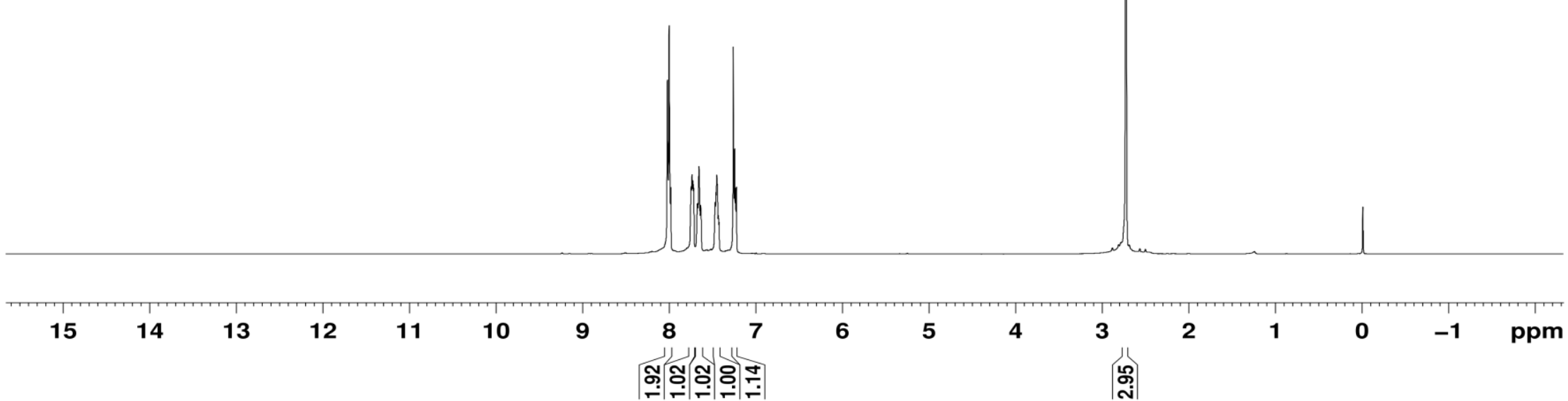

Figure $\mathbf{S 4 7 .}{ }^{1} \mathrm{H}$ NMR spectrum of $\mathbf{2 p}\left(\mathrm{CDCl}_{3}, 400 \mathrm{MHz}\right)$. 

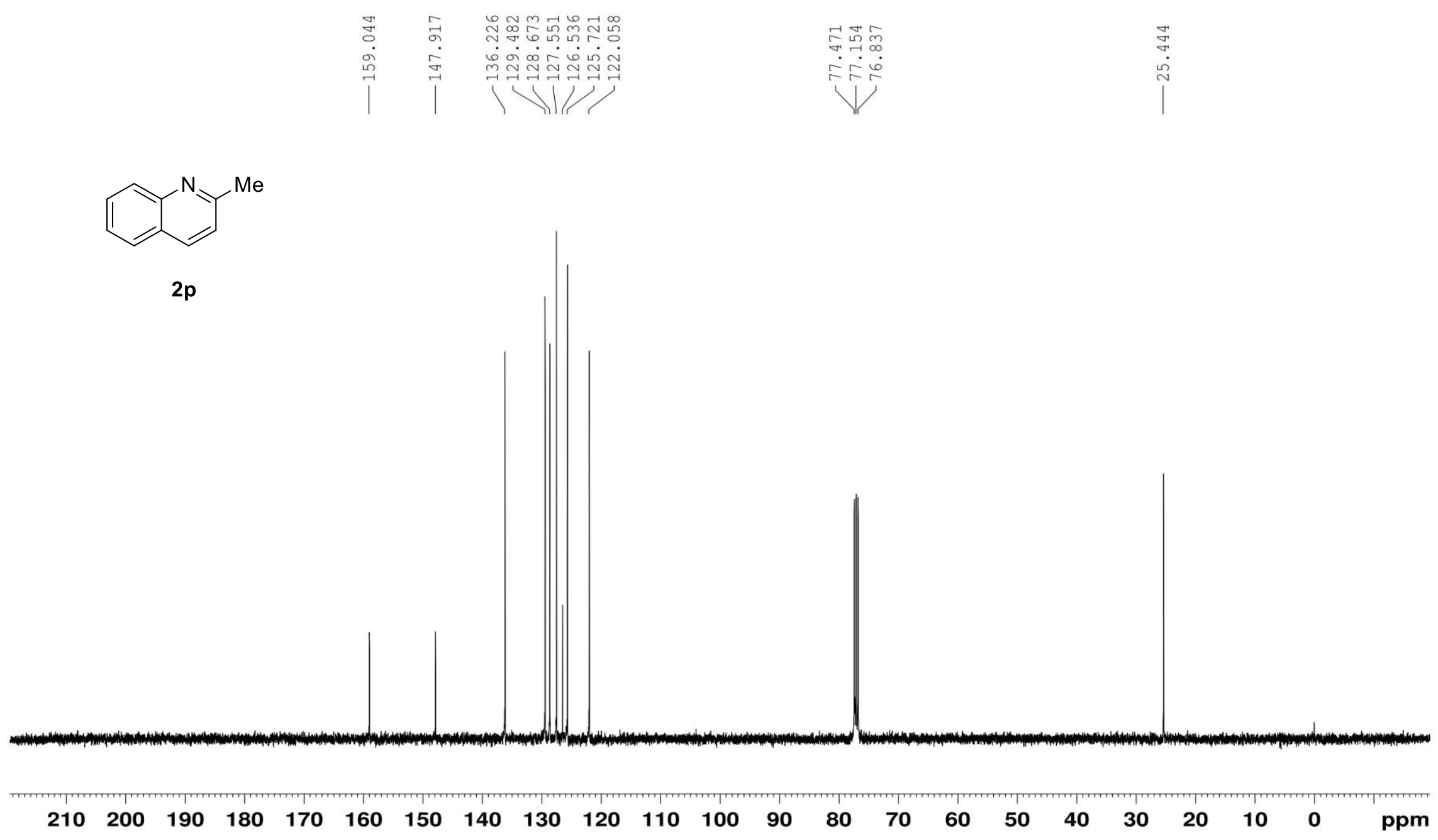

Figure S48. ${ }^{13} \mathrm{C}$ NMR spectrum of $\mathbf{2 p}\left(\mathrm{CDCl}_{3}, 100 \mathrm{MHz}\right)$. 

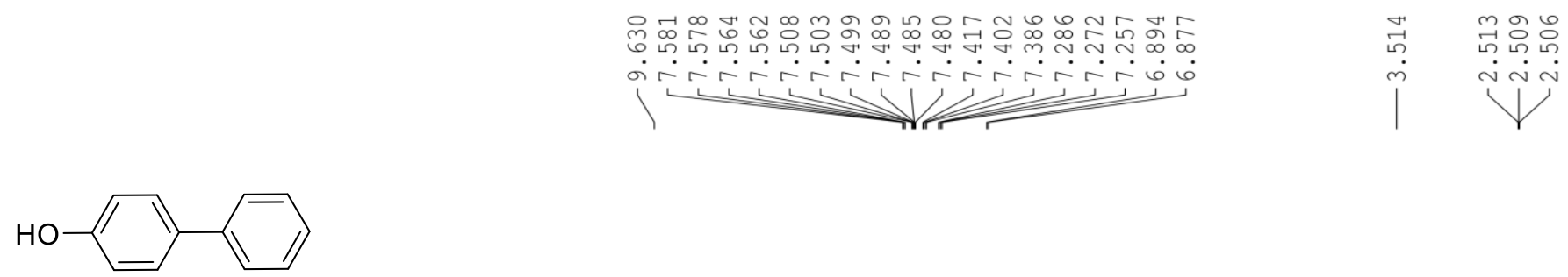

$2 r$

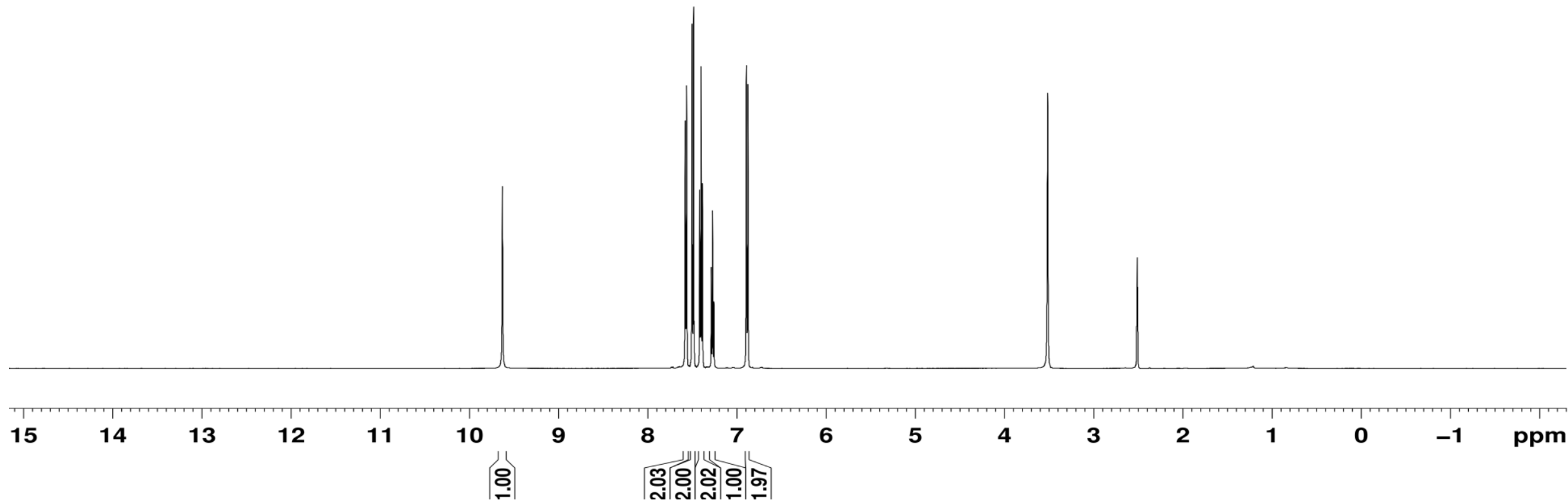

Figure S49. ${ }^{1} \mathrm{H}$ NMR spectrum of 2 r ( $d$-DMSO, $400 \mathrm{MHz}$ ). 


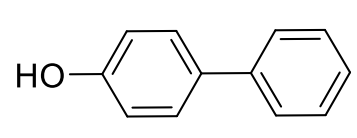

$2 r$

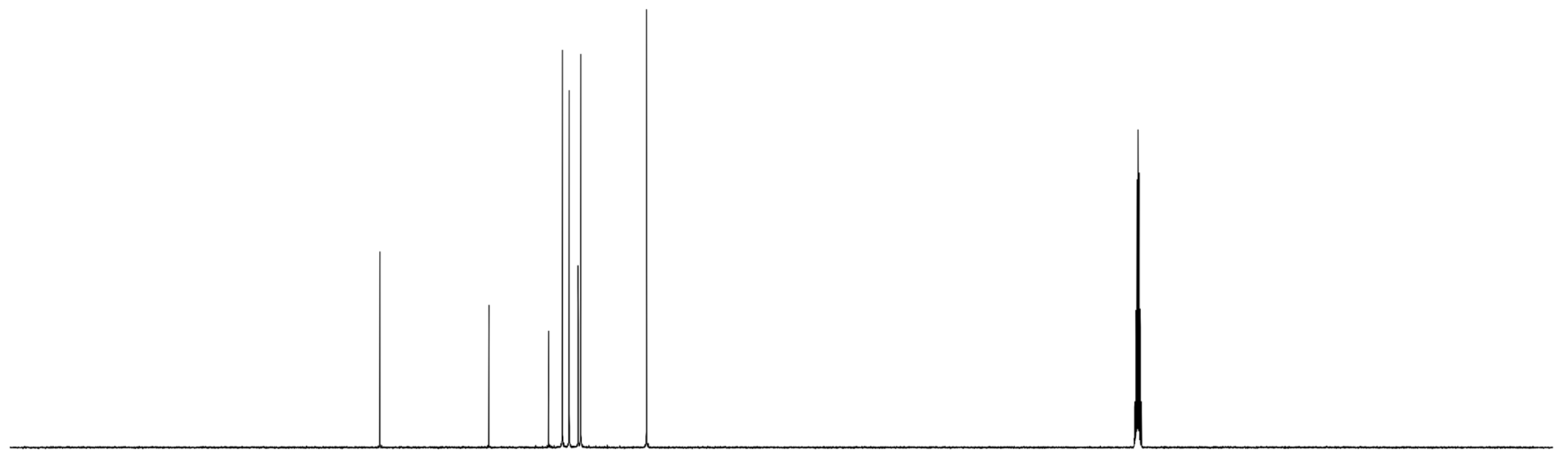

$\begin{array}{llllllllllllllllllllllll}210 & 200 & 190 & 180 & 170 & 160 & 150 & 140 & 130 & 120 & 110 & 100 & 90 & 80 & 70 & 60 & 50 & 40 & 30 & 20 & 10 & 0 & -10 & \text { ppm }\end{array}$ Figure S50. ${ }^{13} \mathrm{C}$ NMR spectrum of $2 \mathbf{r}(d-\mathrm{DMSO}, 100 \mathrm{MHz})$. 


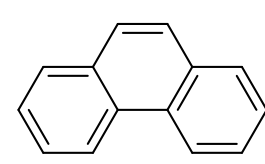

$2 s$
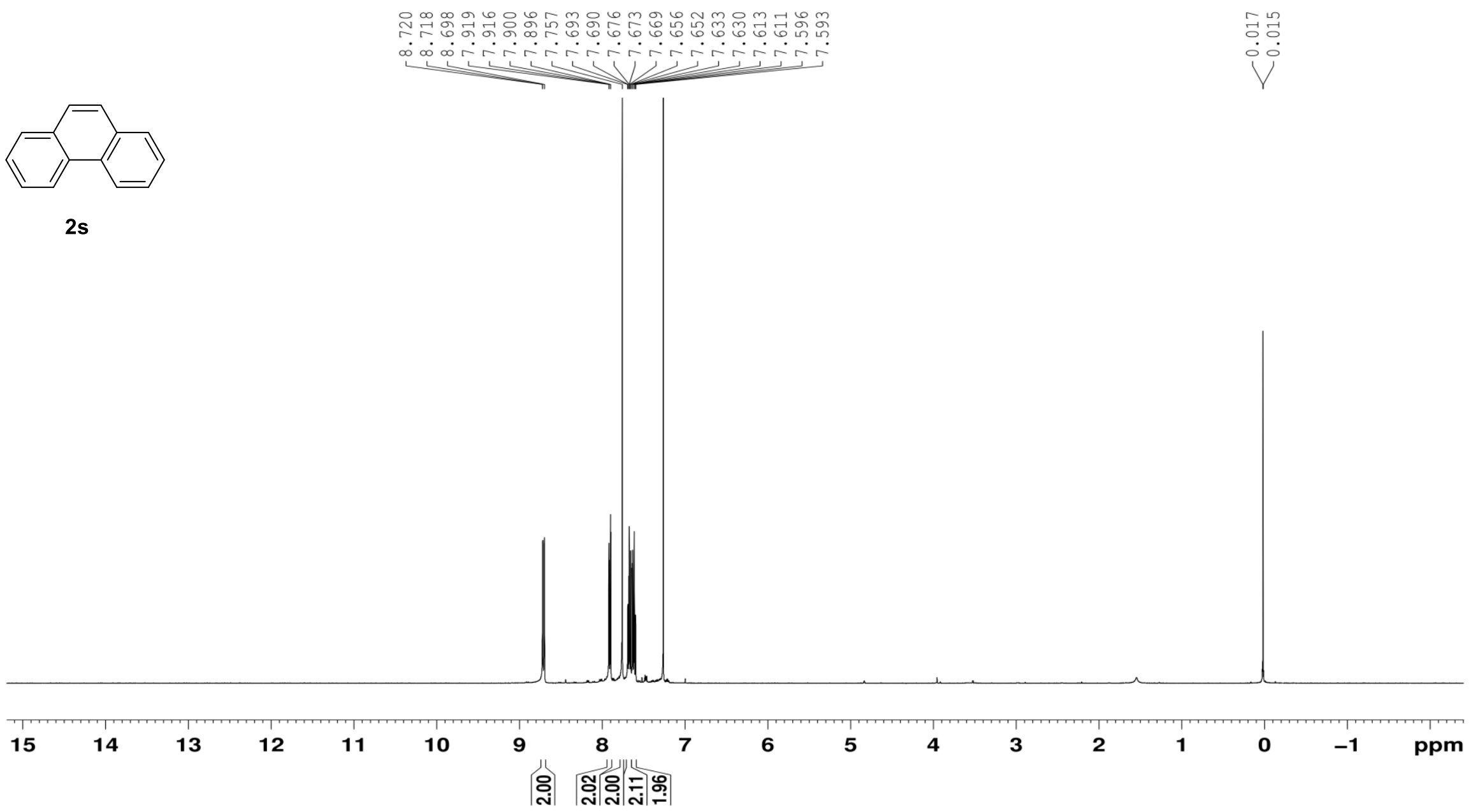

Figure S51. ${ }^{1} \mathrm{H}$ NMR spectrum of $\mathbf{2 s}\left(\mathrm{CDCl}_{3}, 400 \mathrm{MHz}\right)$. 


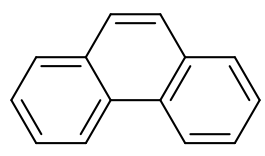

2s

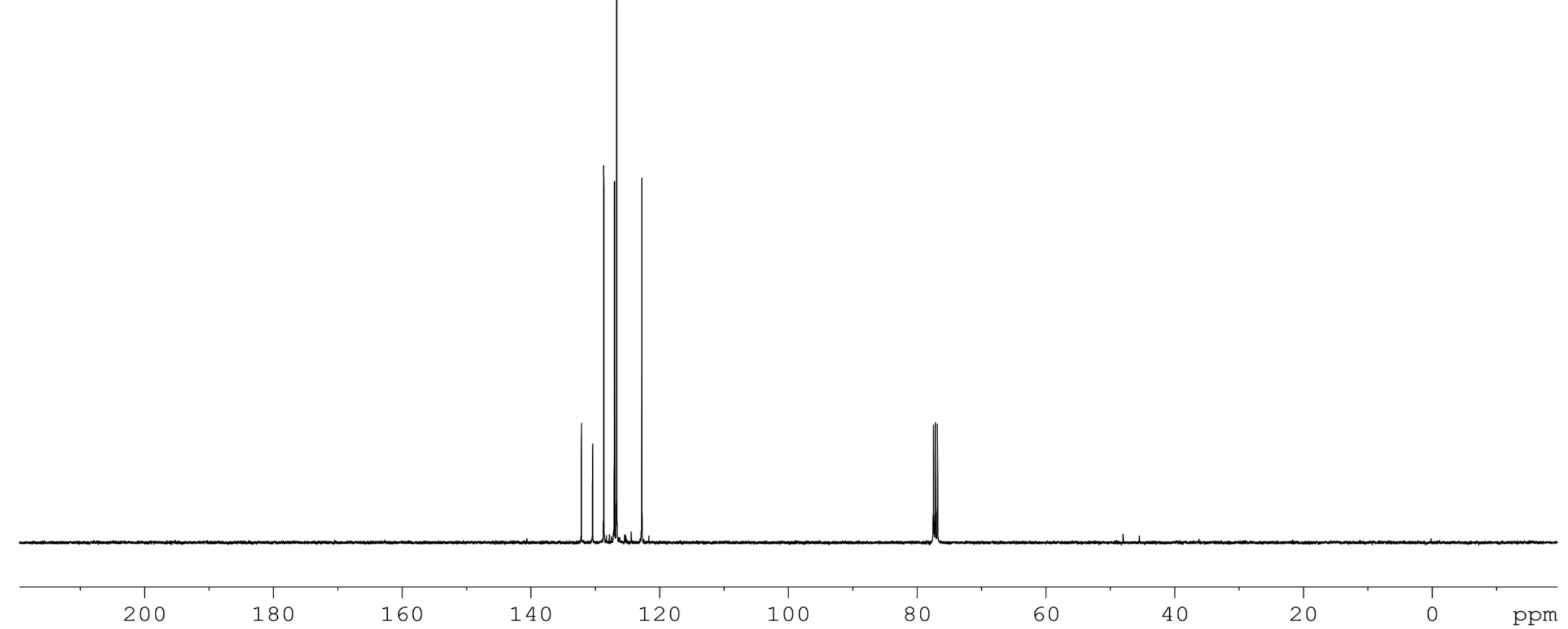

Figure $\mathbf{5 5 2} \cdot{ }^{13} \mathrm{C}$ NMR spectrum of $\mathbf{2 s}\left(\mathrm{CDCl}_{3}, 100 \mathrm{MHz}\right)$. 


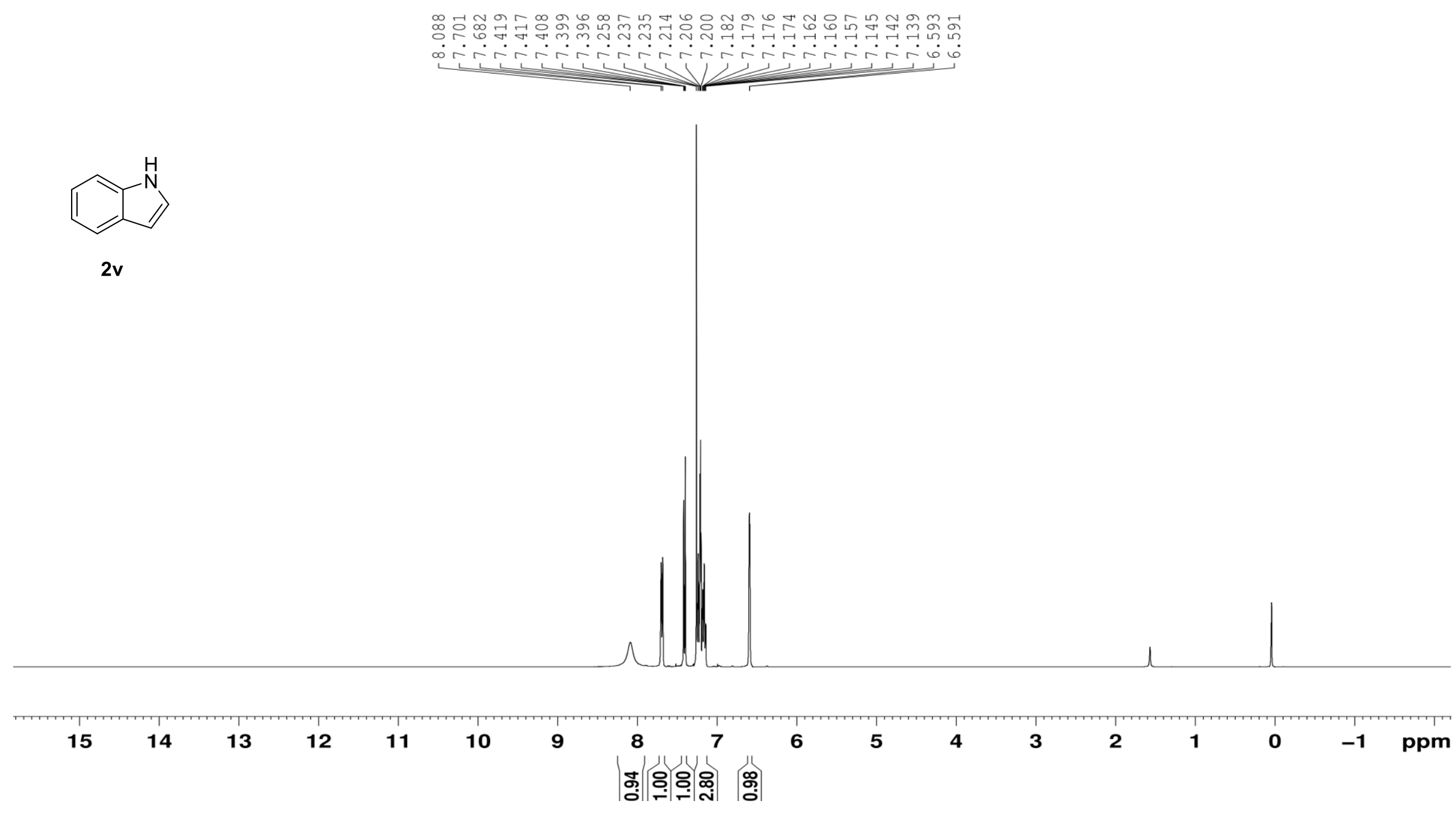

Figure S53. ${ }^{1} \mathrm{H}$ NMR spectrum of $\mathbf{2 v}\left(\mathrm{CDCl}_{3}, 400 \mathrm{MHz}\right)$. 


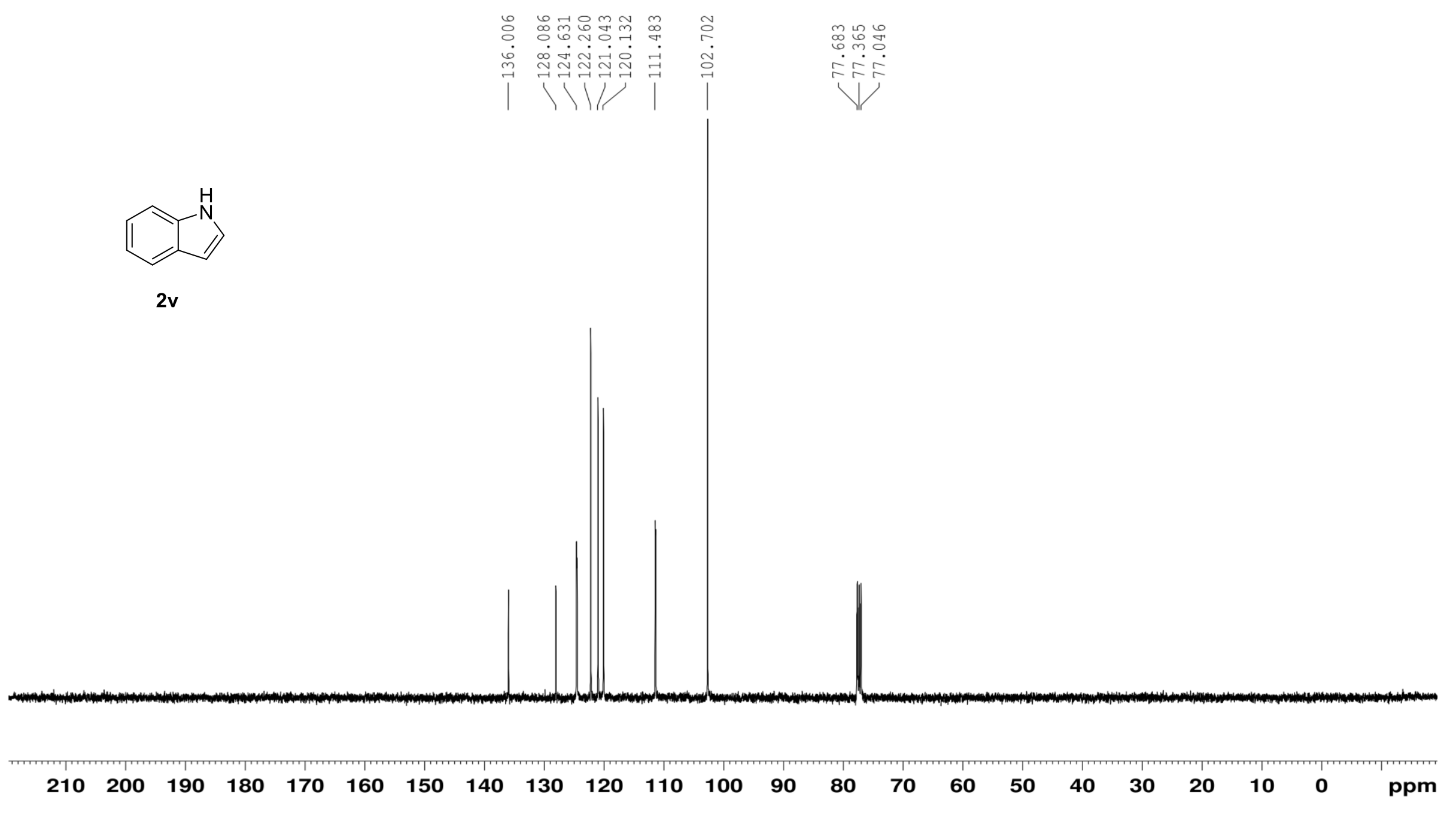

Figure S54. ${ }^{13} \mathrm{C}$ NMR spectrum of $\mathbf{2 v}\left(\mathrm{CDCl}_{3}, 100 \mathrm{MHz}\right)$. 


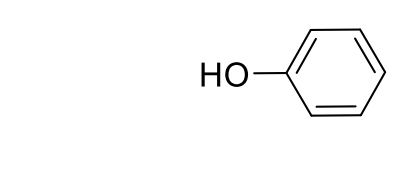

2Aa

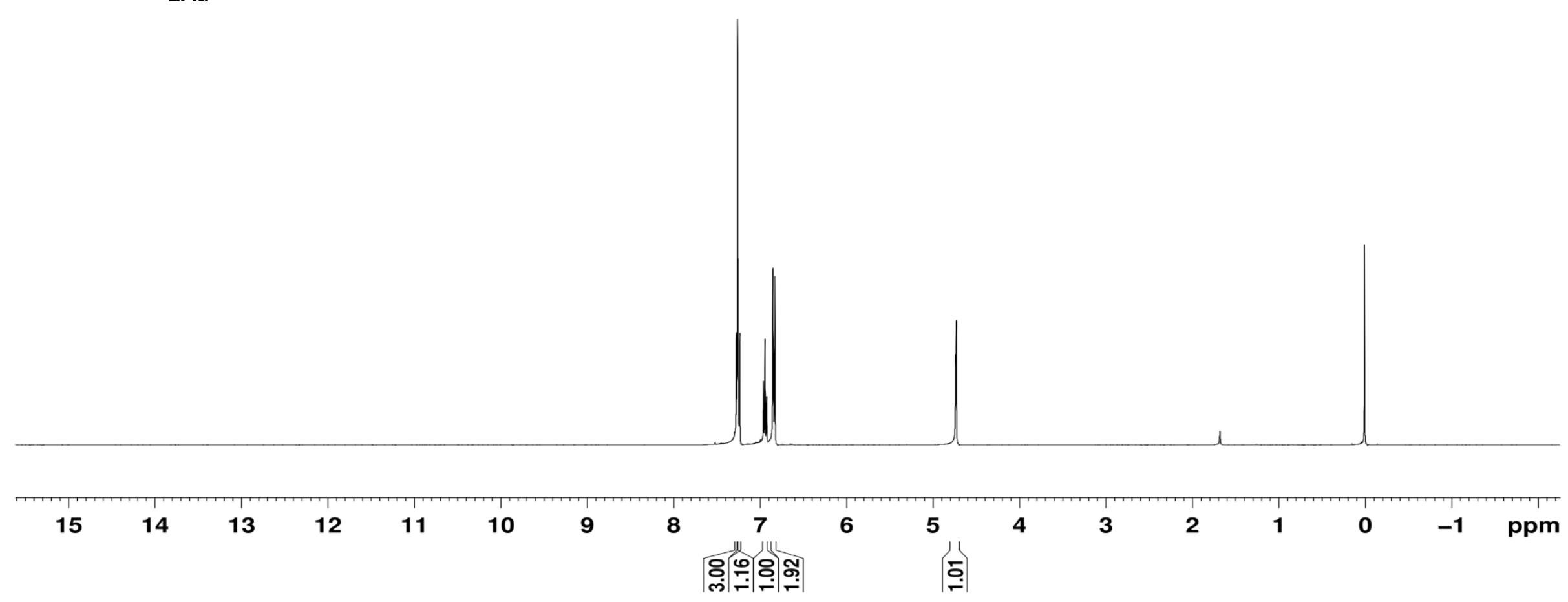

Figure S55. ${ }^{1} \mathrm{H}$ NMR spectrum of $\mathbf{2} \mathbf{A a}\left(\mathrm{CDCl}_{3}, 400 \mathrm{MHz}\right)$. 


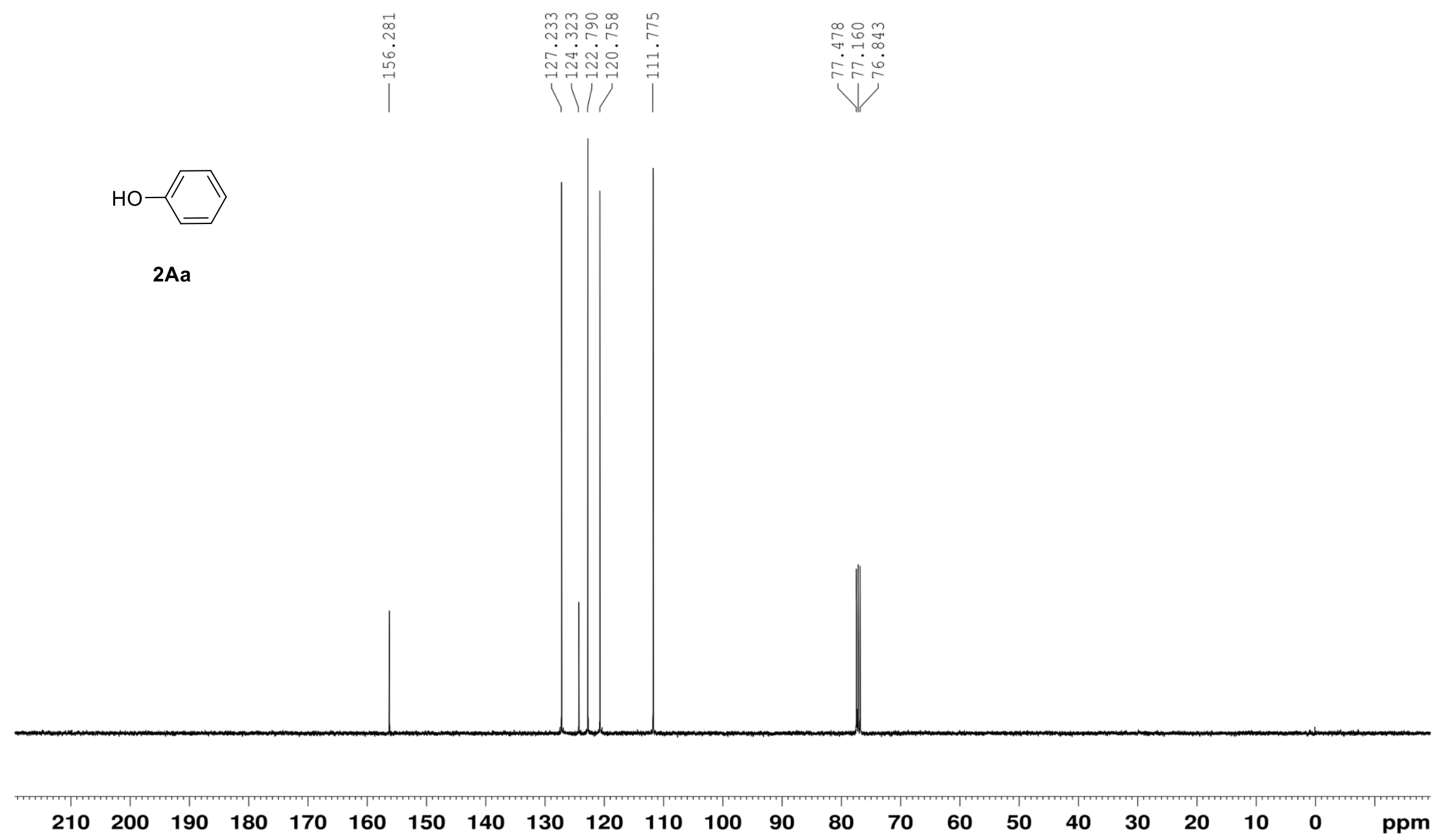

Figure S56. ${ }^{13} \mathrm{C}$ NMR spectrum of $\mathbf{2} \mathbf{A a}\left(\mathrm{CDCl}_{3}, 100 \mathrm{MHz}\right)$. 


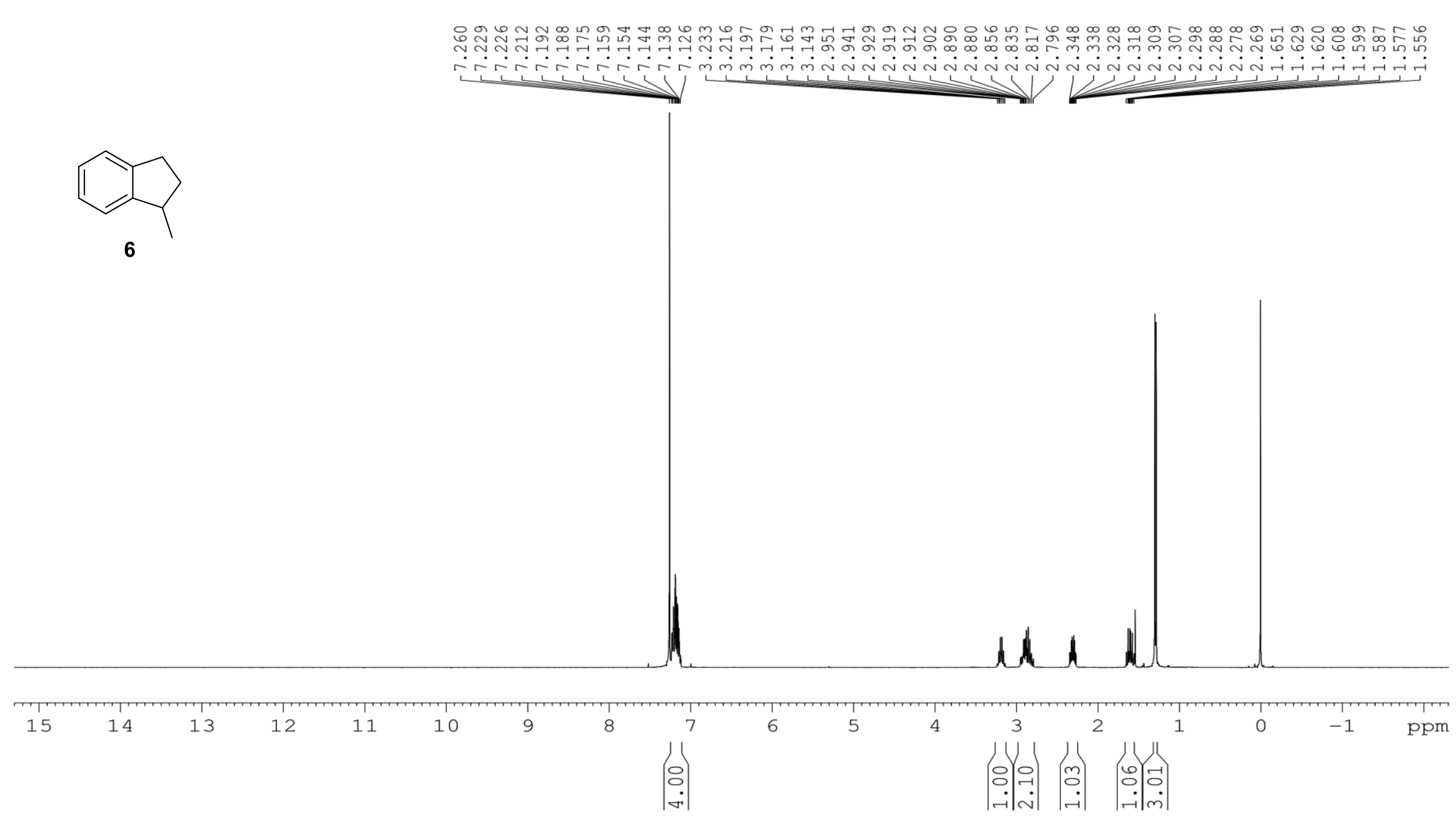

Figure S57. ${ }^{1} \mathrm{H}$ NMR spectrum of $6\left(\mathrm{CDCl}_{3}, 400 \mathrm{MHz}\right)$. 


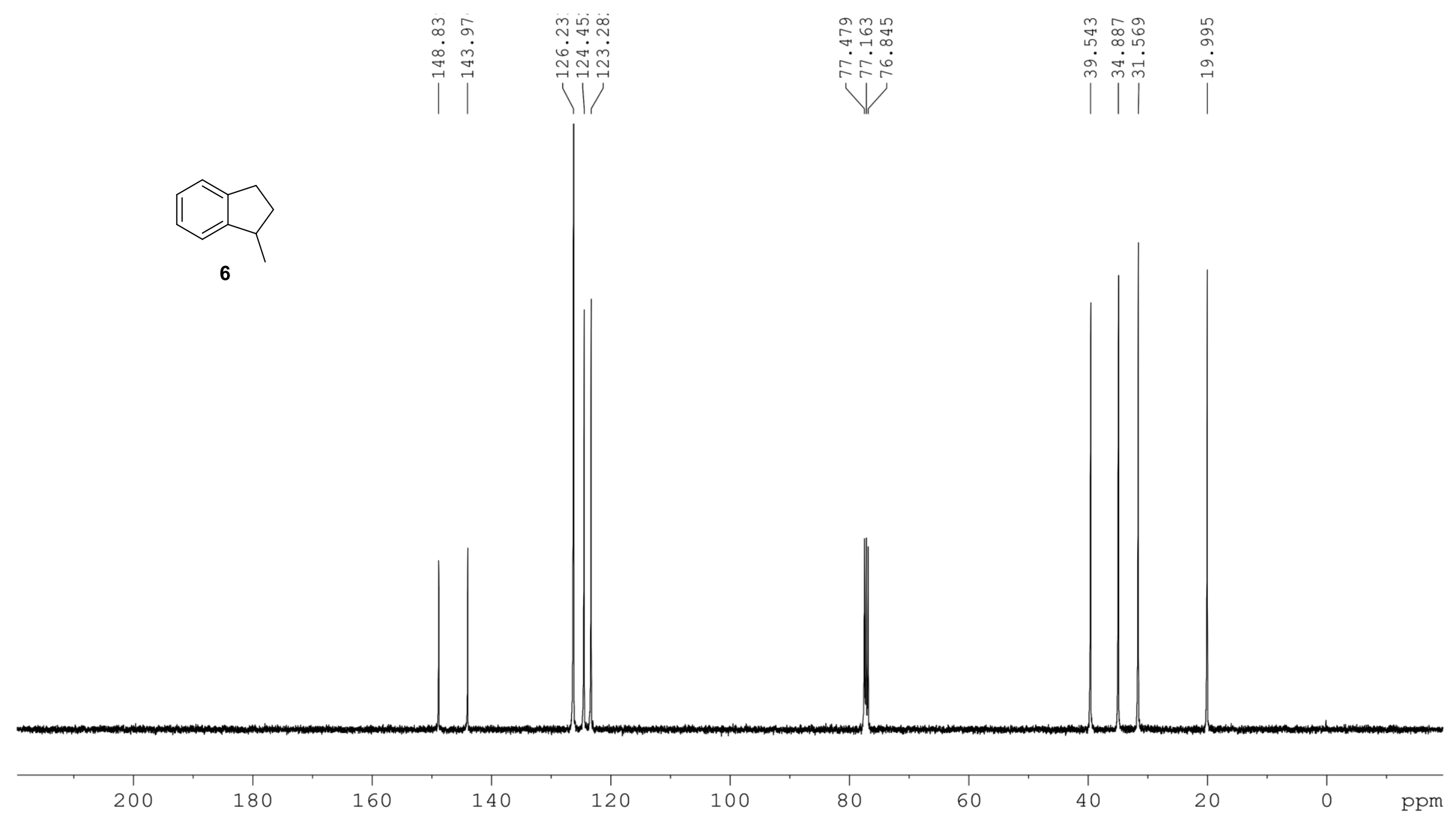

Figure S58. ${ }^{13} \mathrm{C}$ NMR spectrum of $6\left(\mathrm{CDCl}_{3}, 100 \mathrm{MHz}\right)$. 